\title{
Remote sensing based predictive decision support system for assessment of environmental conditions for epidemic cholera
}

Haidar Shakuir Aldaach

Follow this and additional works at: https://researchrepository.wvu.edu/etd

\section{Recommended Citation}

Aldaach, Haidar Shakuir, "Remote sensing based predictive decision support system for assessment of environmental conditions for epidemic cholera" (2015). Graduate Theses, Dissertations, and Problem Reports. 5053.

https://researchrepository.wvu.edu/etd/5053

This Thesis is protected by copyright and/or related rights. It has been brought to you by the The Research Repository @ WVU with permission from the rights-holder(s). You are free to use this Thesis in any way that is permitted by the copyright and related rights legislation that applies to your use. For other uses you must obtain permission from the rights-holder(s) directly, unless additional rights are indicated by a Creative Commons license in the record and/ or on the work itself. This Thesis has been accepted for inclusion in WVU Graduate Theses, Dissertations, and Problem Reports collection by an authorized administrator of The Research Repository @ WVU. For more information, please contact researchrepository@mail.wvu.edu. 


\title{
REMOTE SENSING BASED PREDICTIVE DECISION SUPPORT SYSTEM FOR ASSESSMENT OF ENVIRONMENTAL CONDITIONS FOR EPIDEMIC CHOLERA
}

\section{HAIDAR SHAKUIR ALDAACH}

\author{
Thesis submitted to the \\ Benjamin M. Statler \\ College of Engineering and Mineral Resources \\ at West Virginia University \\ in partial fulfillment of the requirements \\ for the degree of \\ Master of Science \\ in
}

Civil \& Environmental Engineering

\author{
Antarpreet Jutla, Ph.D., Chair \\ Radhey S. Sharma, Ph.D. \\ Greg Elmes, Ph.D.
}

Department of Civil and Environmental Engineering

\author{
Morgantown, West Virginia \\ 2015
}

Keywords:

Environmental, Waterborne diseases, Cholera, Outbreak, Epidemic, Hydroclimatic factors Copyright 2015 Haidar Shakuir Aldaach 


\section{ABSTRACT \\ Remote sensing based predictive decision support system for assessment of environmental conditions for epidemic cholera}

\section{HAIDAR SHAKUIR ALDAACH}

Cholera, a water borne diarrheal disease, is strongly associated with environmental processes. However, quantitative linkages of environmental processes with cholera and climate is still emerging. Linking diseases such as cholera with climate will aid in development of models that can predict spatial and temporal outbreaks in resource constrained regions of the globe. With the limited efficacy of cholera vaccines, it is necessary to develop mechanisms to predict cholera occurrence and thereafter devise intervention strategies for mitigating impacts of the disease. Hydroclimatic processes, primarily precipitation and air temperature are related to epidemic and episodic outbreak of cholera. However, due to coarse resolution of both datasets, it is not possible to precisely locate the geographical location of the disease. Here, using Land Surface Temperature (LST) from MODIS sensors, we have developed an algorithm to identify regions susceptible for cholera.

Conditions for occurrence of cholera were detectable at least one month in advance in several regions of Africa and were statistically sensitive to hydroclimatic anomalies of land surface and air temperature and precipitation. In order to ascertain the integrity of the hypothesis, there are four epidemic regions were picked in Africa with different outbreak's time: Mozambique, Central African Republic, Cameroon and Rwanda. Our results indicate significant spatial and temporal averaging required to infer usable information from LST over selected areas. 
I am grateful to Gad far making my dream a reality by abtaining a Master's degree in Cuil $d$ Enwiranmental Engineering at West Virginia Uniuersity. This wark is dedicated ta my family, especially ta my lavely parents, Shakir and Sajeda. Dad and mam, I lave you bath wery much. Mast Impartantly, I wauld like ta dedicate my master's wark ta my gargeaus wife Zainale and my little angel, my san Mahamad and all my family members. They patiently gave me all their support in every step of my jaurney tawards my degree.

Ta My Family 


\section{ACKNOWLEDGEMENT}

I would like to take this opportunity to thank several people who played an important role in the successful completion of this work. First and foremost, I would like to thank my advisor and committee chairman, Dr. Antarpreet Jutla, for providing his valuable guidance. I thank Dr. Radhey Sharma and Dr.Greg Elmes for reviewing my thesis and being a part of my examination committee.

I gratefully acknowledge the financial support provided by NASA West Virginia Space Grant Consortium and I would like to thank the Department of Civil and Environmental Engineering at West Virginia University for their financial and moral support.

A big thanks to my loving wife Zainab Sahib Jawad; she has been always loving, patient, and supportive. Words cannot express the gratefulness I have for her; I would like to thank her for having all that faith in me. Finally, I would like to thank my family and friends for all the love and support I have received from them. I really appreciate all the help that I have received from each member of my family; without them I would never have gone to the U.S. and been able to finish my degree. I would also like to express my deepest thanks to each and every one of my friends Rakibul Khan, Ghassan AlSinbol, Hadi Rashidi, Youyi Feng, Murat Dink, Natalie Liovnis and Rachel Boothby. I would like to thank them for all the wonderful things they have done for me; this work would not have been possible without their support and advice. 


\section{TABLE OF CONTENT}

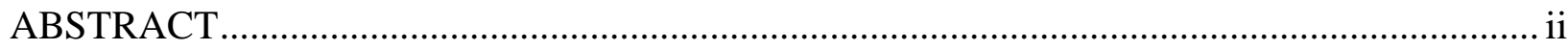

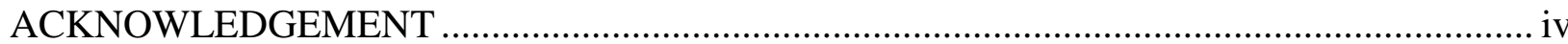

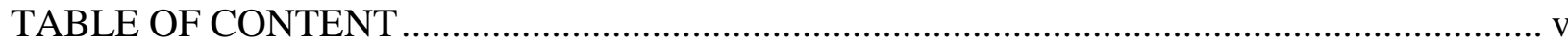

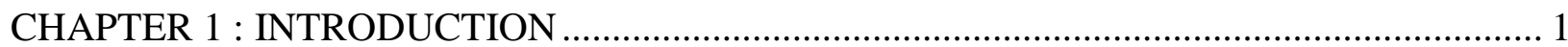

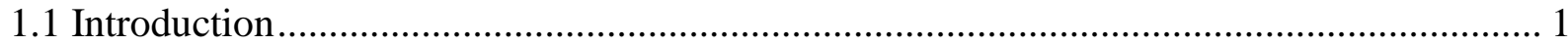

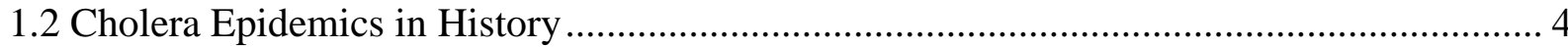

1.3 Problem statement/research objectives ...................................................................... 7

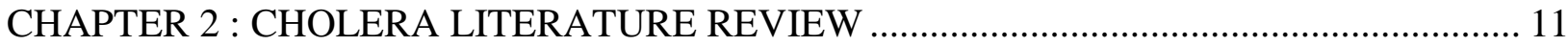

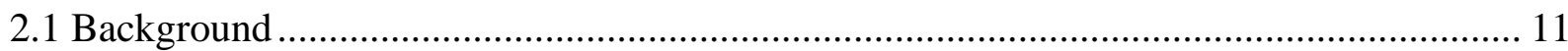

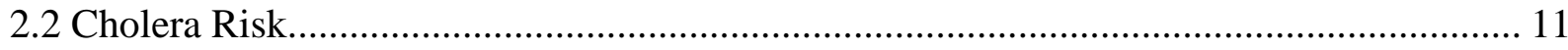

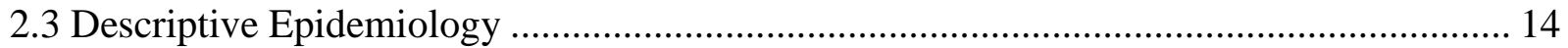

2.4 Epidemiology of cholera (Endemicity and epidemics) .................................................. 15

2.5 Cholera cases reported to the World Health Organization (WHO) …………..................... 16

2.6 Hydroclimatic control of epidemic cholera ................................................................... 20

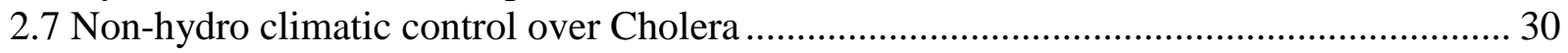

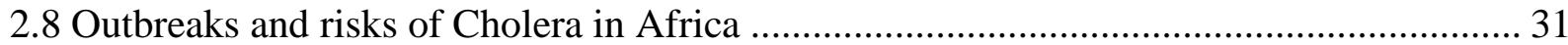

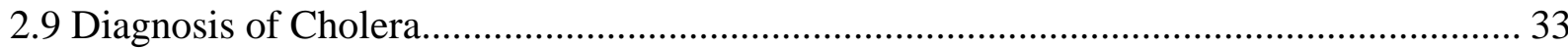

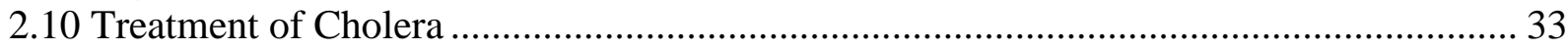

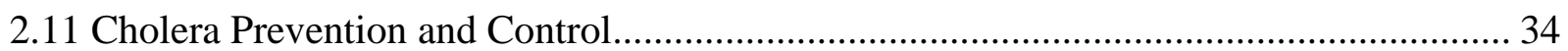

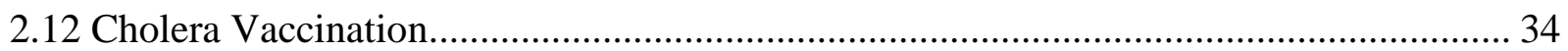

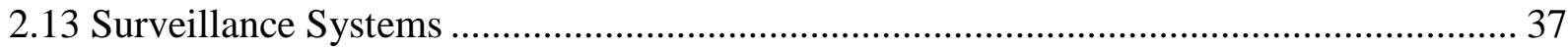

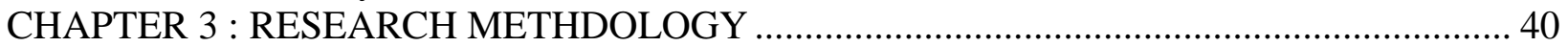

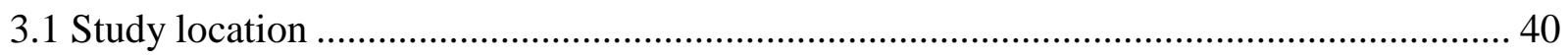

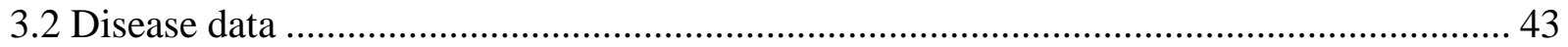

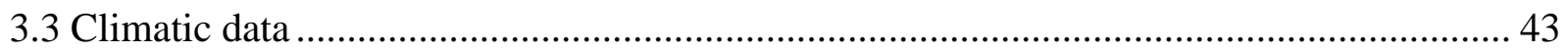

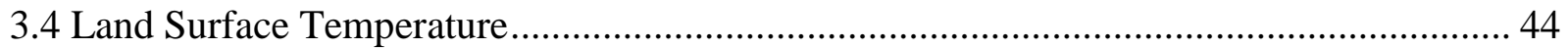

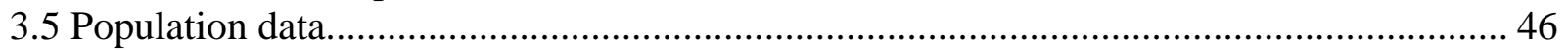

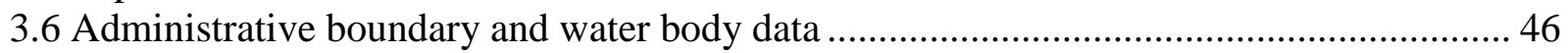

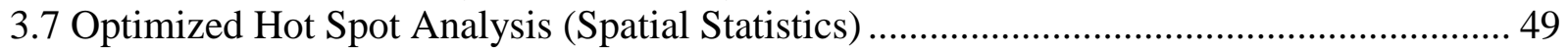

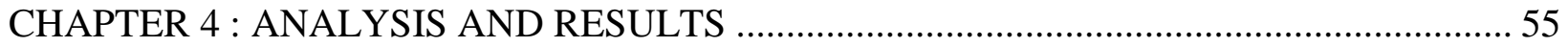

4.1 Temporal hydro-climatic control over Cholera ………................................................ 57

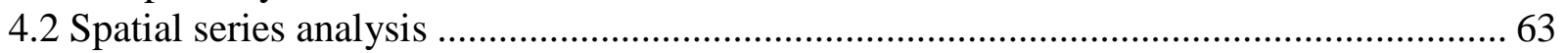

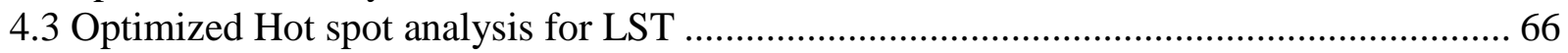

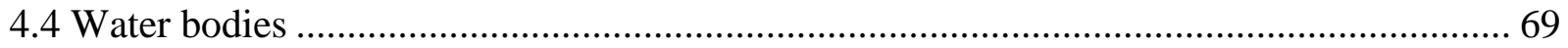

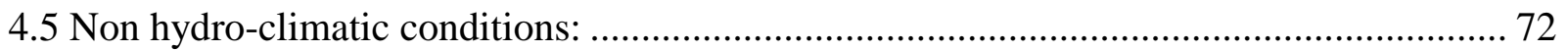

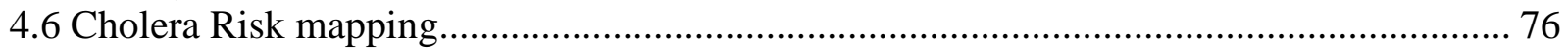

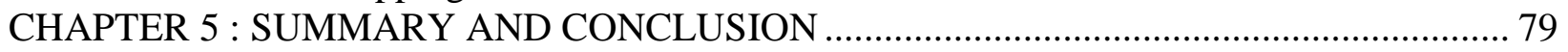

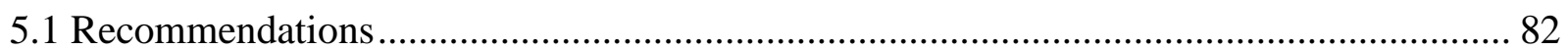

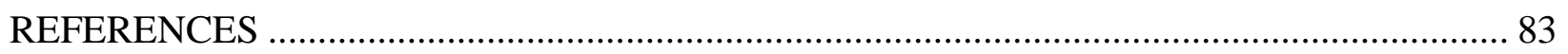




\section{TABLE OF FIGURES}

Figure 1.1: Theoretical hypothesis for linking macro-, micro- environmental and sociological conditions with epidemic cholera [e.g. March precipitation above climatological average=mean of March precipitation for several years minus precipitation in March for a particular year].....

Figure 1.2: Cholera outbreaks in some areas around the world, 2010 - 2013 (World Health

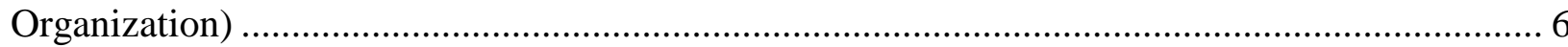

Figure 1.3 : Total Cholera cases for every 10 years from 1949 to 2012 (Data from WHO) ......... 7

Figure 1.4: Number of epidemic regions in Africa from 1993 to 2012 (Data from WHO) .......... 8

Figure 2.1: V.cholerae serogroups, phenotypes, and serotypes that could cause cholera. .......... 13

Figure 2.2: Countries/areas reporting cholera cases for the period of 2000 to 2013 (WHO, 2013).

Figure 2.3: Number of cholera cases reported to WHO in 2013 (WHO, 2013) ........................ 17

Figure 2.4 : Number of reported cholera outbreaks in the African Great Lakes region, 1999-

2008, (Nkoko at el, 2011) ....................................................................................... 26

Figure 2.5: Haiti's average air temperature and air temperature in 2010 (Jutla et al, 2013) ....... 28

Figure 2.6: Haiti's average rainfall compared with rainfall in 2010 (Jutla et al, 2013).............. 29

Figure 2.7: Total cholera cases in some regions around the world (1949-2012) (Data from WHO)

Figure 2.8: Basic information categorized by person, place, and time (World Health

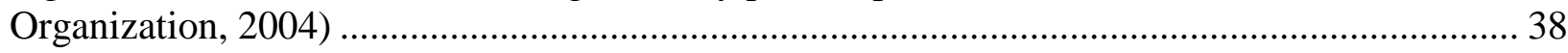

Figure 2.9: the role of surveillance systems in some issues and the level that they can achieve

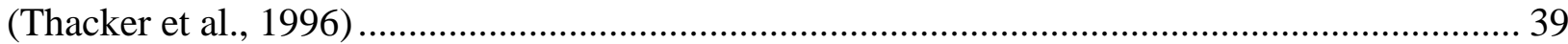

Figure 3.1: The five epidemic cholera regions in Africa are: a) Cameroon; b) South Sudan; c)

Rwanda; d) Mozambique and e) The Central African Republic. ......................................... 42

Figure 3.2: Example of optimized hot spot analysis (ArcGIS Resources, 2014)..................... 49

Figure 3.3: Drawing of Z-scores and P-values (ArcGIS Resources, 2014)............................. 51

Figure 4.1: Cholera assessment framework in epidemic regions. .......................................... 57

Figure 4.2: Precipitation and temperature anomalies five different regions in Africa. Black

arrows on the $\mathrm{x}$-axis of plots indicates month when cholera was first reported........................ 61

Figure 4.3: the difference between the month/year deviation of cholera outbreaks and the same month value for many years preceding the disease outbreak. Blue color refer to negative deviation while the red indicate the positive deviation in air temperature and the opposite indication with precipitation.

Figure 4.4: Spatial series of land surface temperature; yellow and red indicate values higher than long term average: a) The Central African Republic; b) South Sudan; c) Mozambique; d)

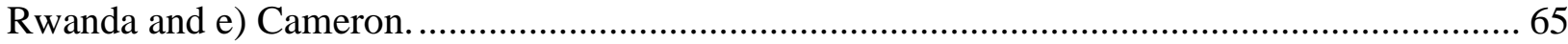

Figure 4.5: Optimized hot spot analysis of land surface temperature anomalies: a) The Central

African Republic; b) South Sudan; c) Mozambique; d) Rwanda and e) Cameron..................... 68

Figure 4.6: Water bodies close to affected disease region: a) The Central African Republic; b)

South Sudan; c) Mozambique; d) Rwanda and e) Cameron.................................................. 71

Figure 4.7: Population density in the affected disease region: a) The Central African Republic; b)

South Sudan; c) Mozambique; d) Rwanda and e) Cameron................................................. 73

Figure 4.8: Venn diagram for cholera risk mapping principles........................................... 77

Figure 4.9: Cholera Risk Map: a) The Central African Republic; b) South Sudan; c)

Mozambique; d) Rwanda and e) Cameron. ....................................................................... 78 


\section{LIST OF TABLES}

Table 1.1: Summary of prediction diarrheal disease remote sensing .......................................... 9

Table 2.1: Imported cholera cases reported to WHO in different regions around the world in

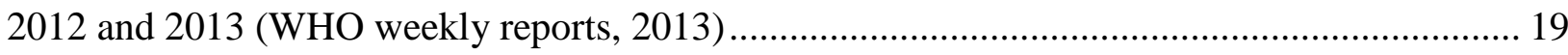

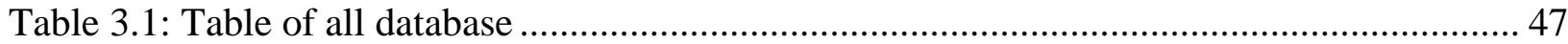

Table 3.2: Confidence levels for different p-values and z-scores............................................... 52

Table 4.1: Social disturbance in five epidemic cholera regions in Africa.................................... 74 


\section{CHAPTER 1 : INTRODUCTION}

\subsection{Introduction}

Cholera remains one of the serious diarrheal diseases in developing countries in South Asia, Africa, and Latin America. The disease continues to be a major public health threat affecting around 3 to 5 million people and causes more than 100,000 cases of death every year (Zuckerman et al, 2007). The over-populated communities and refugee camps represent some of the potential targets to the risk of this disease because of the poor sanitation and unsafe drinking water (World Health Organization, 2004). In developing countries, cholera is considered a major public health issue because of the unavailability of safe water and sanitation facilities. For that reason, developing water supply and sanitation is an important sustainable approach for preventing the disease (Trærup et al, 2010).

Cholera transmits via drinking water contaminated with Vibrio cholerae bacteria, which is the main causative agent of cholera (Reidl and Klose, 2002). The symptoms of this disease include diarrhea (watery stools), nausea, abdominal discomfort, and vomiting. If these symptoms are not treated as quickly as possible, the loss of fluid and salts from the body may cause a severe dehydration that could lead to death within hours. The dehydration in a patient usually can be noticed within 12 to 24 hours of cholera outbreak. The main treatment of these symptoms is oral rehydration therapy, such as oral rehydration solution, in order to replace water and electrolytes (Lamond \& Kinyanjui, 2012). Mortality should be below 1\% if treatment is applied appropriately and it could be as high as 30 to $50 \%$ if left untreated. Minimizing exposure to pathogenic strains of cholera bacteria is considered one of the most effective ways to control outbreaks (Jutla et al, 2013). In addition, early detection of environmental conditions favorable for cholera remains one of the most effective ways to prevent the trigger and transmission of the disease. Furthermore, 
appropriate responses to confirmed cases are required to reduce the threat of the disease (World Health Organization, 2004).

Recent studies (Payment and Hunter, 2001) have established that cholera could occur in three forms: epidemics, endemics and mixed-mode. Epidemics can be defined as the sudden occurrence of cholera at a particular time and place. However, if the disease occurs frequently in a region for a period of at least 10 years, a region may be defined as an endemic one. Endemics are usually observable close to coastal regions. Mixed-mode is a combination of epidemic and endemic cholera occurrence. Epidemic cholera is usually associated with higher mortality rates when compared to endemic cholera (Enserink et al, 2010). The following are some recent mortality rates of epidemic cholera in some countries: Haiti 6.4\% in 2010, Madagascar 6\% in 2000, Zimbabwe $4.3 \%$ in 2008-09, and Nigeria 3.8\% in 2010 (Enserink et al, 2010).

With limited efficacy of cholera vaccines and the health threat posed by this disease, it is very important to understand hydroclimatic connection with disease dynamics (Emch et al, 2008).

The environmental impact on cholera has been the subject of interest for several previous studies (Emch et al, 2008; Kelly-Hope et al, 2008; Jutla et al, 2013; Pascual et al, 2000; Griffith et al, 2006; Reyburn et al, 2011; Bompangue et al, 2009). Heavy rainfall, river level, blooms of plankton, floods, coastal salinity, dissolved organic material, and increased sea surface temperatures have been identified as the main environmental risk factors that could increase the risk of cholera (Bompangue et al, 2009). Appropriate treatment can be provided in a region in advance, if cholera epidemics can be predicted depending on hydroclimatic factors.

The goal of this research is to highlight the effect of hydroclimatic factors, particularly air and land surface temperature and precipitation, as well as non-hydroclimatic factors, such as population and water access, on the trigger of cholera in several locations in Africa (Mozambique, 
Central African Republic, Rwanda, South Sudan and Cameroon). Recently, an epidemic hypothesis is proposed by Jutla et al (2013), that's related precipitation and air temperature with episodic occurrence of cholera (Figure 1.1).

Accordingly, the inner red rectangle in Figure 1.1 shows elevated temperatures when followed by above average precipitation create environmental conditions favorable for bacterial growth. If these conditions are combined with societal mechanisms of water insecurity this will trigger epidemic cholera. Transmission of disease in a community or region occurs via secondary means of community instabilities such as human to environmental route, resulting in widespread disease outbreaks. On the other hand, the outer rectangle, Figure 1.1, encapsulates those conditions under which cholera generally does not occur (Jutla et al, 2013b). This causal mechanism is markedly different from endemic cholera where tidal intrusion of seawater carrying bacteria from estuary to inland regions, results in outbreaks occurring annually in seasonal patterns (Akanda et al., 2009, 2011; Jutla et al., 2013b).

This hypothesis was tested using historical disease data from the Indus Basin in Asia. However, the validity of the hypothesis using real time cholera data remains exclusive. For example, currently satellite based precipitation is available at $25 \mathrm{~km}$, which puts practical limits on usability of such information to local populations. Remote sensing is a useful tool for estimating and evaluating the risk of cholera incidence by linking large-scale hydroclimatic processes to epidemiological data (Jutla et al, 2010). 


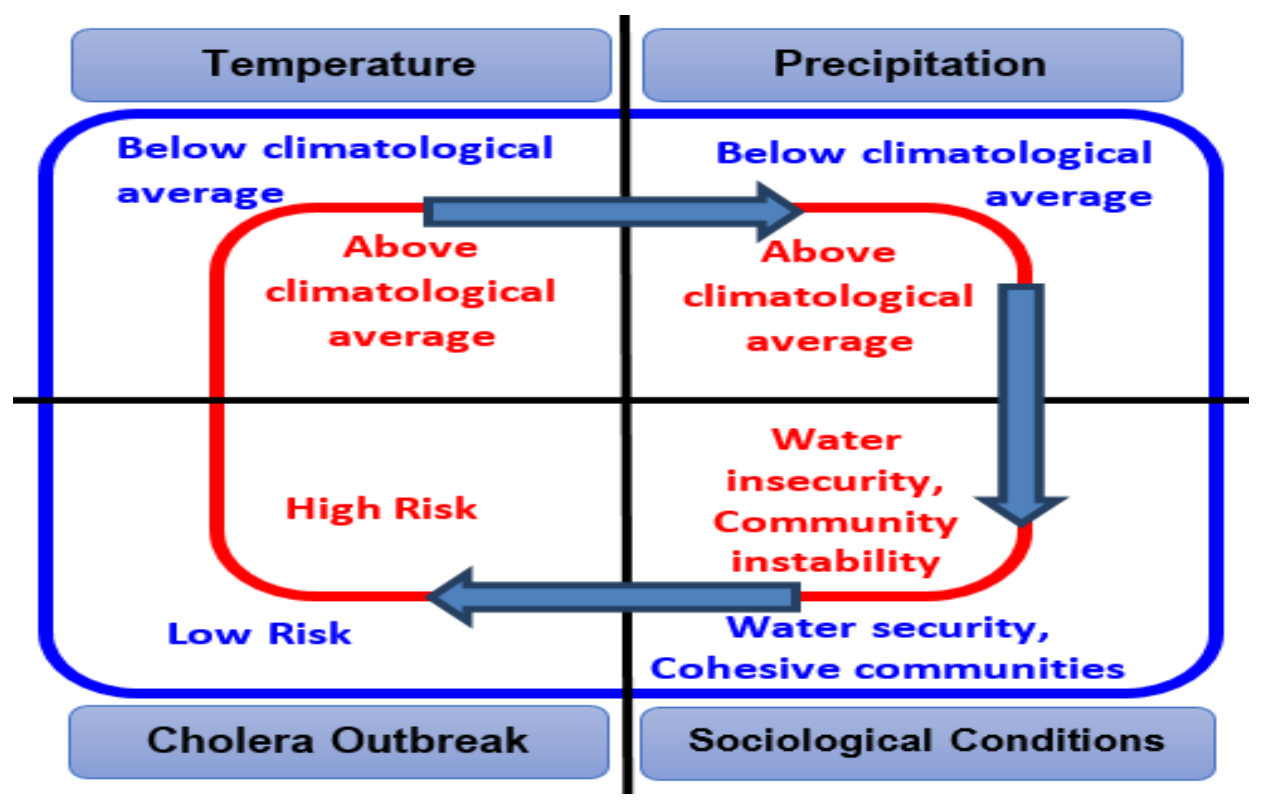

Figure 1.1: Theoretical hypothesis for linking macro-, micro- environmental and sociological conditions with epidemic cholera [e.g. March precipitation above climatological average=mean of March precipitation for several years minus precipitation in March for a particular year].

\subsection{Cholera Epidemics in History}

Cholera outbreaks or epidemics can be defined as a sudden peak in the number of cholera cases in a specific region, and that number is usually above the expected number of cases in that area or population. Epidemics are usually created by heavy rainfall which could result in a breakdown of sanitation infrastructure. Most of the time, epidemic regions are located near regional rivers (Jutla et al, 2013). The first documented pandemic outbreak of the cholera disease was in 1438 in Southeast Asia, the modern history of this disease started in May of 1817 when the first pandemic occurred in Kishnagur, India (Reidl and Klose, 2002).

The second pandemic occurred between the years of 1826 and 1837 and it spread from India, across Asia and Europe, and even reached most major cities in the United States and Canada. The third pandemic took place from 1846 to 1863 and it caused 23,000 cases of death across England and more cases in southern Europe. By the end of 1923, a total of six cholera pandemics occurred affecting Asia, North America and Europe (Reidl and Klose, 2002). 
The seventh pandemic of cholera, which is considered the most recent one and is still ongoing, started in 1961 in Indonesia, then spread out to the Indian subcontinent, Middle East, and Africa; by the early 1990s, it was able to reach South America. It affected over 50 countries and 7 million people around the world, which is greater than the impact of the old six pandemics combined (Gleick, 2008; Gaffga et al, 2007; Lan et al, 1998). Ever since, cholera has become a public health problem in many countries around the world and a subject of interest for a lot of studies. Figure 1.2 shows the reported outbreaks in some areas around the world between the years of 2010 to 2013.

The theory of cholera transmission through contaminated water was first proposed by Dr. John Snow in 1849 (Faruque et al, 1998). After 20 years of research, Pacini (1854) was able to describe the "comma bacillus" and confirm their responsibility for cholera, but his data was not accepted until a year after his death when the Vibrio cholerae was discovered by Robert Koch (Bentivoglio and Pacini, 1995). 


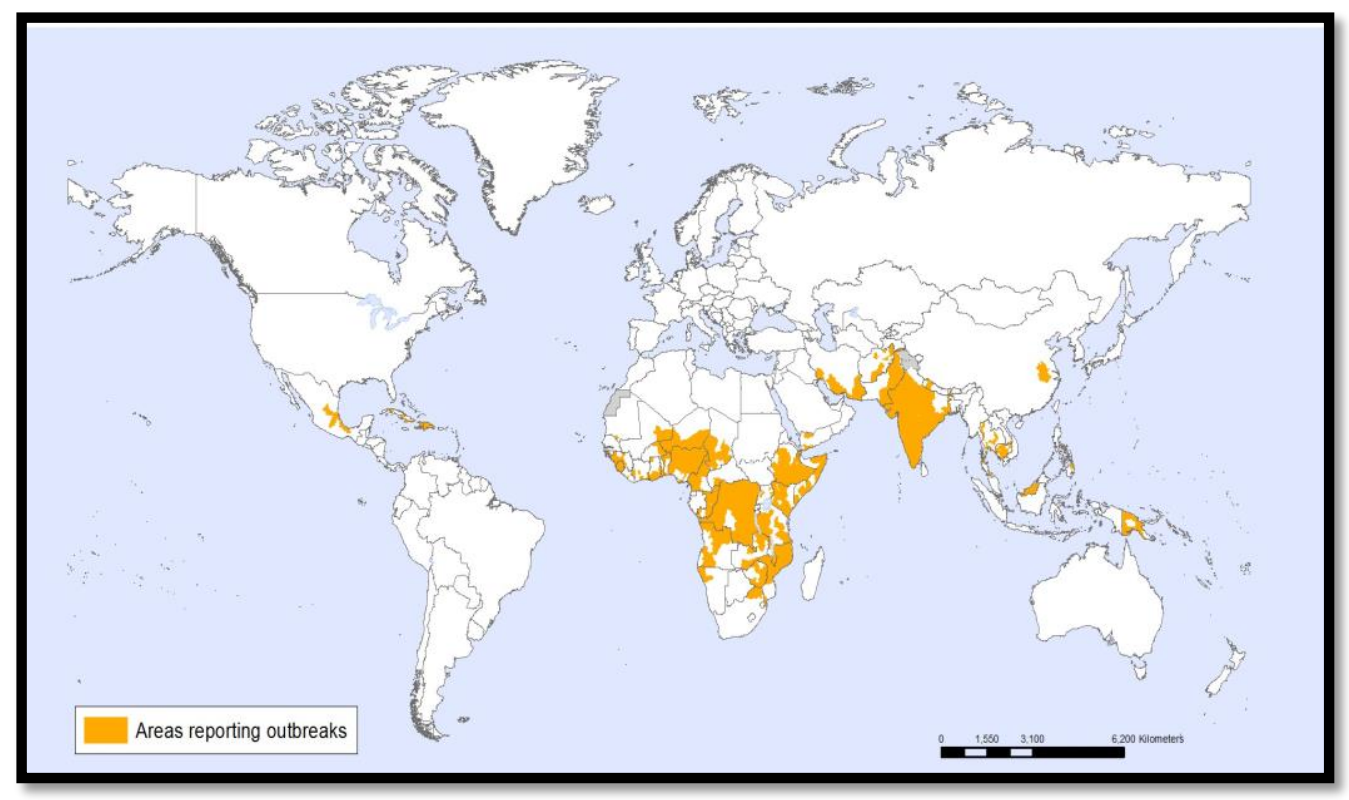

Figure 1.2: Cholera outbreaks in some areas around the world, 2010 - 2013 (World Health

\section{Organization)}

Figure 1.3 shows the total number of cholera cases in the period between 1949 and 2012. The figure shows that during the last twenty years (1994-2013) the number of cases have increased by more than $43 \%$ if compared to the preceding twenty years (1974-1993). According to some published literature (Fernández et al, 2009), the number of cholera cases reported between the years of 2003 to 2006 is considered the highest in more than a decade. Additionally, a total rise of 79\% was reported in 2006 if compared to the previous year (Fernández et al, 2009). 


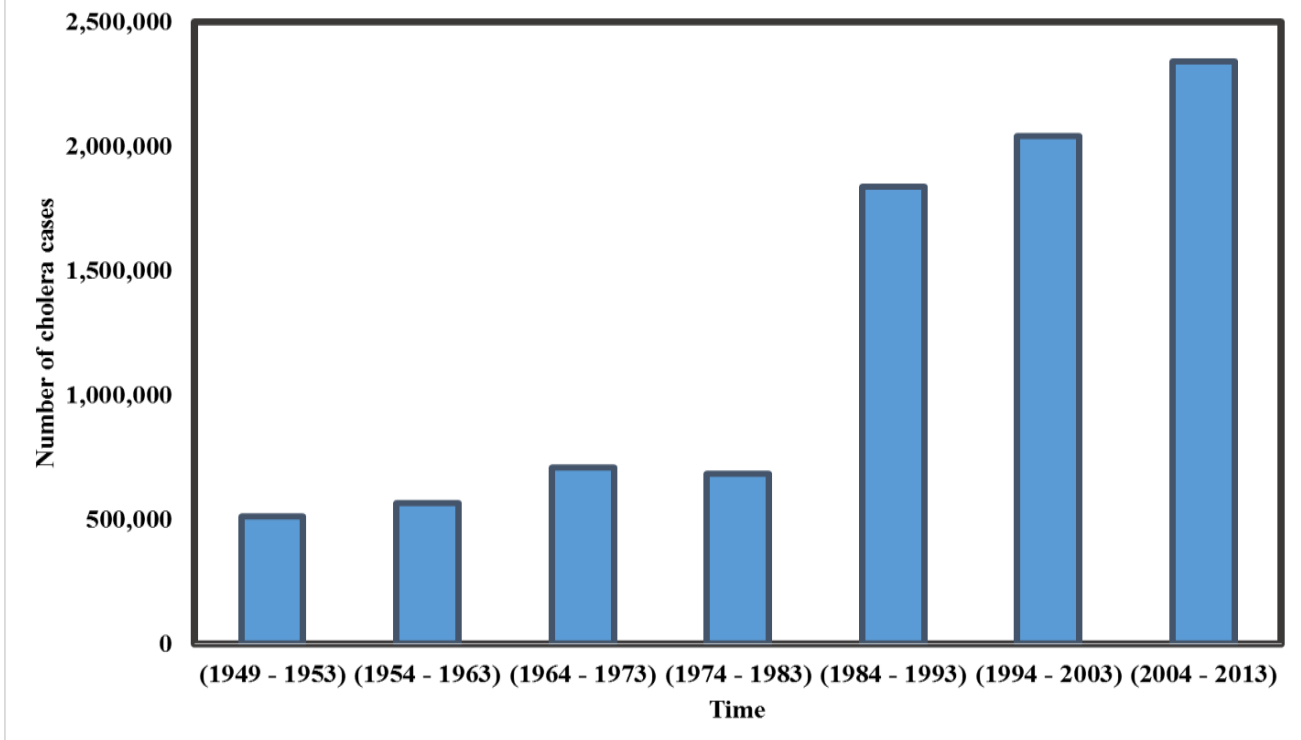

Figure 1.3 : Total Cholera cases for every 10 years from 1949 to 2013 (Data from WHO)

\subsection{Problem statement/research objectives}

Cholera can be defined as an acute water-borne diarrheal disease. It represents a significant health threat in many regions around the world. Cholera infection and transmission experienced a rise in many regions since 1961, especially in South Asia and Africa. Contaminated water supplies and crowded living conditions are considered very suitable for the transmission of cholera. It is believed that some underlying environmental factors could be associated with the spread of this disease. For that reason, it is very important to understand the disease dynamics and how it interacts with the environment (Reidl and Klose, 2002).

Remote sensing is considered a useful tool for estimating and evaluating the risk of cholera incidence by linking large-scale hydroclimatic processes to epidemiological data (Jutla et al, 2010). Underscore sensitivity in satellite derived precipitation, air temperature and land surface temperature (LST) is one important objective of the current research work.

Some of the most important observations that motivate us to explore the relationship between hydroclimatic conditions and epidemic cholera are (i) the increase in the number of 
epidemic regions in Africa the last 10 years as shown in Figure 1.4, and (ii) Few studies using only satellite information to predict diarrheal disease has been done for the purpose of this research. As shown in Table 1.1.

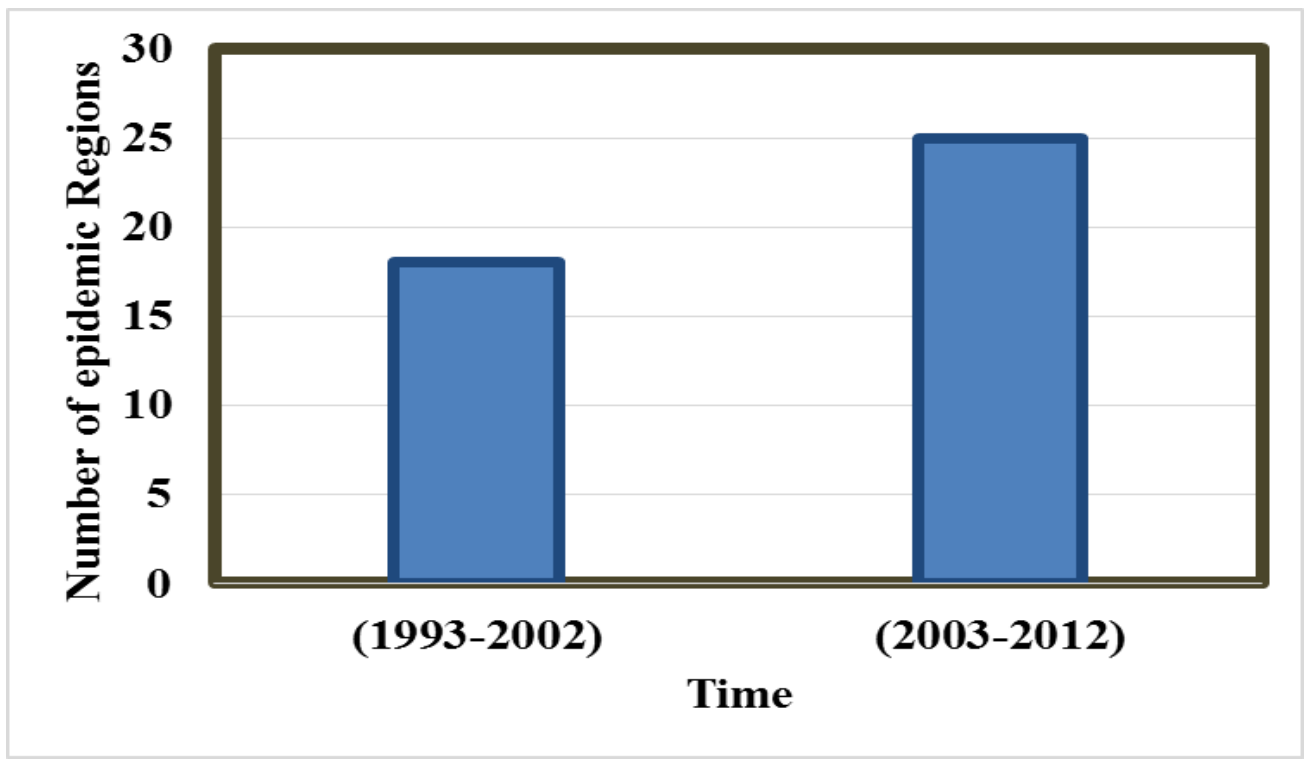

Figure 1.4: Number of epidemic regions in Africa from 1993 to 2012 (Data from WHO) 
Table 1.1: Summary of prediction diarrheal disease remote sensing

\begin{tabular}{|c|c|c|c|}
\hline Author & Disease & Type of data & Results \\
\hline Lobitz et al, 2000 & Cholera & SST, SSH & $\begin{array}{c}\text { Provided strong } \\
\text { evidence that cholera } \\
\text { epidemics are } \\
\text { climate-linked }\end{array}$ \\
\hline Emch et al, 2008 & Cholera & $\begin{array}{c}\text { Chlorophyll, SST, } \\
\text { SSH }\end{array}$ & $\begin{array}{l}\text { Increase SST, SSH } \\
\text { and Chlorophyll play } \\
\text { significant role in } \\
\text { predicting cholera }\end{array}$ \\
\hline Jutla et al, 2010 & Cholera & Chlorophyll & $\begin{array}{c}\text { Links between } \\
\text { disease dynamics and } \\
\text { various hydroclimatic } \\
\text { and oceanic variables }\end{array}$ \\
\hline $\begin{array}{l}\text { Abdul Rasam et al, } \\
2011\end{array}$ & Cholera & $\begin{array}{l}\text { SST, Coastal } \\
\text { phytoplankton }\end{array}$ & $\begin{array}{l}\text { Cholera transmission } \\
\text { risk connected with } \\
\text { environmental factors }\end{array}$ \\
\hline Yomwan et al, 2011 & Diarrhea & NDVI, NDWI & $\begin{array}{l}\text { Association between } \\
\text { epidemic risk and } \\
\text { flood }\end{array}$ \\
\hline Wang et al, 2012 & Norovirus & $\begin{array}{c}\text { Salinity, } \\
\text { Temperature, } \\
\text { Precipitation, and } \\
\text { Humidity } \\
\end{array}$ & $\begin{array}{l}\text { Norovirus linked with } \\
\text { hydroclimatic drivers }\end{array}$ \\
\hline Jagai et al, 2012 & Rotavirus & $\begin{array}{l}\text { Vegetation index } \\
\text { (VI), MODIS for } \\
\text { locations, air } \\
\text { temperature and } \\
\text { precipitation }\end{array}$ & $\begin{array}{c}\text { Low temperatures } \\
\text { and precipitation can } \\
\text { be used to predict } \\
\text { Rotavirus }\end{array}$ \\
\hline Jutla et al, 2012 & Cholera & Chlorophyll & $\begin{array}{c}\text { Establish the link } \\
\text { between plankton and } \\
\text { cholera in Bengal } \\
\text { Delta }\end{array}$ \\
\hline Eisenberg et al, 2013 & Cholera & TRMM & $\begin{array}{l}\text { A strong relationship } \\
\text { between rainfall and } \\
\text { cholera was found }\end{array}$ \\
\hline Rose-Dye et al, 2014 & Diarrhea & Rumen Temperature & $\begin{array}{c}\text { Relationship between } \\
\text { temperature and } \\
\text { diarrhea }\end{array}$ \\
\hline Finger et al, 2014 & Cholera & $\begin{array}{l}\text { Temperature and } \\
\text { Precipitation }\end{array}$ & $\begin{array}{c}\text { Few models can } \\
\text { indicate cholera } \\
\text { dynamics in the area }\end{array}$ \\
\hline
\end{tabular}


Two objectives of this research are to (i) validate the epidemic cholera hypothesis in Africa and establish links between disease occurrence and Land Surface Temperature (LST), and (ii) develop a decision support system to predict risks of cholera.

Subsequent chapters present the research work performed to achieve the above mentioned objectives. Chapter 2 provides a review of some previous literature and detailed information about cholera. Chapter 3 presents the methodology that has been followed to achieve the goal of this research. The analysis and results are presented in Chapter 4. A brief summary, conclusions and future recommendations are presented in Chapter 5. 


\section{CHAPTER 2 : CHOLERA LITERATURE REVIEW}

\subsection{Background}

Cholera is known as one of the major causes of morbidity and mortality in the poor regions around the world (Luquero et al, 2011). According to the World Health Organization (WHO), Saharan African countries are considered the most affected by cholera with $95 \%$ of reported cholera cases and $99 \%$ of deaths which are accounting from the officially notified global cholera (WHO weekly reports, 2008). Although genomics of V.cholerae has been the subject of interest for many researchers, it is still very difficult to predict precisely when the next cholera epidemic will occur or even the location of that outbreak (Kelly-Hope et al 2008 and Penrose et al, 2010). The limited understanding of the climatic association of this disease with Vibrio cholerae, a causative agent of cholera, results in triggering conditions of cholera related to high cholera prevalence and incidence rates. Some significant advances showed that the highest rates of cholera cases and outbreaks are associated with poor standards of living, poor water supply, and poor human behaviors related to personal hygiene (Kelly-Hope et al 2008 and Penrose et al, 2010). Around 6,141 people in South Sudan have been affected by the recent outbreak of cholera (WHO Juba health updates, 2014).

\subsection{Cholera Risk}

Cholera can spread rapidly, resulting in explosive outbreaks, because of its short incubation period which ranges from few hours to 5 days after infection (WHO media center, 2014; Siddique et al, 1995). Mortality should be below $1 \%$ if treatment is applied appropriately and it could be as high as 30 to $50 \%$ in untreated cases (Penrose et al, 2010 and Zuckerman et al, 2007). In addition, the oral rehydration therapy and antibiotics are the main treatments to shorten the recovery period 
for cholera patients (Penrose et al, 2010). Furthermore, the reemerging of the bacteria as a newly form or serotypes in some regions makes it more difficult to treat the cases with traditional treatments.

Vibrio cholerae is a comma-shaped bacterium, it is usually transform via water or food that have been exposure to feces (poop) from a person infected with cholera, it is known as the main causative agent of cholera, which is a severe dehydrating diarrhea in humans (Bentivoglio and Pacini, 1995). Vibrio cholera is known for its ability to cause pandemics, for that reason it is considered unique among the diarrheal pathogens (Austin, 2010 and Faruque et al, 2004). Warm air temperature and low river flow usually create conducive environmental conditions for cholera bacteria to grow (Jutla et al, 2013). Aquatic environments, such as marine, estuarine and rivers, are considered appropriate environments for the bacterium to grow (Gaffga et al, 2007; Acosta et al, 2001). Vibrio cholerae can survive refrigeration and freezing but it is sensitive to acid and dies in solutions with $\mathrm{pH}$ less than 6. Vibrio cholerae are known for their short incubation period (1 to 5 days), which explains the quick increases in the number of cases a very short time after an outbreak (WHO media center, 2014).

There are around 200 serogroups of this bacteria denoted by O1, O2, etc. Two strains of cholera are now associated with the infection: $\mathrm{O} 1$ and $\mathrm{O} 139$; however, some other strains can cause diarrhea (Reidl and Klose, 2002; Penrose et al, 2010; Faruque et al, 2004). Inaba, Ogawa, and Hijokima are three serotypes of O1. Strains from O1 serogroup can be divided into two biotypes, Classical and El Tor. Figure 2.1 shows cholera serogroups and phenotypes that could cause cholera.

The ongoing pandemic, which is the seventh one, is the first pandemic identified to be caused by the El Tor biotype of Vibrio cholerae O1 (Gaffga et al, 2007 and Acosta et al, 2001; 
Nasser, 2009; Zuckerman et al, 2007; Dutta et al, 2013). It should be noted that V.cholerae O1 biotype El Tor was first observed in Indonesia and has since spread worldwide (Mukhopadhyay et al, 2014). In addition, $V$. cholerae $\mathrm{O} 1$ of El Tor biotype and Ogawa serotype (El Tor Ogawa) were observed in some cholera cases in Thailand in the 1990s (Kondo et al, 2001). However, V. cholerae O139 was responsible for the outbreaks which occurred in the Bengal area in 1992 (Kondo et al., 2001; Dutta et al., 2013; WHO weekly reports, 2013; Waldor et al, 1996 and Hoge et al, 1996). This serogroup (V. cholerae O139) has been isolated in India and Pakistan during the past 7 years (Zuckerman et al, 2007). Currently, the number of cholera cases caused by the serogroup O139 represents a very small proportion with respect to the total number of cholera cases (Mukhopadhyay et al, 1998 Zuckerman et al, 2007). For that reason, the concern of an eighth pandemic caused by the $\mathrm{O} 139$ serogroup was neglected. Other $V$. cholerae serogroups can cause human illness every now and then, but have not caused any known (Finkelstein et al, 1996).

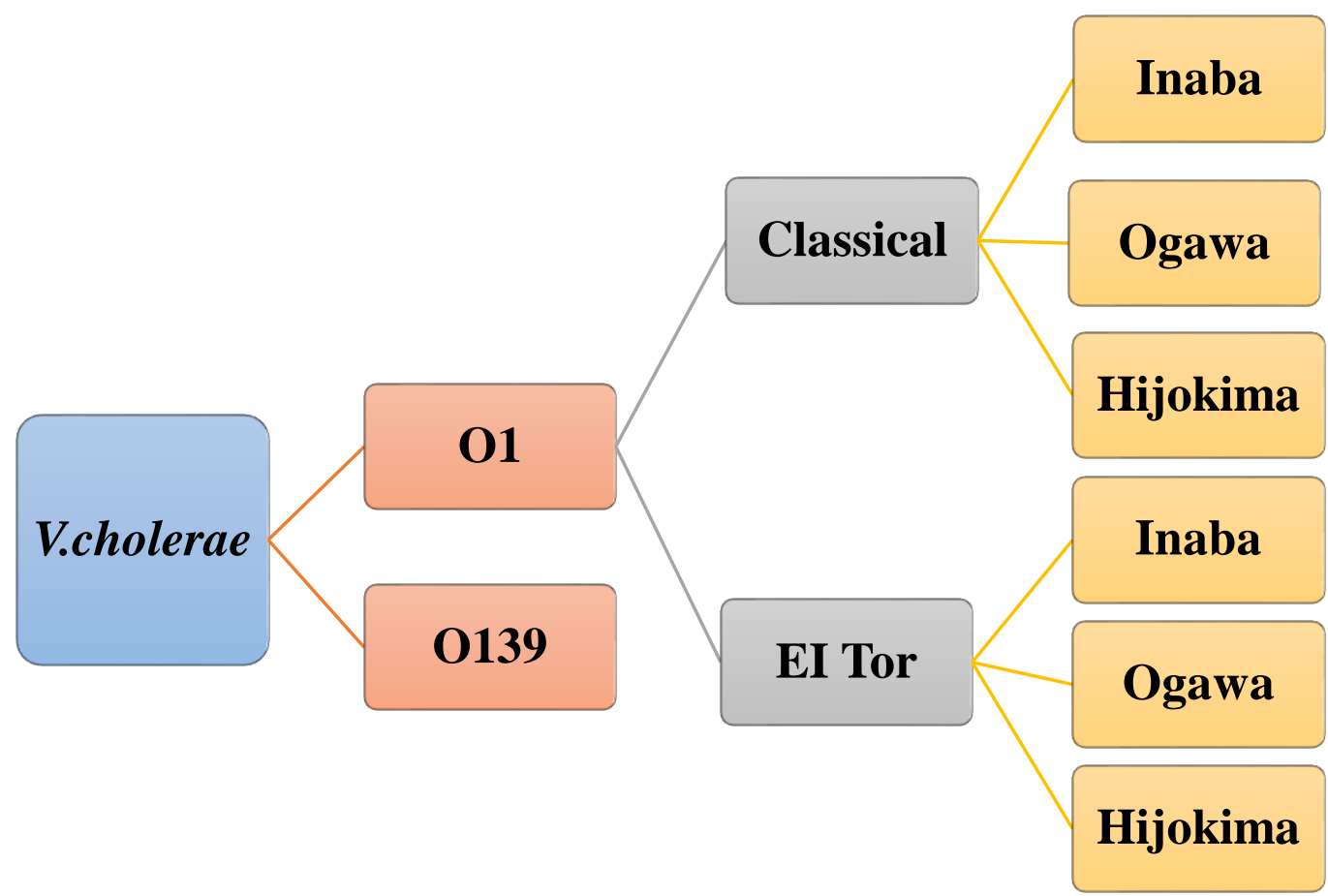

Figure 2.1: V.cholerae serogroups, phenotypes, and serotypes that could cause cholera. 
Numerous antibiotics, such as tetracycline, erythromycin, cotrimoxazole, furazolidone and new quinolones, were first used to treat cholera cases caused by V.cholerae O1 (Kitaoka et al, 2011; Falbo et al, 1999, Pierce et al, 1968 and Kondo et al, 2001). The treatment was effective until research showed that some strains of the bacteria have become resistant to one or more antibiotics. Resistant strains were observed in Africa, Asia, and Latin America (Kondo et al, 2001 and Yu et al, 2012). Some published literatures (Siddique et al, 1995; Islam et al, 1995) illustrated that tetracycline, ampicillin, cotrimoxazole, nalidixic acid, and doxycycline were no longer effective for cholera patients in Zaire with 33.3\% resistant strains of EI Tor Ogawa. However, erythromycin and mecillinam are still effective to treat cholera patients in Zaire. Kondo et al, 2001 reported that the EI Tor Ogawa strains isolated in Bangladesh were resistant to ampicillin, but still susceptible to tetracycline. However, EI Tor biotype and Inaba serotype by a percentage of 3.8 and classical biotype and Ogawa serotype by a percentage of 98.1 were resistant to tetracycline in Bangladesh (Kondo et al, 2001).

\subsection{Descriptive Epidemiology}

Epidemiology involves the studying of the distribution of a specific health issue and identifying the factors associated with that issue. Furthermore, epidemiology includes identifying the tools to prevent and control that health problem. Generally, the most important data that are related to health problems are number of cases, number of deaths if available, the area that is facing the problem, and the time period of the problem. Some of the most important terminologies which are very common in epidemiology are Case-Fatality Rate and Attack Rate. Case-Fatality Rate can be defined as the percentage of number of deaths resulting from a specific health issue to the number of cases diagnosed with the same issue. More than $1 \%$ Case Fatality Rate indicates one of 
three things: poor management, late arrival to health care centers or hospitals, or bias of surveillance (World Health Organization, 2004). Poor management at health care centers or hospitals could be caused by poor training for workers and medical personnel or could be caused by lack of supplies. On the other hand, Attack Rate refers to number of cases to the population at risk. An elevated number of attack rate refers to a very crowded area (World Health Organization, 2004).

\subsection{Epidemiology of cholera (Endemicity and epidemics)}

The sudden peak in the number of cholera cases in a disease-free region is known as epidemic (Jutla et al, 2013). Cholera epidemics are still unpredictable which make them a real threat (Clemens et al, 2011). Underdeveloped areas are considered a very good atmosphere for epidemics that is due to inadequate sanitation, poor hygiene, and limited access to safe water supplies (UNICEF, 2012; Finkelstein et al, 1996). Therefore, the relationship between cholera and seasonality has been the subject of interest for recent research. Cholera epidemics can affect both children and adults, but since children have weak immunity levels if compared to adults, children are affected with higher incidence rates (Clemens et al, 2011).

On the other hand, if the disease occurs frequently in a region for a period of at least 10 years, this region can be defined as an endemic region (Clemens et al., 2011). Endemic cholera usually occur in coastal areas. Cholera is endemic in many areas around the world, especially subSaharan Africa and South Asia. Additionally, cholera has recently become endemic in South and Central America (Brunette et al, 2014). Cholera is endemic is many populations in the Ganges Delta (Glass et al, 1982). In addition, mixed-mode cholera is a combination of epidemic and endemic disease occurrence. 


\subsection{Cholera cases reported to the World Health Organization (WHO)}

According to the World Health Organization, cholera is less prevalent when compared to 50 years ago with annual reported cases of 100,000 to 300,000. The reported cases of cholera in the period from 2000 to 2013 and the number of involved countries is shown in Figure 2.2. Figure 2.3 shows the number of cholera cases for different regions around the world in 2013.

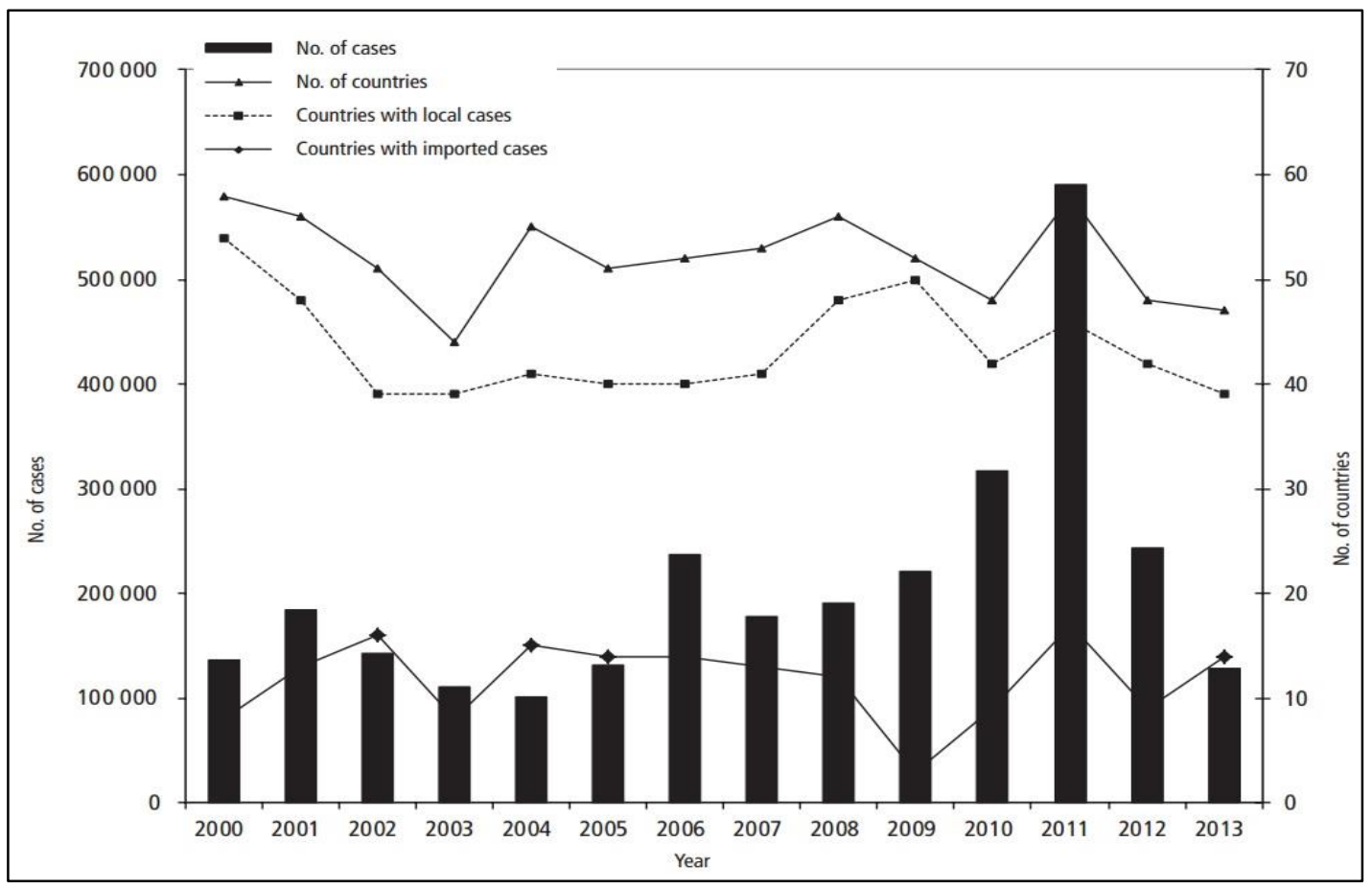

Figure 2.2: Countries/areas reporting cholera cases for the period of 2000 to 2013 (WHO, 2013). 


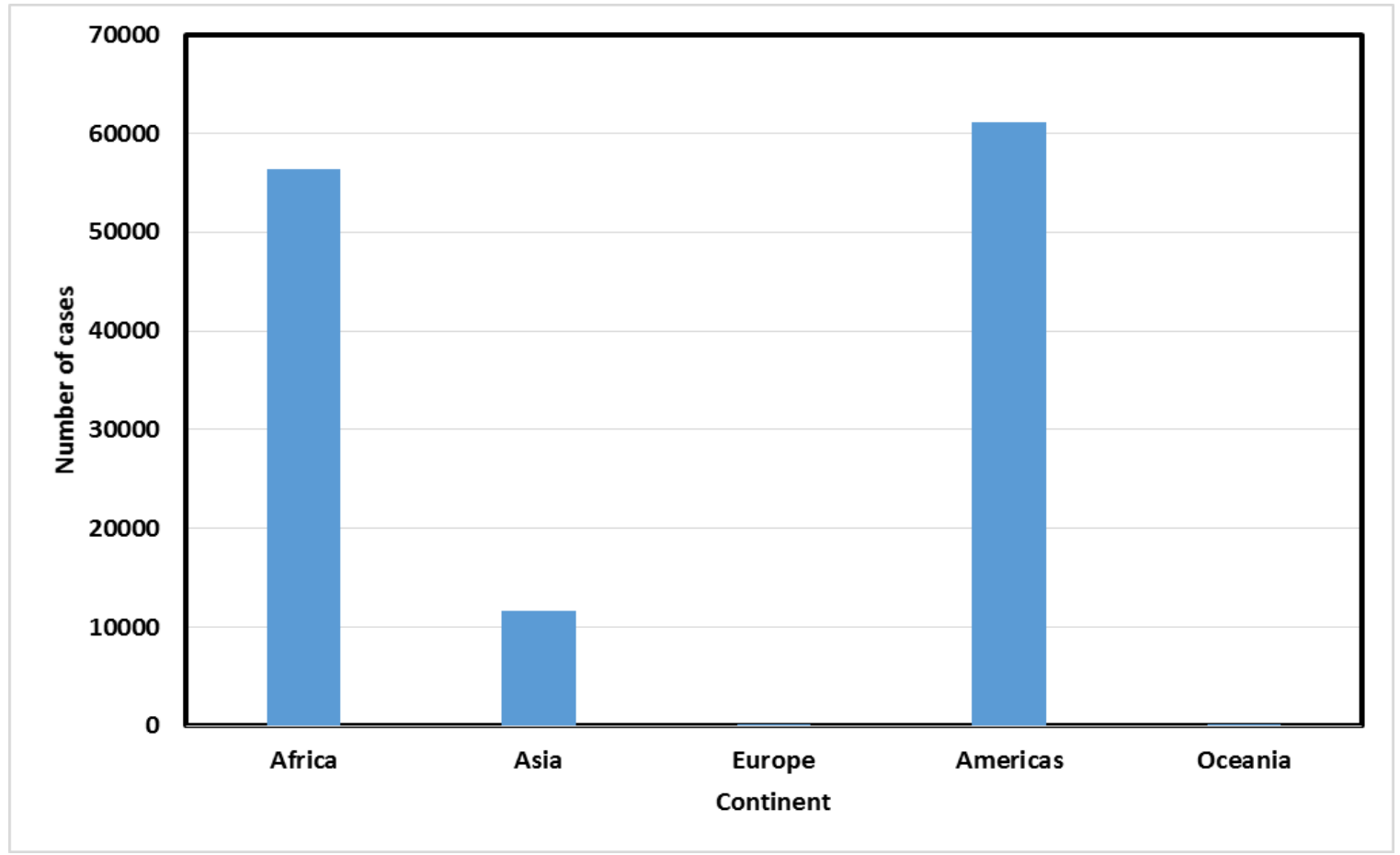

Figure 2.3: Number of cholera cases reported to WHO in 2013 (WHO, 2013)

A decrease of 47\% in cholera cases was reported by the World Health Organization in 2013 when compared to 2012; however, Asia has reported that cases have increased by $57 \%$ in 2013 compared with 2012 (WHO weekly reports, 2013). Furthermore, it is believed that the actual number of cholera cases differ from one report to another and that can be explained by the fear of negative impact on travel and trade (Zuckerman et al, 2007 and WHO weekly reports, 2013).

Imported cholera is considered as another threat for disease-free regions (Zuckerman et al, 2007). That is due to several reasons, such as immigration from low-income countries which tend to import the disease (Polsky et al, 2006; Bacaner et al, 2004; Noah et al, 2000). Furthermore, emergency relief workers and military personnel in cholera endemic and epidemic areas is another factor that could contribute to the spread of the disease. That is because of the direct contact with local population and the exposure to crowded living conditions, spatially after natural disasters, 
civil unrest, or war (Steffen et al, 2003). Additionally, tourism to visiting tropical countries is another source of imported cholera cases (Zuckerman et al, 2007).

Long-haul travel also tends to increase the risk of imported cholera (World Tourism Organization, 2001; Zuckerman et al, 2007). According to the World Health Organization, the actual number of cholera cases among travelers are likely to be higher than recorded since only the most severe cases of cholera are recorded (Steffen et al, 2003). During the year of 2012, around 129 were reported as imported cases, while the number was increased to 325 in 2013 (WHO weekly reports, 2012 and WHO weekly reports, 2013). Table 2.1 shows the imported cholera cases for some countries in 2012 and 2013. Asia has the largest share of total number of imported cholera cases during that period when compared to Europe and the Americas. These cases were discovered because of the intensive surveillance for the returning travelers with diarrhea in Asia (WHO weekly reports, 2013 and Zuckerman et al, 2007).

According to the World Health Organization (WHO), the reported numbers of cholera cases are underestimated when compared to the real numbers. That can be explained by the fear of the negative impact on travel, tourism, trade and limitations of surveillance systems. Also, lack of laboratory diagnostic capacities in some cases is considered another reason for underestimation, only severe laboratory-confirmed cases are being reported in some countries (Zuckerman et al, 2007 and WHO weekly reports, 2013; Alam et al, 2010 and WHO weekly reports, 2008; Steffen et al, 2003). For instant, an estimated cost of US\$770 million was the effect of the cholera epidemic in Peru in 1991 (Talavera et al, 2009). The WHO estimate that the actual number of cholera cases ranges between 3 to 5 million cases every year worldwide with more than 120,000 death cases (Jutla et al, 2013 and Gaffga et al, 2007). Africa is considered the origin of most of the reported cases of cholera to the World Health Organization (Mandal et al, 2011). 
Table 2.1: Imported cholera cases reported to WHO in different regions around the world in 2012 and 2013 (WHO weekly reports, 2013)

\begin{tabular}{|c|c|c|}
\hline & 2012 & 2013 \\
\hline \multicolumn{3}{|l|}{ Asia } \\
\hline China & 2 & 2 \\
\hline Iran & $\mathrm{O}$ & 211 \\
\hline Isreal & $\mathrm{O}$ & 1 \\
\hline Japan & 3 & 3 \\
\hline Malaysia & 81 & 77 \\
\hline Republic of Korea & $\mathrm{O}$ & 3 \\
\hline Singapore & 2 & 2 \\
\hline Total & 86 & 299 \\
\hline \multicolumn{3}{|c|}{ Europe } \\
\hline Italy & $\mathrm{O}$ & 1 \\
\hline United Kingdom & 17 & 6 \\
\hline Russian Federation & 1 & $\mathbf{O}$ \\
\hline Total & 18 & 7 \\
\hline \multicolumn{3}{|c|}{ Americas } \\
\hline Canada & O & 1 \\
\hline Bahamas & 1 & $\mathbf{O}$ \\
\hline Chile & $\mathrm{O}$ & 2 \\
\hline United States of America & 17 & 12 \\
\hline Venezuela & $\mathrm{O}$ & 4 \\
\hline Total & 18 & 19 \\
\hline \multicolumn{3}{|c|}{ Oceania } \\
\hline Australia & 5 & 2 \\
\hline Total & 5 & 2 \\
\hline Overall Total & 129 & 325 \\
\hline
\end{tabular}

Furthermore, a lot of cholera cases in Asia were not reported to WHO (Zuckerman et al, 2007; Schwartz et al 2006). In July of 2004, thousands of diarrhea cases were admitted to hospitals in Dhaka, Bangladesh. Around 22\% of laboratory specimens (3740 cases) tested positive for V.cholerae O1, but were not reported to WHO (Adagbada et al, 2012 and Schwartz et al 2006). These not reported cases were often linked to natural disasters and crowded living conditions (Clemens et al 2011). 


\subsection{Hydroclimatic control of epidemic cholera}

Climate has an effective role in the triggering some of severe infectious diseases such as shigellosis/dysentery, typhoid fever, and cholera (Kelly-Hope et al, 2008 and de Magny et al, 2008; Pascual et al, 2002 and Lipp et al, 2002). Additionally, the interannual variability and long-term trends of these diseases can be influenced strongly by climate (Kelly-Hope et al, 2008, Pascual et al, 2002 and Lipp et al, 2002). Research about cholera in Africa has shown an active role of climatic factors on the transmission of the disease (Mboera et al, 2012).

Climate variables that affect cholera incidence can be divided into global and local scales (de Magny et al, 2007). The El Niño Southern Oscillation (ENSO) is one of the global climate variables which is associated with dynamics of cholera in endemic regions such as Bengal and few African countries (Bouma et al, 2001; Hashizume et al, 2013; Finger et al, 2014). Increased rainfall and warm temperature have a strong association with cholera outbreaks in many regions around the world (Reyburn et al, 2011, Fernández et al, 2009 and Nkoko at el, 2011). Furthermore, high temperature along with inadequate water and sanitation services play a very effective role in making diarrhea more common (Mboera et al, 2012). Flooding and low levels of water might trigger factors related to outbreaks of cholera and other diarrhoeal diseases (Hashizume et al, 2008).The connection between local climatic conditions, such as rainfall, air temperature, and sea surface temperature (SST), and cholera transmission has long been the subject of interest for many researchers (Pascual et al, 2002, Henschel et al, 2013 and de Magny et al, 2008, Fernández et al, 2009, Patz et al, 1996, Patz et al, 2002).

As it was mentioned before optimal temperature and physicochemical conditions (salinity, $\mathrm{pH}$, humidity etc.) are necessary factors for Vibrio cholerae to grow and survive (Fernández et al, 2009, Lipp et al, 2002 and Akoachere et al, 2014). For that reason coastal and estuarine ecosystems, commensal with algae and the roots of aquatic plants, phytoplankton, zooplankton, 
and in particular copepods are considered a very good atmosphere for Vibrio cholerae (Colwell et al, 2009). Around $10^{3}-10^{5}$ Vibrios can be found attached to the gut wall of a single copepod; for that reason copepods are considered a significant vector that can transmit V.cholerae and thus cholera the disease (Reyburn et al, 2011, Fernández et al, 2009, Takemura et al, 2014 and de Magny et al, 2008). Phytoplankton, which represent a host of a very large population of zooplankton, tend to grow with warm surface temperature and thus the population of V.cholerae would increase since it is attached to it (Hashizume et al, 2008; Mboera et al, 2012). Sari cloth was used by Colwell et al, 2003 in Bangladesh in a laboratory experiment to remove zooplankton and all V.cholerae attached to plankton. The sari was folded around four to eight times, so it made a good filter of $\approx 20-\mu \mathrm{m}$ mesh size. The results of that experiment showed that the sari with at least four folds removed 99\% of $V$. cholerae attached to the plankton (Colwell et al, 2003).

Few studies have examined the impact of climatic factors on cholera (Fernández et al, 2009, Nkoko at el, 2011 and Reyburn et al, 2011). Literature suggests several climatic factors affecting cholera knowing the effects of some environmental factors on cholera could be crucial in identifying high risk periods (Kelly-Hope et al, 2008). The impact of some environmental factors, such as rainfall, flooding, water temperature and depth, sea surface temperatures, and the El Niño Southern Oscillation (ENSO), on cholera incidence has been addressed by some previously published literature (Emch et al, 2008; Kelly-Hope et al, 2008; Jutla et al, 2013; Pascual et al, 2000; Griffith et al, 2006; Reyburn et al, 2011; Nkoko at el, 2011, Fernández et al 2009 and Evengård et al, 2009).

Previous studies (Reyburn et al, 2011 and de Magny et al, 2008; Lobitz et al 2000) have been conducted in Kolkata, India; Matlab, Bangladesh; and Hue, Vietnam in order to predict cholera outbreaks and study the effect of three marine environmental factors (sea surface height (SSH), sea surface temperature (SST), and ocean chlorophyll concentration) on cholera incidence. 
Satellite imagery has been used by Lobitz et al, 2000 to observe ocean parameters values. The results of these studies have shown that a rise in the SST would cause phytoplankton populations to bloom, which is known for its association with V.cholerae, which indicate a positive association between the SST and cholera cases. Positive association between SSH and cholera cases was observed. Additionally, the results showed that the rise in ocean chlorophyll concentration encourages the growth of copepod populations, which in turn allows V.cholerae population to grow, which means that ocean chlorophyll concentration and cholera incidence are positively associated.

Some previously published literature (Emch et al, 2008; Kelly-Hope et al, 2008; Jutla et al, 2013; Pascual et al, 2000; Griffith et al, 2006; Reyburn et al, 2011; Fernández et al, 2009) have addressed the hydroclimatic impact on cholera incidence. Some of these studies are discussed briefly below.

In order to evaluate the development of three cholera epidemics in Lusaka, Zambia, a Poisson autoregressive model controlling for seasonality and trend was built by Fernández et al, 2009. Lusaka, the capital of Zambia is considered one of the regions that are more prone to epidemics than other regions (Fernández et al, 2009). The three epidemics took place during the years of 2003 to 2006 . Another objective of the study was to investigate the correlation between the increased weekly number of cholera cases and the maximum daily recorded maximum temperature and rainfall. It is worth mentioning that during the year of 2003 only $55 \%$ of the total country population had access to drinking water (Fernández et al, 2009 and FAO, 2009). The following results were observed from the study: 
1. About $5.2 \%$ of the increase in the number of cholera cases were associated with the $1{ }^{\circ} \mathrm{C}$ rise in temperature 6 weeks before the start of the outbreaks. The increased temperature encourage the growth of copepods and zooplankton and thus the growth of V.cholerae since it is attached to it, which means that aquatic environmental reservoirs play a very effective role in hosting the disease (Codeço et al, 2001; Tamplin et al, 1990 and Filho et al, 2010).

2. The three epidemics showed a seasonal trend associated with the rainy season that lasts from November to March, which indicates a significant association between cholera cases and rainy seasons.

A multivariate seasonal autoregressive integrated moving average (SARIMA model), has been used by Reyburn et al. (2011) in order to determine the influence of some environmental factors on cholera occurrence in Zanzibar, Tanzania. The influences of temperature and rainfall on the incidence of cholera were investigated in this study. Between 1997 and 2006, the SARIMA model showed temporal clustering of cholera. Additionally, the results of this study showed a double increase of cholera cases with a $1^{\circ} \mathrm{C}$ increase in temperature at 4 months lag. In addition, 1.6-fold rise of cholera cases have been identified with a $200 \mathrm{~mm}$ increase of rainfall at 2 months lag. Finally, the study showed that the interaction between temperature and rainfall can result in a positive association of $(\mathrm{P}<0.04)$ with cholera at a 1 month lag. More details about the results can be found elsewhere (Reyburn et al, 2011).

In order to demonstrate the effect of some local environmental parameters, such as ocean chlorophyll and sea surface temperature and height, on cholera incidence, Bivariate and multivariate statistical models were built by Emch et al (2008). In addition, tests for probability models for cholera outbreaks and severity were developed. The relationship between the 
mentioned environmental parameters and cholera incidence was examined by linking the temporal fluctuations of cholera incidence in Bangladesh and Vietnam with satellite-derived and in situ local environmental data. The results of this study indicated the following points:

1. Ocean chlorophyll concentration has a significant effect on cholera outbreaks in Bangladesh.

2. Cholera outbreaks were mostly affected by the increases in sea surface temperature in Hue, Vietnam.

3. The probability of a cholera outbreak could be raised by $15 \%$ with an increase of 3.6 degrees Celsius in temperature in Hue, Vietnam.

4. The effects of rain, river height, and river discharge have a positive effect on cholera outbreak in Nha Trang, Vietnam.

5. An increase in one standard deviation $(39 \mathrm{~cm})$ in Dinh River height increases the likelihood of an outbreak by more than $14 \%$ in Nha Trang, Vietnam.

6. A decrease in cholera severity was associated with increases in river discharge at both Bhairab and Demra.

7. Sea surface temperature and height, temperature, and rainfall have no significant effect on the severity of cholera in Bangladesh. More details about the results can be found elsewhere (Emch et al, 2008).

Cholera is considered a significant public health concern in Vietnam. Thus, prediction models are very important tools in forecasting cholera and identifying high risk and outbreaks periods (Emch et al, 2008). Kelly-Hope et al (2008) used general linear models to compare some environmental factors, such as precipitation, high temperature, and humidity, between high and low risk periods. The results of this study showed that cholera cases appeared during 1991-1996, with four main peaks in May 1992 (1,851 cases), August-September 1993 (943-1,054 cases), 
May 1994 (1,127 cases), and June-July 1995 (1,097-1,492 cases). Cholera decreased dramatically in the year of 1997 and after that. That decrease could be due to immunity, economic development, improvements and interventions in hygiene and sanitation, and the introduction of a new locally produced vaccine in 1997. The results also indicated that during high-disease periods, conditions were warmer, wetter, and more humid than low-disease periods. Additionally, the analysis showed that the differences in the weather conditions between the months during or proceeding each outbreak period with non-outbreak periods in previous years is not that significant. Precipitation ranged from 37 to $311 \mathrm{~mm}$ during the outbreaks.

Time-series analysis and field investigations have been performed by Nkoko et al, 2011 in order to investigate the association between cholera outbreaks and climate, and environmental factors in Burundi, Rwanda, Democratic Republic of Congo, Tanzania, Uganda, and Kenya. Those places were known to face cholera outbreaks every year during the period from 1977 to 1978. A multiscale, geographic information system was used to conduct the analyses. The following points were observed from the results of this study:

1. During the abnormally warm events, a great increase in cholera cases was noticed while a stable number of cholera cases was observed between these warm events.

2. Lakeside areas have the largest share of epidemics.

3. Season, rainfall and fluctuations of plankton control the weekly incidence of cholera.

4. Around 5 hotspots, with 84,465 cholera cases, were identified by using the time-series analysis. 
5. In the African Great Lakes region, cholera patterns are greatly affected by rainfall. Figure 2.4 shows the number of reports and localization of cholera outbreaks in the African Great Lakes region for the period of 1999-2008 (Nkoko at el, 2011).

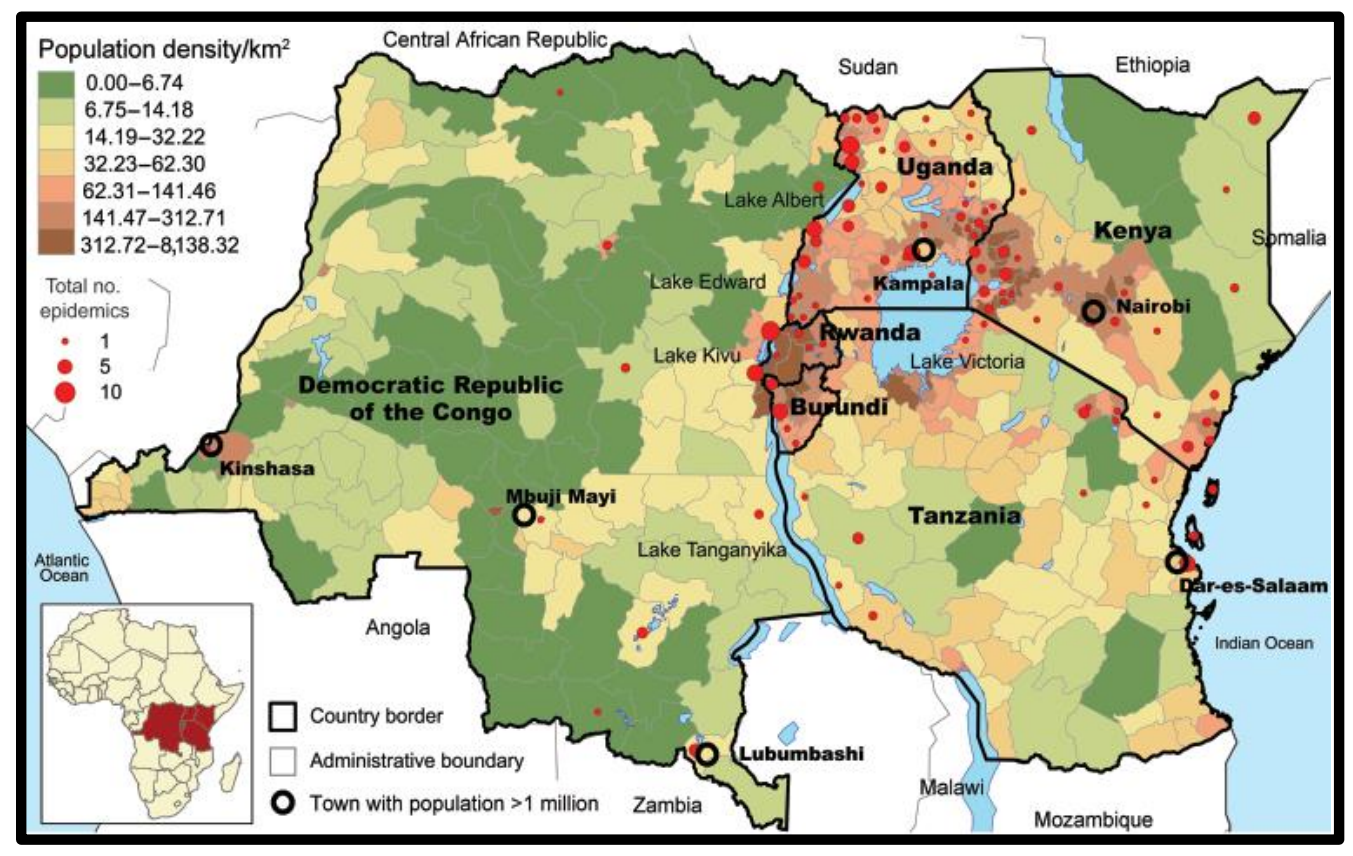

Figure 2.4 : Number of reported cholera outbreaks in the African Great Lakes region, 1999-2008, (Nkoko at el, 2011)

For better understanding of the relationship between hydro-environmental processes and cholera incidence in some epidemic regions, surveillance data for cholera outbreaks in some inland areas in India and Pakistan were analyzed by Jutla et al (2013). The analysis in this research work was done by using Microsoft Excel and MATLAB software. Cholera data were obtained by collecting and processing some historical environmental data from annual reports of the Meteorological Reporter to the Government of India for the time period of 1875 to 1900. Additionally statistical statements appended to the Annual Reports of the Sanitary Commissioner to the Government of Punjab were used to obtain cholera mortality observations. The research focused on nine inland areas in India and Pakistan: Delhi, Lahore, Ludhiana, Sialkot, Rawalpindi, 
Peshawar, Der Ismail Khan, Multan, and Sirsa. All of these areas received heavy rainfall from the month of June through the month of September and during the summer period; the average air temperature was greater than $30{ }^{\circ} \mathrm{C}$. The odds of cholera incidence during, above, and below average air temperature have been calculated in addition to the corresponding odds ratios. The results of this research work indicated the following:

1. When the air temperature is higher than the average over the previous two months, the odds of cholera incidence were higher, which means that cholera outbreaks have a very significant association with warm air temperature.

2. When the air temperature was more than $31{ }^{\circ} \mathrm{C}$, more than $50 \%$ of cholera outbreaks happened.

3. Appropriate transmission mechanisms, such as unsafe drinking water, unviability of sanitation infrastructure, rainfall, along with air temperature above the environmental average will result in an epidemic. More details about the results can be found elsewhere (Jutla et al, 2013).

A hydroclimatologic processes with cholera incidence in epidemic regions was presented by Jutla et al, 2013. They suggested a theoretical pathway for predicting cholera outbreaks connecting cholera occurrence with the hydroclimatic factors in two months in advance. According to the pathway, the probability of epidemic cholera diffusing in a specific region increases if the region witness a two months of above average air temperature followed by above average rainfall. In addition to the previous two factors, poor or damaged water and sanitation access, increases the risk of the outbreak increases. However, outbreaks' risk decreases if the air temperature and rainfall were below average and the water and sanitation access were available. An example of the relationship between the mentioned hydroclimatologic processes and cholera incidence is the 2010 
outbreak in Haiti. A huge earthquake, which destroyed sanitation infrastructure and water sources, hit Haiti before the outbreak, and then it witnessed above average warm air temperatures for a while. The results shows average air temperature in Haiti for 50 years and air temperature in 2010 was one standard deviation higher than the average and rainfall was higher than average one month preceding the outbreak (Figure 2.5) and (Figure 2.6) It is believed that these three factors (earthquake, air temperature, and rainfall) combined have an association with outbreak of that year (Jutla et al, 2013).

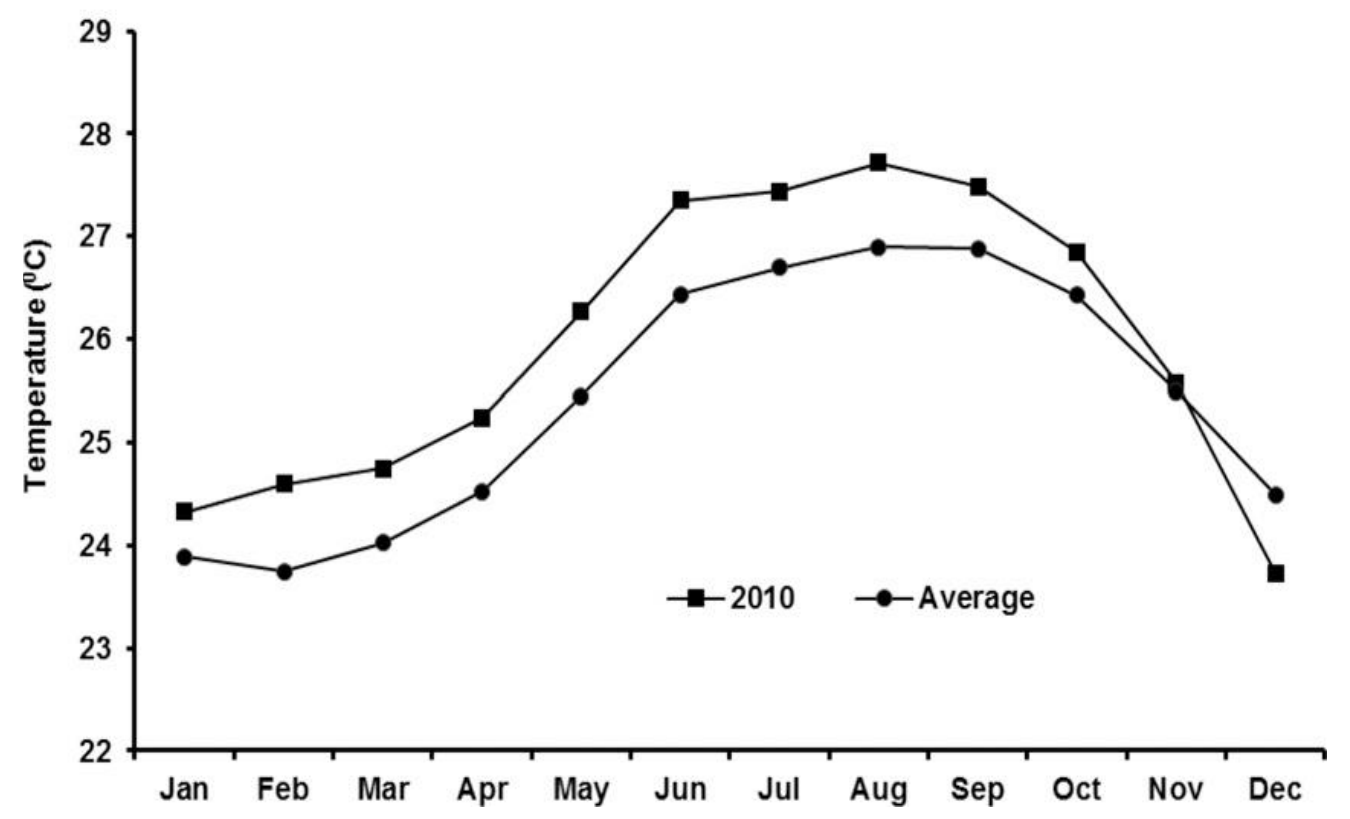

Figure 2.5: Haiti's average air temperature and air temperature in 2010 (Jutla et al, 2013) 


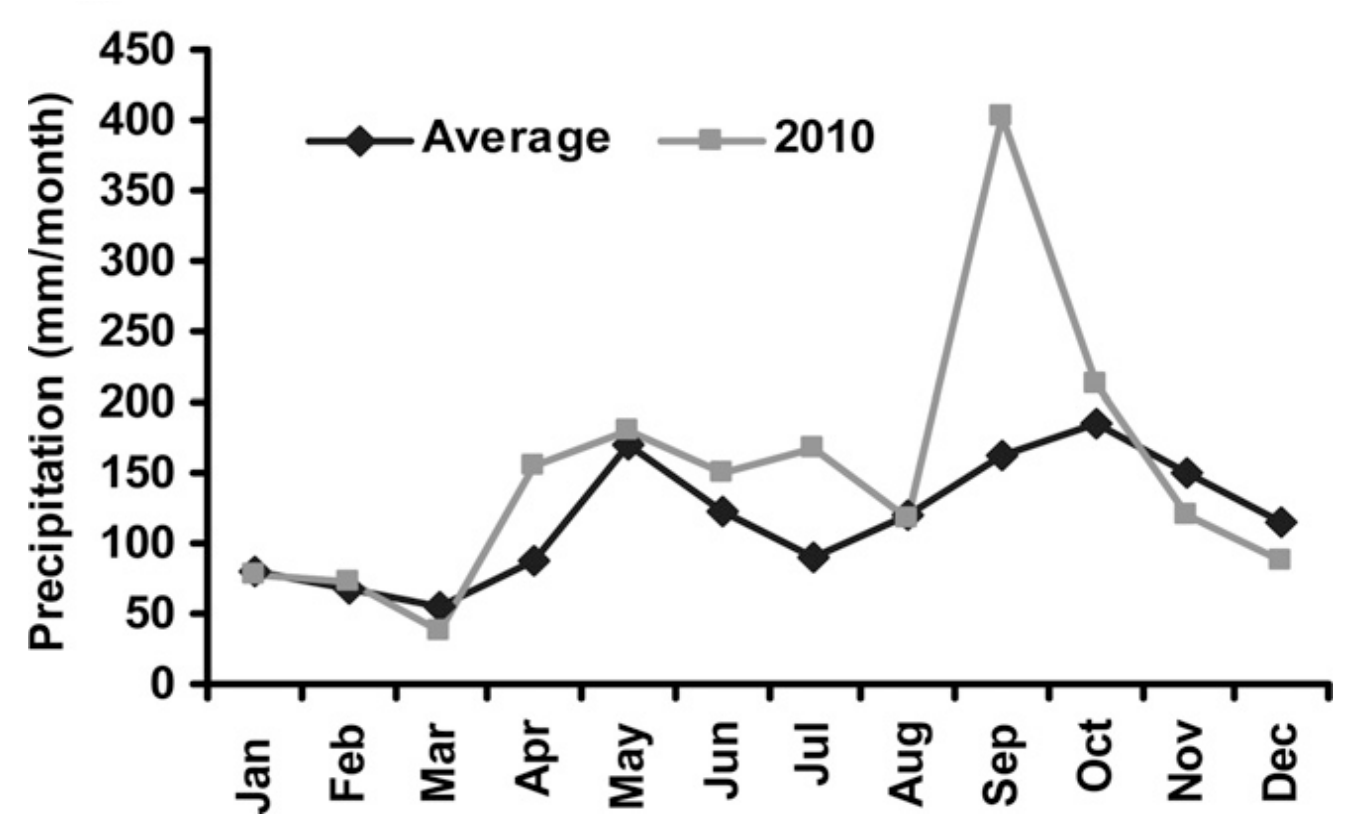

Figure 2.6: Haiti's average rainfall compared with rainfall in 2010 (Jutla et al, 2013).

Traerup et al. (2010) is considered one of the first studies that talk about the relationship between cholera incidence and environmental factors. The study showed how the mentioned relationship can be used to predict the effect of climate change on cholera outbreaks. Temperature was one of the environmental factors that this study has focused on. Cholera data were collected from the Ministry of Health in Tanzania, and the Tanzania Meteorological Agency. In this research work, the number of cases, deaths, and burden of disease were calculated. The results of this study indicated that the relationship between cholera occurrence and temperature is very significant. Additionally, the study indicated that a $1{ }^{\circ} \mathrm{C}$ increase in annual mean temperature would result in an increase of 23 to $51 \%$ in cholera's risk ratio in Tanzania. More details can be found elsewhere (Traerup et al., 2010).

Wandiga et al, (2006) demonstrated that the increase in sea surface temperature along with flooding in 1997 to 1998 in Djibouti, Somalia, Kenya, Tanzania, and Mozambique have been identified as two effective factors on cholera epidemics. Intensive rainfall in conjunction with low 
water table was associated with cholera outbreak in Dar el Salaam (Mayala et al., 2003). High temperatures before and during El Niño years, which is a global climate variable, has been identified in another study as a trigger factor to cholera epidemics in Lake Victoria basin (Wandiga et al., 2006).

\subsection{Non-hydro climatic control over Cholera}

Population is considered a non hydroclimatic factor affecting the cholera epidemic and the density of population may effect in the incidence of cholera. Cholera is easily transferred because of poor water management. Common areas of risk are semi-urban slums and refugee camps. This is because basic and necessary infrastructure is unavailable and clean water standards at camps are not upheld. If any disruptions hit an at risk community such as a refugee camp then the rate of transmission for cholera will speed up once it has been introduced into the community. An example disruption would be the sanitation and water system. Cholera is still a threat to the world's health and can represent areas where social development is lagging. The reoccurrence of cholera is shown to be linked to an increasing number of unsteady and at risk populations which are exposed to unsanitary conditions. (Penrose et al, 2010, WHO Media Centre, 2014).

On the other hand, Cholera outbreaks can be linked to destruction of water and sanitation infrastructure after social disruption or natural disaster (Jutla et al, 2013). Actually, a natural disaster caused flooding, property damage, and damage to the water treatment and sanitation system. As example, the disease increased in Rwanda after natural disaster (Flooding) (ReliefWeb Rwanda, 2014). Similarly to Cameroon situation, the displacement of people and disruptions to water and sanitation systems increased disease throughout the region (ReliefWeb Cameroon, 2014 and WHO Country Profile, 2011). 


\subsection{Outbreaks and risks of Cholera in Africa}

Most regions in Africa are coastal regions so they considered as endemic. However, there are many noncoastal regions are considered epidemic such as Zambia and Congo. Studies about the association between cholera outbreaks and climate factors in Africa is still limited since Africa is considered a new homeland of the disease (Gaffga et al, 2007). The results of some previous research work showed that sea surface temperature (SST), precipitation, and coastal phytoplankton have a direct association with the two years (2000-2001) of cholera outbreaks in KwaZulu-Natal in South Africa (Mendelsohn et al, 2008). Furthermore, temperature and rainfall impact on cholera incidence was investigated in Tanzania and a positive association was identified (Traerup et al, 2011). About 234,349 cholera cases were reported to the World Health Organization (WHO) in 2006 (Gaffga et al, 2007). Some hospital reported cases for children under the age of thirteen have shown a positive correlation with historical precipitation and temperature in previous studies (Thompson et al, 2012; Rebaudet et al 2013). Approximately $38 \%$ of cholera cases showed a direct association with temperature and rainfall based on a regression analysis (Thompson et al, 2012). Since it is not possible to eliminate the pathogen of cholera from the environment, it is necessary to figure out some new strategies to mitigate the effects of the disease on any population.

According to the world health organization (WHO), the available data of cholera over (1942-2012), Africa has the largest share of total number of cholera cases during that period with around 4 million cases compared with 2 million in Americas and 3 million in Asia over the same period of time (Figure 2.7). The World Health Organization (WHO) inspected the risk of waterrelated diarrheal diseases, especially cholera burden, to predict the increase in the relative number of diarrheal incidences for 2030 in Sub-Saharan Africa (Mathers et al, 2006). Based on the previous studies that were used for that purpose, WHO used an average of 5 percent to forecast the increase 
in the relative number of diarrheal occurrences, taking socio-economic development and increased coverage of water and sanitation into consideration (Mathers et al, 2006; Trærup et al, 2011).

Waterborne diseases are considered a significant economic burden, especially in SubSaharan Africa, because of its impact on the health sector and households (Trærup et al, 2011), and thus country's budgets (Kosek et al, 2003). Additionally, studies about climate change in SubSaharan Africa refer to increased rainfall variability, temperatures, and prolonged droughts, thus climate will cause large additional economic burdens to societies (Ringler et al, 2011). Hence, adaptation measures, which means taking suitable actions into consideration based on the expecting climate change to prevent the damage that they could cause, is considered the main strategy to mitigate the impact of climate change during the next few decades. Adaptation examples include building flood defenses, raising the level of dams, and growing drought-tolerant crops (Sena et al, 2014 and Furgal et al, 2006; WHO Europe, 2002).

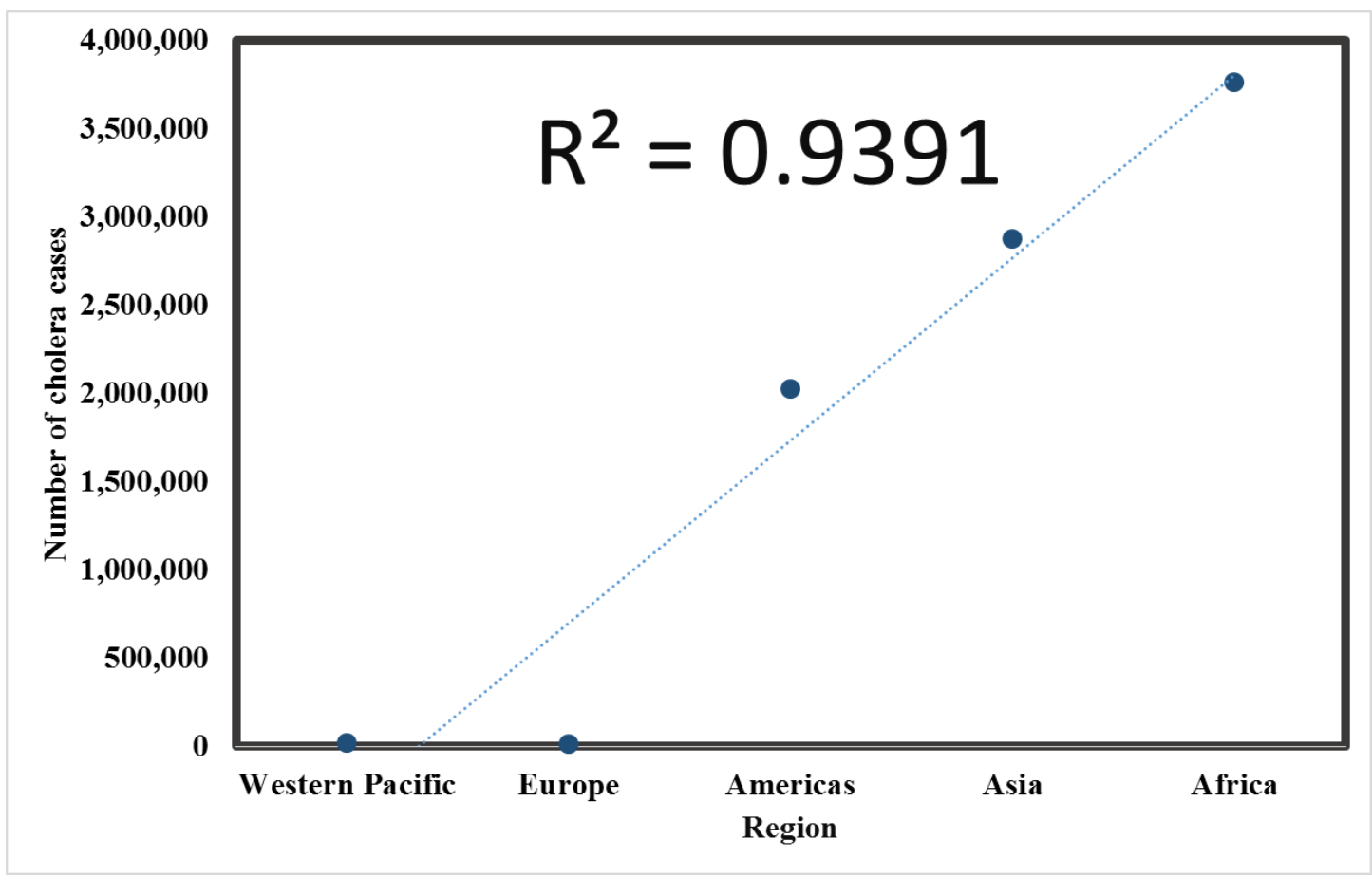

Figure 2.7: Total cholera cases in some regions around the world (1949-2013) (Data from WHO) 


\subsection{Diagnosis of Cholera}

Early detection of cholera cases can be achieved by the rapid diagnostic test (RDT). Confirmation can be done by using traditional laboratory procedures if samples that are taken from patients tested positive with the RDT (WHO, 2009). A dark-field microscope can be used in the laboratory to view the patients' stool. The organisms are usually clear in the stool sample. Stool testing is considered very important in diagnosing cholera, because it is almost impossible to distinguish between patients with cholera and patients who suffer from any other type of watery diarrhea (Volk et al, 1991). Observed organisms can be isolated and identified by using selective medium, such as thiosulfate-citrate-bile salts agar. In addition, confirmation of the organisms can be done by using labeled antiserum (Volk et al, 1991). V.cholerae O1 is the most common cause of the disease, so if an epidemic of cholera is suspected, the laboratory should be looking for V.cholerae O1. Otherwise, V.cholerae O139 should be detected (WHO, 1999).

\subsection{Treatment of Cholera}

Oral Rehydration Salts (ORS) is considered the main treatment for cholera patients to prevent death cases (Gaffga et al, 2007). Comparing the mortality of an epidemic before and after the use of ORS could be a tool to determine the efficacy of the therapy (Volk et al., 1991). Replacement of fluids and electrolytes within appropriate time could reduce the rate of mortality to less than $1 \%$. Additionally, for electrolyte replacement, any metabolizable carbohydrate together with $\mathrm{NaCl}$ is known to be very effective. Antibiotic therapy, particularly Tetracyclines, is considered another way to reduce the period of illness and it is considered effective in severe cases. In rural areas, glucose is usually added to the salt solution in order to be used for the oral 
replacement of electrolytes. Salted rice soup that is cooked very well is recommended for cholera patients who face difficulties obtaining a glucose-salt solution (Volk et al., 1991).

\subsection{Cholera Prevention and Control}

Proviing safe drinking water is considered the most important requirement to control cholera and other diarrhoeal disease transmission (WHO Media Centre, 2014). Thus, increased access to clean, affordable and safe water and sanitation is the main objective of decision-makers and national governments (Trærup et al, 2011). Acceptable water sanitation, as well as the detection and treatment of cholera requires heavy investment of significant financial resources especially in populations at risk (Steffen et al, 2003). Another way to protect against cholera is vaccines and mass chemoprophylaxis with antimicrobials (Seas and Gotuzzo, 1996). Support any activity or intervention by national government that could help in changing hygienic practices and spread health awareness and thus reduce or mitigate the risk of the disease.

\subsection{Cholera Vaccination}

Beside improved water supplies, adequate sanitation, and health awareness, cholera vaccine is considered as another strategy to control the disease. The World Health Organization (WHO) recommends the cholera vaccine in emergencies; however WHO doesn't recommend the vaccine during outbreaks. That is because of the massive logistics concurrent to the application of the vaccine in addition to time lap required for obtaining protective efficacy. Other reasons that make vaccines undesirable are side-effects, limited efficacy, cost, and the fact that vaccination cannot stop the spread of disease (Zuckerman et al, 2007). Cholera vaccine was produced after the discovery of Vibrio cholerae in the 1880s and it was first used by travelers during the early part of the 20th century (David et al., 2004; Aumatell et al, 2011). 
A live, attenuated, genetically modified strain of cholera was used to prepare the vaccine, CVD 103-HgR. The O1 strain was used for this vaccine (Simanjuntak et al, 1992). Volunteer studies in North America showed a noteworthy increase in vibriocidal antibody levels in $92 \%$ of individuals. Furthermore, these studies showed a high level of protection, as high as $94 \%$ to $100 \%$, could be reached by the use of CVD 103- HgR. The vaccine in this study was protective against severe and moderate diarrhea caused by different types of V.cholerae O1 (Ryan et al, 2000). Even though the results of these studies were significant, the manufacturer of this vaccine stopped producing in 2004 for some reason (Chaignat et al, 2007). A combination of killed whole-cell V.cholerae $\mathrm{O} 1$ and recombinant $\mathrm{B}$-subunit of cholera toxin $(\mathrm{WC} / \mathrm{rBS})$ is another type of vaccine which has been sold in the market since the early 1990s (Chaignat et al, 2007; Ryan et al, 2000; WHO Programmes, 2015). After the second oral vaccination, a level of protection as high as $85 \%$ to $90 \%$ for 6 months can be reached (Chaignat et al, 2007). However, a level of $50 \%$ protection can be maintained after 3 years of vaccination in vaccines who are 5 years or older at the time of vaccination (Chaignat et al, 2007).

Three oral doses is the primary immunization for children aged 2 to 5 years, while adults and children 6 years old and above should have two oral doses according to WHO. In all ages, the delay of the second dose for more than 6 weeks result in re-vaccination. The immunization should be repeated after 2 years for adults and children aged 6 years or more, while 2 to 5 year old children should be vaccinated every 6 months. WHO doesn't allow the vaccination for children aged less than 2 years. Based on V.cholerae serogroups $\mathrm{O} 1$ and $\mathrm{O} 139$, two cholera vaccines were certified in India and Vietnam. Toxin Bsubunit is not included in these two vaccines and the percentage of protection is ranged between 66 to $67 \%$ (Zuckerman et al, 2007). 
Peru-15 is another type of vaccine that could be used against cholera, this vaccine is derived from V.cholerae O1 El Tor strain (Kenner et al, 1995). The volunteer studies in Bangladesh and North America about this type of vaccine showed that the protection level is at least $62 \%$. Other types of live attenuated vaccines that could be used against cholera are in development (Zuckerman et al, 2007). Some cases where cholera vaccines have been given are discussed briefly below.

\subsubsection{Refugee Camps}

About 44,000 people in refugee camps in Uganda were vaccinated with WC/rBS in 1997. According to literature the vaccination was very effective since none of the vaccinated individuals got infected by cholera during the epidemic that occurred a year later (Legros et al, 1999). In Sudan, in 2004, around 88 to $94 \%$ vaccine coverage was achieved by the World Health Organization (WHO). The vaccination was done in camps in south Darfur, Kalma and Mussei where frequent cholera outbreaks have been reported from December to April. Reports indicate no cholera cases from Sudan in 2004, which means that the vaccination was successful (Zuckerman et al, 2007, Martin et al, 2014).

\subsubsection{Endemic Regions}

Cholera vaccine WC/rBS was used to vaccinate individuals in Beira, Mozambique. Cholera outbreaks are frequent in Mozambique during rainy seasons; for that reason, vaccines were introduced to people before the rainy season. The results of these immunization campaigns showed a protective rate of $78 \%$, even though the population have a high prevalence of HIV (Zuckerman et al, 2007; Lucas et al, 2005).

\subsubsection{Travelers}

According to the World Tourism Organization (WHO), only severe cholera cases among travelers are reported, which means that the reported cases do not reflect the actual numbers of infection (UNWTO, 2005; Zuckerman et al, 2007). In order to avoid cholera infections and 
importing cholera, travelers from high income countries should be vaccinated especially if their destination is one of the endemic regions or high risk of infection regions (Zuckerman et al, 2007). Cholera vaccine is usually recommended for a specific group of travelers, such as individuals who take medication that lowers gastric acidity, individuals with medical disorders, and individuals who are at increased risk of exposure (emergency relief, health workers, and military personnel). $\mathrm{WC} / \mathrm{rBS}$ cholera vaccine is recommended for travelers because it is the only vaccine with proven effectiveness against cholera and Enterotoxigenic E coli, which is a diarrhea that is very common in cholera epidemic and endemic regions (López-Gigososet et al, 2007; Zuckerman et al, 2007; WHO Programmes, 2015; Lilliestierna et al, 2006).

\subsection{Surveillance Systems}

The Surveillance Systems can be defined as the process of gathering, studying, and interpreting data about a specific health issue in a specific region (Thacker et al., 1996). After the interpreting of the data, the information should be transferred to the authorities responsible for prevention and control if hazards were diagnosed.

Surveillance Systems are considered a great tool to predict outbreaks and control cholera spread. Good information can be gathered if workers are trained in how to collect basic information. Analyzing this basic information by person, place, and time is an important part of the preparation process for cholera outbreaks (World Health Organization, 2004). The role of this analyzed information emerged when there was a sudden increase in cases of diarrhoeal syndrome. Rapid action was taken to prevent the spread of the disease according to the information provided by the surveillance system (Zuckerman et al., 2007; World Health Organization, 2004). Figure 2.8 shows how the information was gathered for person, place, and time manner. 


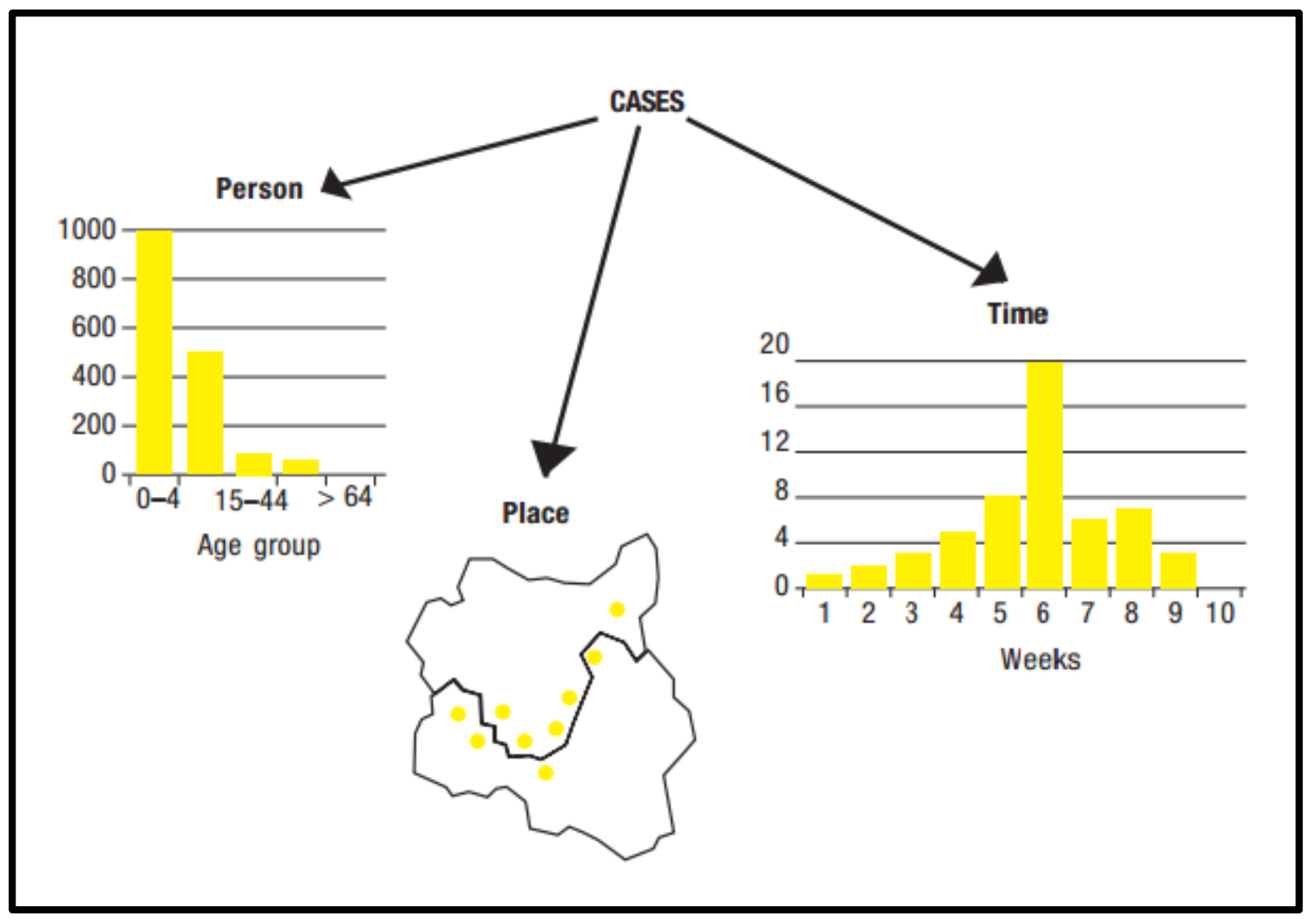

Figure 2.8: Basic information categorized by person, place, and time (World Health Organization, 2004)

Surveillance Systems include three different types: hazard surveillance, exposure surveillance, and outcome surveillance (Thacker et al., 1996). The evaluation of the incidence and distribution of a disease is known as the hazard surveillance. The exposure surveillance can be defined as the continuous monitoring of a population or even individuals of that population for any environmental factor that might represent a health threat. Moreover, outcome surveillance means the action that will be adopted by officials (Thacker et al., 1996). Figure 2.9 demonstrates the role of surveillance systems in some issues and the level that they can achieve.

Evaluating the true threat of cholera on any population is considered a difficult task due to underreporting of cases, poor surveillance, and weak laboratory reports which don't represent the 
actual cholera cases. Integrated surveillance systems have been used by some developing countries in high risk places in order to identify the real numbers of cholera cases (WHO, 2015).

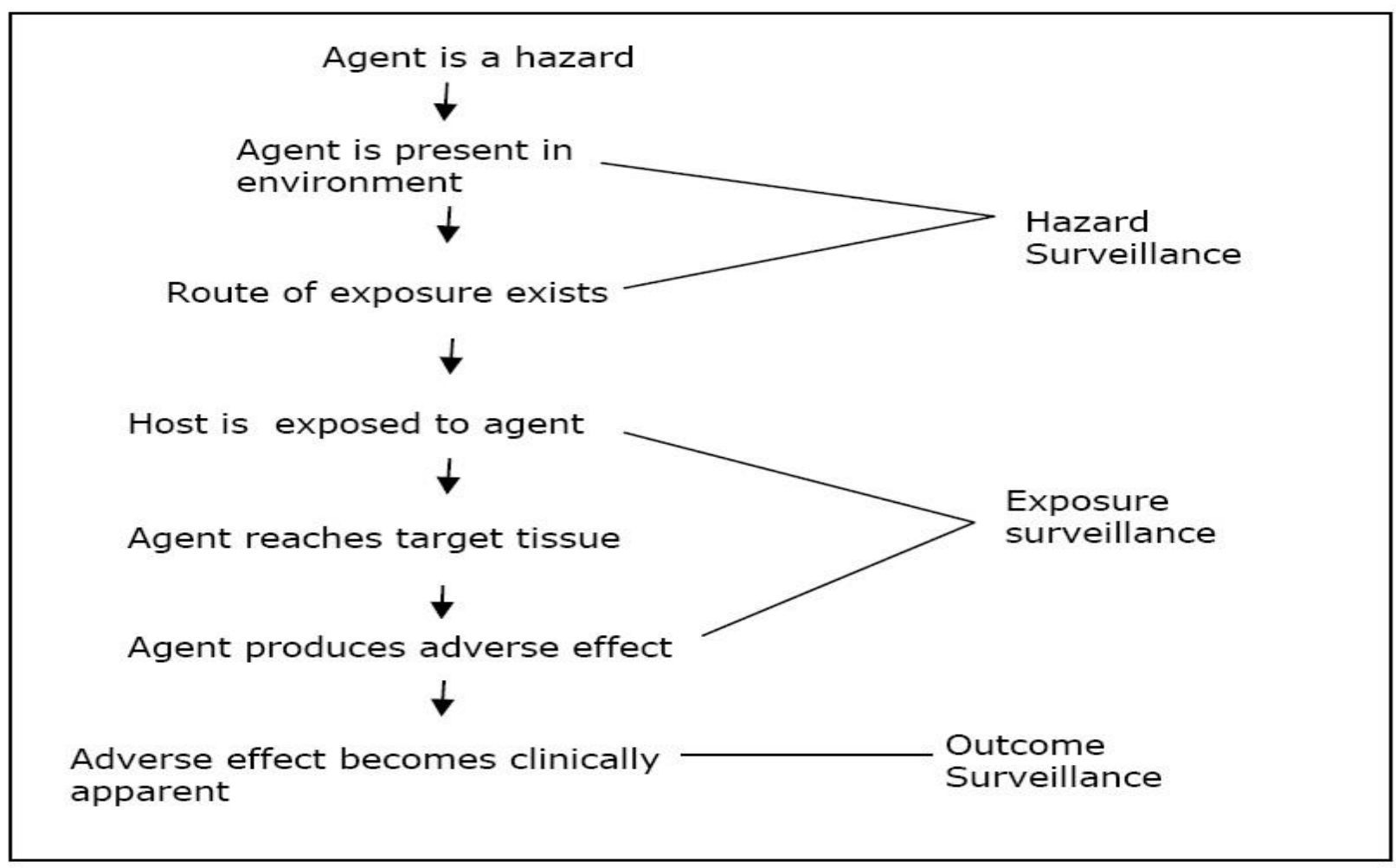

Figure 2.9: the role of surveillance systems in some issues and the level that they can achieve (Thacker et al., 1996) 


\section{CHAPTER 3 : RESEARCH METHDOLOGY}

\subsection{Study location}

The study was designed to seek an understanding of the relationship between hydro climatic processes and cholera in five epidemic regions in Africa. The regions analyzed for cholera outbreak were Central African Republic, Rwanda, Mozambique, Cameroon and South Sudan as shown in Figure 3.1. The cholera outbreaks of 2009 in Cameroon, 2011 in the Central African Republic, 2012 in Rwanda, 2013 in Mozambique, and 2014 in South Sudan were selected in this study. Listed below are the details for every affected region in Africa:

1- The Central African Republic is bounded by $2^{\circ} \mathrm{N}$ to $11^{\circ} \mathrm{N}$ latitude and $14^{\circ} \mathrm{E}$ to $26 \mathrm{E}$ longitude. The cholera outbreak occurred in September, 2011, in Bangui, which is located in the south of the country Figure 3.1e. Bangui has a tropical, wet climate with a dry season from October to April and a rainy season from May to September. There are no large fluctuations in the seasonal temperatures, which have a mean of about $27^{\circ} \mathrm{C}($ Georges et al, 1984).

2- South Sudan is bounded by $3^{\circ} \mathrm{N}$ to $12^{\circ} \mathrm{N}$ latitude and $24^{\circ} \mathrm{E}$ to $34^{\circ} \mathrm{E}$ longitude. South Sudan is located within the tropics. The climate is considered equatorial. The climate always falls within conditions of high humidity and abundant rainfall. The rainy season generally occurs between the months of April and November and vary from one part of the region to another (United Nations, 2011). In April, 2014, the cholera outbreak started in Juba County, which is located in the South of the country displayed by Figure 3.1b (WHO Juba health updates, 2014). 
3- Mozambique is located on the eastern coast of southern Africa and bounded by $10^{\circ} \mathrm{S}$ to $27^{\circ}$ $\mathrm{S}$ latitude and $29^{\circ} \mathrm{E}$ to $40^{\circ} \mathrm{E}$ longitude. Mozambique has a tropical climate with two seasons during each year. The wet season occurs from October to March. The dry season occurs from April to September. Depending on the altitude, the climate conditions may vary in all parts of the country. Rainfall is heavy along the coast and decreases from north to south. The outbreak started in February, 2013 in Nassa and Delgado Cabo, which are located in the north of the country as shown by Figure 3.1d (WHO Country Profile, 2013).

4- Rwanda is bounded by $0^{\circ} \mathrm{S}$ to $2^{\circ} \mathrm{S}$ latitude and $28^{\circ} \mathrm{E}$ to $30^{\circ} \mathrm{E}$ longitude. The country has two rainy seasons. These seasons occur from February to May and from September to December. The daily average temperature is $22.8^{\circ} \mathrm{C}$ (World Travel Guide, 2015). The cholera outbreak occurred in October, 2012, in Rutsiro, which is located in the Western Province (Figure 3.1c).

5- Cameroon is bounded by $1^{\circ} \mathrm{N}$ to $13^{\circ} \mathrm{N}$ latitude and $8^{\circ} \mathrm{E}$ to $16 \mathrm{E}$ longitude. The climate varies over the terrain. The climate goes from tropical along the coast, to semiarid, while being hot in the north. The study will highlight the cholera outbreak in the Nord Region, in the north of the country, (Figure 3.1a) that started in September, 2009 (WHO Country Profile, 2012). 


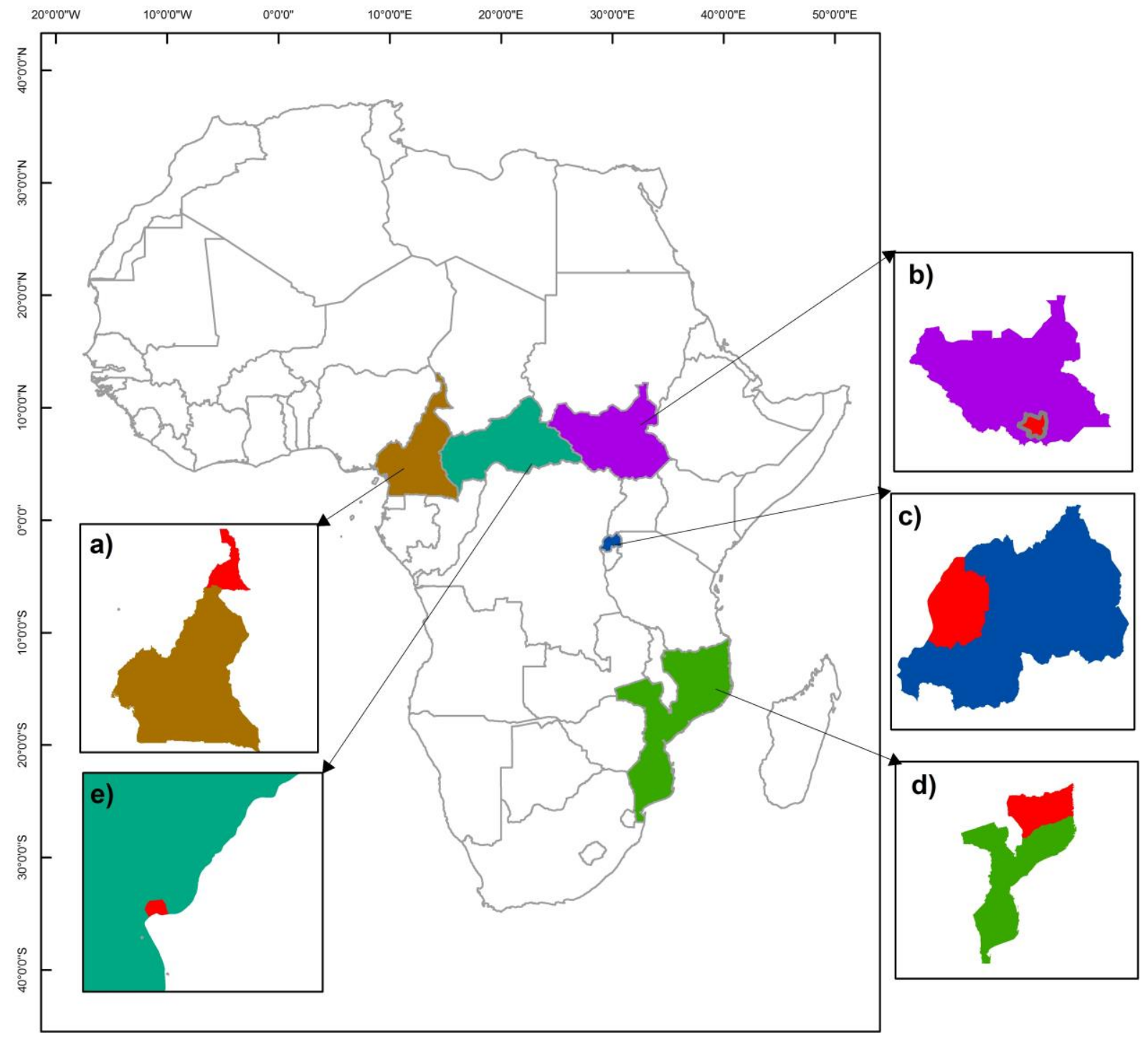

\section{Legend}

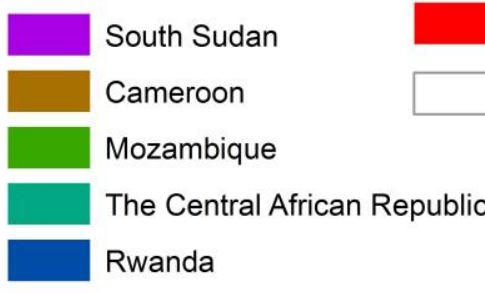

Cholera outbreak location Country Boundary

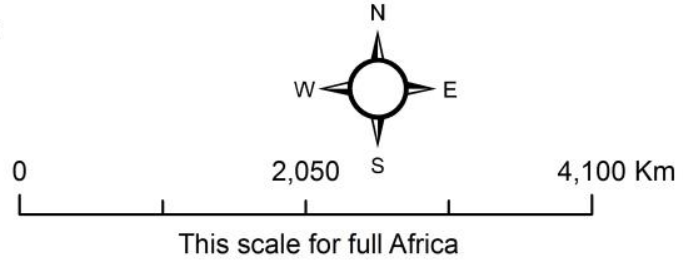

Figure 3.1: The five epidemic cholera regions in Africa are: a) Cameroon; b) South Sudan; c) Rwanda; d) Mozambique and e) The Central African Republic. 


\subsection{Disease data}

We obtained data on the cholera outbreak in Juba County, South Sudan, in April, 2014, from the World Health Organization (WHO) website. The data of the cholera outbreak in the Nord region, Cameroon in September, 2009 and Mozambique in February, 2013 were obtained from the profile page of each country on the WHO website (WHO Juba health updates, 2014; WHO Country Profile, 2011 and WHO Country Profile, 2013). Also, the Centers for Disease Control and Prevention (CDC) has provided important information about the cholera epidemic in Bangui, The Central African Republic (CDC Foundation, 2011). The bulletin served in east Africa, the East African Integrated Disease Surveillance Network (EAIDSNet), made reports that explained the cholera incidence in Rutsiro district in Rwanda in October, 2012 (EAIDSNet, 2013).

\subsection{Climatic data}

During the time period from 1998 to 2014, satellites have recorded data for the hourly precipitation from the tropical rainforest by the "Tropical Rainfall Measuring Mission" (TRMM; data product $3 \mathrm{~B} 43$ at $0.25 \times 0.25$ degree resolution). TRMM is a part of the National Aeronautics and Space Administration (NASA) Earth Science Enterprise. The TRMM contains a 3B43 file that can retain a one-month estimate of the precipitation. The data is represented on a $0.25 \mathrm{deg} \times 0.25$ deg grid (latitude-longitude) with an array of points that range $50 \mathrm{~N}-\mathrm{S}$ latitude. The grid is sized to $400 \times 1440$, the $\mathrm{x}$-axis refers to the latitude and the $\mathrm{y}$-axis refers to the longitude (Giovanni NASA, 2014). Due to the changing number of days in each month, the units of $\mathrm{mm} / \mathrm{hr}$ are used to compare the data from month to month. The data is formatted into a monthly average by the $3 \mathrm{~B} 43$ product. An Excel spread sheet can be utilized to convert the data or to multiply the hourly rain rate by the total number of hours in that month (Giovanni NASA, 2014). 
Air temperature data were obtained from the Global Historical Climatology Network version 2 Climate Anomaly Monitoring System (GCHN CAMS-0.5x0.5 degree resolution) for the same time period. Raw data for that time period was obtained, processed, and imported to Matlab software (The MathWorks, Inc., Natick, MA, USA) and Microsoft Excel (Microsoft Corporation, Redmond, WA, USA), allowing both temporal and spatial data to be analyzed with the cholera data (ESRL NOAA).

\subsection{Land Surface Temperature}

Land Surface Temperature (LST) can be defined as the temperature of the interface between the Earth's surface and its atmosphere. The earth has many different geologically defining features. However, the "surface" refers to what the satellite sees when looking at the earth. There are many different examples of types of surfaces. These can include man-made surfaces, such as the top of a building, or natural surfaces such as the top of a mountain. However, the inside of a cave would not be considered a surface. Thus, there is a difference between land surface temperature and air temperature that is included in the daily weather report (NASA Earth Observatory).

Data from the Moderate Resolution Imaging Spectroradiator (MODIS) by the NASA Terra Satellite shows temperatures varying between -25 degrees Celsius and 45 degrees Celsius. A higher level latitudes, land temperatures show more variance throughout different seasons of the year. Regions that are close to the equator are almost always warm. Other regions that have very consistent temperatures are Antarctica and Greenland, except rather than being hot they remain consistently cold. One of the main factors in temperature variation is altitude. The mountains are always cooler than their surrounding regions simply because of the high elevation. 
Both satellites, Terra (EOS AM) and Aqua (EOS PM), have a moderate-resolution Imaging Spectroradiometer (MODIS) attached to them. The Terra satellite was launched into Earth orbit by NASA in 1999 (Edwards et al, 1999). The Aqua satellite was launched in 2002 (Barnes et al, 2002). Terra's orbit around Earth scheduled to pass from north to south over the equator in the morning (Coops et al, 2007). The Aqua passes south to north across the equator in the afternoon (Coops et al, 2007). MODIS and captures data of the lower atmosphere and land surface characteristics in 36 bands with a wavelength ranging from $0.4 \mu \mathrm{m}$ to $14.4 \mu \mathrm{m}$ (Barnes et al, 2002). The resolution varies from $250 \mathrm{~m}, 500 \mathrm{~m}, 1 \mathrm{~km}, 5 \mathrm{~km}$ and $10 \mathrm{~km}$ (King et al, 2003). In the present day, the data that is obtained in a HDF-EOS (Hierarchical Data Format - Earth Observing System) from MODIS produces the land surface data that is provided by the USGS MODIS, reprojection tool web interface (MRTWeb). A brief description of the data used in the study is given below:

1- MYD11A2 (Aqua): The level-3 MODIS global Land Surface Temperature (LST) and Emitted 8-day data are composed from the daily 1-kilometer LST product (MYD11A1) (Xu et al, 2013). The data is then stored on a 1-km Sinusoidal grid which displays the average values of clear-sky LSTs, during an 8-day period. MYD11A2 is comprised of daytime and nighttime LST instruments that account for the quality assessments, observation times, view angles, bits of clear sky days and nights, and emitted estimation in the bands of 31 and 32 wave length from the land cover types. Version-5 MODIS products are validated to Stage 2 (Xu et al, 2013). This means that the accuracy of the instrument has been assessed over a variety of locations and time periods. The land surface temperature data was downloaded for the four regions: the Central African Republic, Rwanda, Mozambique and South Sudan. 
2- MOD11A2 (Terra): The Terra utilizes the same level-3 MODIS LST and operating system as the Aqua does. The data is received and averaged the same way. In this case, the land surface temperature data was downloaded for Cameroon.

\subsection{Population data}

To estimate human populations in the year of 2000, the third version of Gridded Population of the World (GPWv3) was used. The resolution of the grid cells was set to 2.5 arc minutes. A similar type of gridding algorithm was used for 300,000 national and subnational units. This algorithm is used to assign a population value to every grid cell. In order to determine these population density grids, the population count grids must be divided by the land area grid. Each of these is representative of persons per square kilometer. This data was downloaded from the webpage of NASA Socioeconomic Data and Applications Center (SEDAC).

\subsection{Administrative boundary and water body data}

DIVA-GIS provides free spatial data as ESRI shapefiles format for the whole world such as:

- Administrative areas (boundaries): Country outlines and administrative subdivisions for all countries. The level of subdivision varies between countries.

- Inland water: Rivers, canals, and lakes. Separate files for line and area features.

Table 3.1 shows all dataset were used in this study. 
Table 3.1: Table of all database

\begin{tabular}{|c|c|c|c|}
\hline Dataset & Resolution & Source & Time \\
\hline Precipitation (TRMM 3B43) & degree & & 1998 to 2014 \\
\hline Air Temperature & $0.5 \times 0.5$ & NOAA GCHN & 1948 to 2015 \\
& degree & CAMS & \\
\hline Land Surface Temperature & $(1 \times 1) \mathrm{Km}$ & MODIS Aqua & 2002 to 2015 \\
& & (MYD11A2) & \\
\hline Land Surface Temperature & $(1 \times 1) \mathrm{Km}$ & MODIS Terra & 2000 to 2015 \\
& & (MOD11A2) & \\
\hline Population (GPWv3) & 2.5 arc minutes & SEDAC & 1990,1995 and \\
& & & 2000 \\
\hline Cholera cases & & WHO, CDC and & $2009,2011,2012$, \\
& & EAIDSNet, 2013 & 2013,2014 \\
\hline
\end{tabular}

The geographic information system (GIS) ESRIs ArcGIS was used to analyze the remote sensing data based on a large-scale process by linking the epidemiological data with various other variables. In turn, the human risk of infection could be determined (Cleckner et al, 2011). These technologies can provide measurements of the unknown factors (Uz and Yoder, 2004; Jutla et al. 2011). Remotely sensed data in the visible and infrared spectra have been widely applied to map and forecast water-borne disease at spatial scales ranging from landscapes to the entire globe. (Henebry et al., 2012; Jutla et al., 2012). The data is vital to produce an estimate for areas where data was not obtained. 
To analyze the data of land surface temperature spatially, it was imported into ArcGIS (version 10.2) (ArcGIS Resources, 2013); the following steps were used with the spatial analysis tool to calculate the anomalies of land surface temperatures over the long term average:

1- Calculate the average of multiple rasters, by using the mean function in the cell statistics tool of spatial analysis. The results of the rasters were displayed for each month per year. Then, by using the same analysis tool, the long term average of land surface temperature was calculated (LST).

2- By using the spatial analysis tool (Trigonometric), the function "Times" is used to multiply the values of the raster on a cell layer by the scale factor of HDF files (0.02) as an input. The input contributed to minimizing the number inside the file. The data is inputted into its right location. Also, by using the spatial analysis tool (Trigonometric), the "Minus" option is used to subtract the values from the long term average, and the affected month per year, from 273 . To obtain the value, a new raster layer is formed to transfer the land surface temperature data into Celsius.

3- Calculate the deviation for the month of July in 2008 compared to the average over the period of 1999-2008. The "Minus" option of the spatial analysis tool subtracted the value of July in 2008 from the long term average over the ten years. 


\subsection{Optimized Hot Spot Analysis (Spatial Statistics)}

A statistically significant hot and cold spot map can be created by using Getis-Ord Gi* Statistic if occurrence points or weighted features for the deviation of land surface temperature (LST) are identified (ArcGIS Resources, 2014). (ArcGIS Resources, 2014). The charts evaluate the characteristics of the input features to produce the optimal results, displayed by Figure 3.2. The statically significant spatial clusters of high values (hot spots) and low values (cold spots) are included in the analysis. The tool checks the inputted data and corrects any errors detected.

The tool of optimized hot spot analysis accepts only the point or polygon feature class as an input to perform the analysis. Due to the raster data of the LST not being a point feature, a tool to convert the raster dataset to a point feature is required. The Conversion toolbox in ArcMap 10.2 contains a tool called "Raster to Point (Conversion)," which helps to obtain point features as outputs.

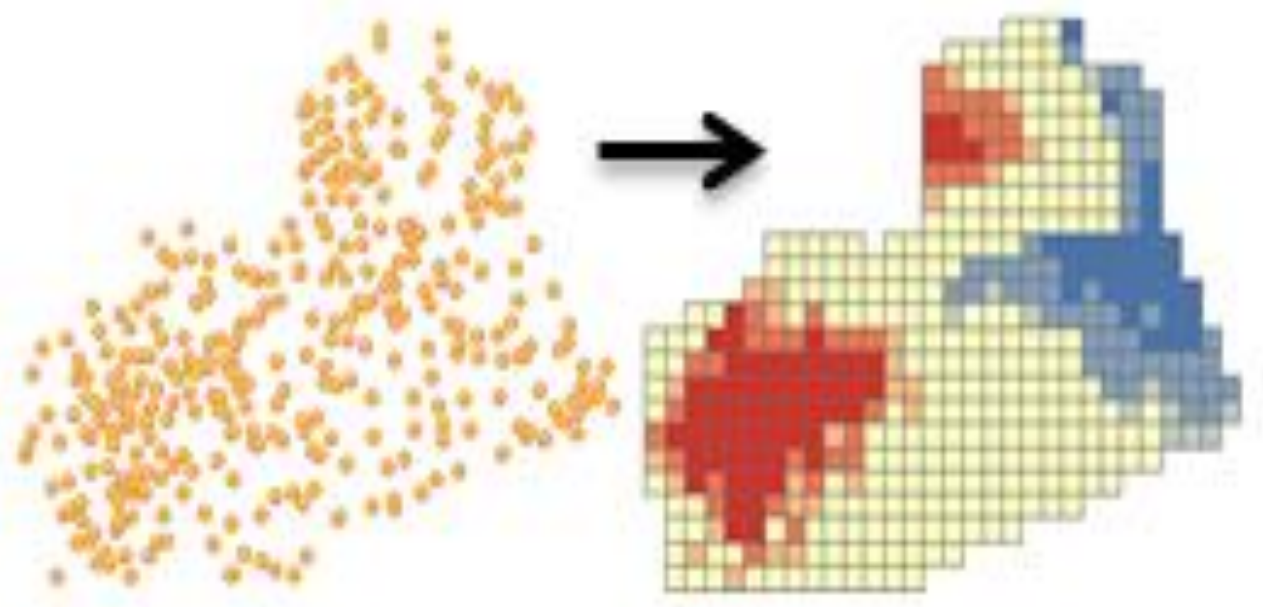

Figure 3.2: Example of optimized hot spot analysis (ArcGIS Resources, 2014). 
Some terms associated with Optimized Hot Spot Analysis are listed below:

- Z-scores are standard deviations. If z-scores are very high or very low then the p-values linked to those points would be very small.

- P-values are used to identify the probability of an event or something from occurring. The p-value can in this case provide important information. For example, when the p-value is small, then the result expected is unlikely. This means that the hypothesis would be rejected. Figure 3.3 shows an example of a normal distribution curve.

Ultimately, the data obtained by the z-scores and p-values determine if hypothesis is valid or not.

The Z-score is given by:

$$
z=\frac{x-\mu}{\sigma}
$$

Where:

$\mu$ : is the mean of the population;

$\sigma:$ is the standard deviation of the population. 


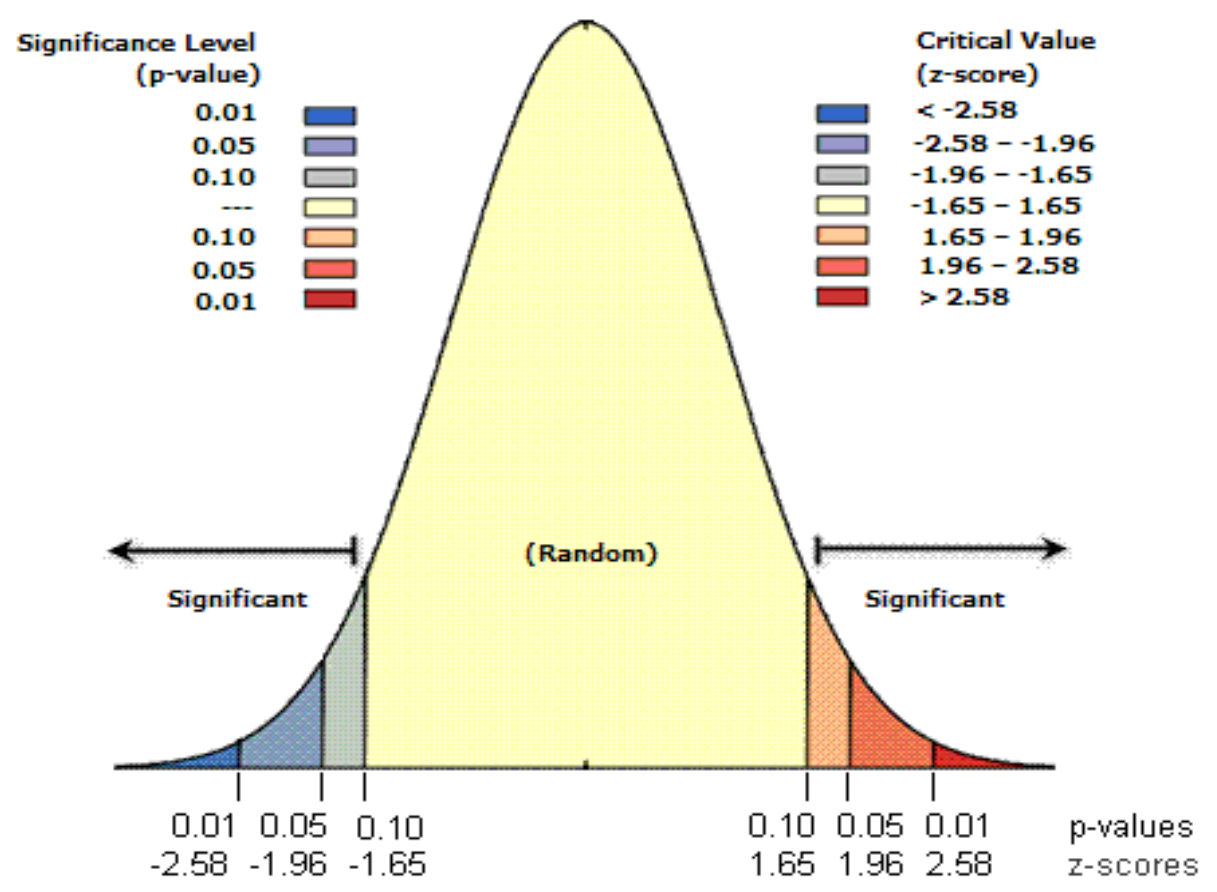

Figure 3.3: Drawing of Z-scores and P-values (ArcGIS Resources, 2014).

Fair judgment is needed to justify the confidence level obtained by using the $\mathrm{z}$-score function. The higher the confidence levels, the greater the chances of the null hypothesis being correct. Fair confidence levels would be considered if a 90, 95, or 99 percent were obtained. A confidence level of 99 percent would mostly prove the hypothesis to be true in this method. The table below shows p-values and z-scores for different confidence levels. 
Table 3.2: Confidence levels for different $p$-values and z-scores.

\begin{tabular}{|c|c|c|}
\hline Z-score (Standard Deviations) & P-value (Probability) & Confidence level \\
\hline$<-1.65$ or $>+1.65$ & $<0.10$ & $90 \%$ \\
\hline$<-1.96$ or $>+1.96$ & $<0.05$ & $95 \%$ \\
\hline$<-2.58$ or $>+2.58$ & $<0.01$ & $99 \%$ \\
\hline
\end{tabular}

- FDR Correction: The False Discovery Rate (FDR) procedure potentially reduces the critical p-value thresholds shown in Table 3.2 above in order to account for multiple testing and spatial dependency.

- Multiple Testing: A confidence level of 95 percent can show that spatial patterns could appear structured within the data set.

- Spatial Dependency: Features appear to be dependent on each other but for a statistical test, independent data is needed in certain cases.

- The Getis-Ord Gi* statistics: The Optimized Hot Spot Analysis tool calculates the GetisOrd Gi* statistic (pronounced G-i-star) for each feature in a dataset. The resultant z-scores and p-values help determine where the clusters of data are located. This tool works by referring to all the data received and placing the data into the correct order. For a statistically significant hot spot, a point will be surrounded by other points with high values. If at any time, a point and another point portioned together do not follow the data then a zscore will be generated and used to correct the data. The FDR correction will be applied 
and will account for multiple tests and spatial dependency of the data (ArcGIS Resources, 2014). The Getis-Ord local statistic is given as:

$$
\mathrm{G}_{\mathrm{i}}^{*}=\frac{\sum_{\mathrm{j}=1}^{\mathrm{n}} \omega_{\mathrm{i}, \mathrm{j}} \mathrm{x}_{\mathrm{j}}-\overline{\mathrm{X}} \sum_{\mathrm{j}=1}^{\mathrm{n}} \omega_{\mathrm{i}, \mathrm{j}}}{S \sqrt{\frac{\left[\mathrm{n} \sum_{\mathrm{j}=1}^{\mathrm{n}} \omega_{\mathrm{i}, \mathrm{j}}^{2}-\left(\sum_{\mathrm{j}=1}^{\mathrm{n}} \omega_{\mathrm{i}, \mathrm{j}}\right)^{2}\right]}{n-1}}}
$$

Equation 2

Where:

$x_{j}$ : is the attribute value for feature $\mathrm{j}$.

$\omega_{i, j}$ : is the spatial weight between feature $\mathrm{i}$ and $\mathrm{j}$.

$\mathrm{n}$ : is equal to the total number of features and:

$$
\begin{gathered}
\bar{X}=\frac{\sum_{j=1}^{n} x_{j}}{n} \\
S=\sqrt{\frac{\sum_{j=1}^{n} x_{j}^{2}}{n}-(\bar{X})^{2}}
\end{gathered}
$$

The Gi* statistic returns a z-score for each feature in the dataset. For statistically significant positive $\mathrm{z}$-scores, the larger the $\mathrm{z}$-score means the more intense the clustering of high values (hot spot). For statistically significant negative z-scores, the smaller the z-score is, the more intense the clustering of low values (cold spot). This tool aggregates the points of the LST deviation in order 
to obtain point counts to use as an analysis field. We used an aggregation scheme: COUNT_INCIDENTS_WITHIN_FISHNET_POLYGONS, which means the incidence point data and the counted number of incidents within each polygon will be overlaid as a fishnet polygon mesh (ArcGIS Resources, 2014).

In order to view the data points spatially, ArcGIS 10.2 imported the data and used georeferencing. To approximate the output of hot spot analysis throughout 5 epidemic regions in Africa, Inverse distance weighted (IDW) was used. It was calibrated to a cell source of 0.5 and power of 2.This allotted for an endless number of data points. IDW evens the data and takes away maximum and minimum values. It is a useful tool for interpolating these data points (Watson \& Philip, 1985).

Using the tools listed below and ArcGIS, a risk map of regional epidemic cholera was created.

1- Buffer (Coverage): This tool is used to obtain a $1 \mathrm{~km}$ buffer for water bodies such as rivers and streams in the affected regions.

2- Plus (Spatial Analysis): This tool is used to obtain the sum of land surface temperatures and populations.

3- Weighted Sum (Spatial Analyst): This tool is used to get the sum of land surface temperatures, water bodies, and populations all on one layer. 


\section{CHAPTER 4 : ANALYSIS AND RESULTS}

The purpose of this study is to precisely determine the location and nature of risk. The research philosophy is to seek understanding the relationship between hydroclimatologic processes (air temperature and precipitation) and cholera in the five epidemic regions that are South Sudan, Mozambique, the Central African Republic, Cameroon and Rwanda by using remote sensing. Due to coarse resolution of both datasets, we check the spatial series of land surface temperature (LST) from MODIS sensors. Figure 4.1 shows the cholera risk assessment framework; the recent framework contains two components: the top ones explain the hydroclimatic controls over cholera, and the bottom ones explain the non-hydroclimatic control over cholera.

Hydroclimatic control can be explained in two forms: temporal hydroclimatic control and spatial hydroclimatic control. If the hypothesis of temporal analysis showed significant evidence of cholera risk, then the spatial analysis should be done because temporal data is not always available at high resolution scale. For further analysis to be done, the spatial hydroclimatic control needs to be checked. Once we have the evidence that the temporal hydroclimatic control is clear enough, along with the spatial hydroclimatic control, non-hydroclimatic conditions should then be checked.

The non-hydroclimatic controls come from spatial distribution of population and sanitation and the incidental of social disturbance and natural disaster. Every scenario considering temporal, spatial and non-hydroclimatic control will always be a binary situation; one is the risk of cholera and the other is non-risk of cholera. The risk of cholera is represented by the red color, while the white color represents the non-risk of cholera. There are two variables for each temporal hydroclimatic control: air temperature and rainfall. If air temperature has evidence of cholera risk then it is a red color on the left side of the figure, while the right red color represents rainfall evidence of cholera risk. Additionally, if both of them merged together and created that total time 
box, a definite evidence of temporal hydroclimatic control would be concluded, which means there is a temporal risk of hydroclimatic control of cholera. Furthermore, for spatial hydroclimatic control, we analyzed the spatial land surface temperature (LST) and water accessibility.

LST will be in the right side of the figure when there are significant hot regions and high accessibility of water. A unique scenario to produce more Vibrio Cholerae can be created if we have significant hot regions of LST and a significantly high access of water merging together. Significant hot regions of LST, high access of water, high population density and inadequate sanitation which could trigger high risk of Vibrio cholerae production. 


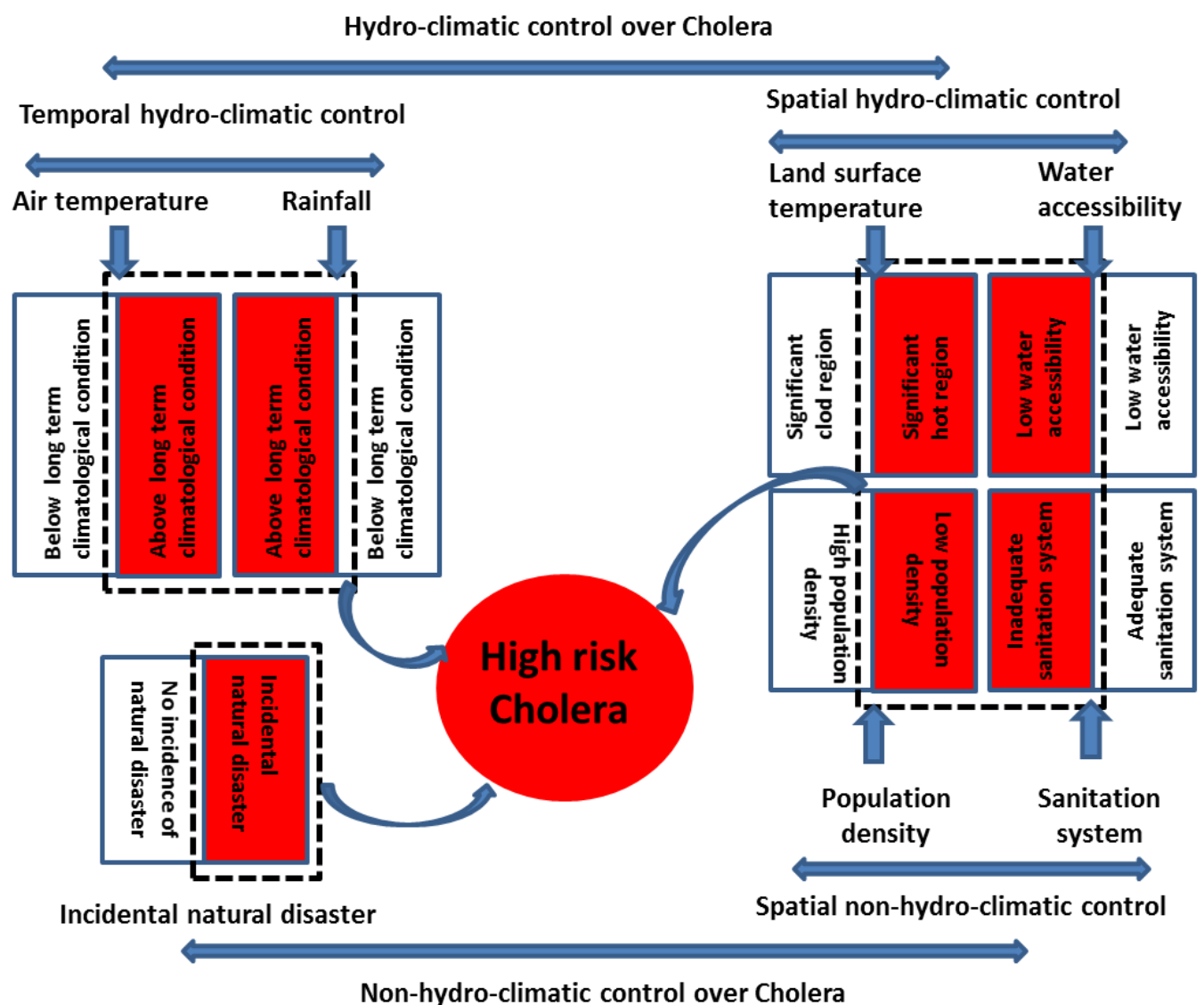

Figure 4.1: Cholera assessment framework in epidemic regions.

\subsection{Temporal hydro-climatic control over Cholera}

The study was designed to determine triggering hydroclimatic conditions of the cholera outbreaks in the five epidemic regions in Africa. To apply an epidemic cholera hypothesis, which will be explained in the results, calculation of monthly anomalies (subtraction of month value from average of 14 years of monthly data) for precipitation and temperature were required. These were calculated for each pixel in both datasets. For example, the daily precipitation data obtained from TRMM sensors were converted to monthly scales for fourteen years for all pixels covering the Central African Republic. The average for 14 years was calculated and then subtracted from each month, resulting in a positive or negative value (thereafter referred to as anomaly). A positive 
anomaly implied that a month received more precipitation from the average over the given pixel in a fourteen year period of time. An additional step of the analysis was to determine percent deviation each month from the average for that month using the following equation:

$$
\begin{aligned}
& \text { Deviation } \text { month,year }(\%) \\
& =\left[\frac{\text { Month value } \text { Precipitation /Temperature }- \text { Average value } \text { Precipitation / Temperature }}{\text { Average value Precipitation / Temperature }}\right]
\end{aligned}
$$

\section{..Equation 5}

For example, $\%$ Deviation $_{\text {August,2011 }}$ will be calculated by subtracting precipitation in the month from the 14 year average August precipitation and dividing it by the 14 year average August precipitation. Air temperature data were processed as were the precipitation data, with the exception that the native temperature dataset was available on a monthly record.

An algorithm was developed by using the statistical software $\mathrm{R}$ to compare the deviation of a particular month/year of cholera outbreak with the same month in previous years. The purpose of this was to compare the difference in anomaly of the hydroclimatic drivers.

The cholera outbreak in the Central African Republic began in six villages in the city of Bangui, in September, 2011. The hydroclimatic processes for the months of July through September are critical, since departure from normal values in Bangui can result in conditions favorable for the growth of cholera bacteria (Jutla et al., 2013). It must be noted that the precise location of a disease outbreak region cannot be determined because of limitations in the resolution of satellite data. Based on the flow diagram above Figure 4.2, the results of provincial analysis (average of all pixels in a particular region) in Bangui showed the anomaly for the months of July for air temperature and August for precipitation were above the long term average of 14 years Figure 4.2. 
The anomaly of observed air temperature over the Rutsiro district in Rwanda in the month of August, 2012 was above the average of 15 years (Figure 4.2). Also, more than 53\% higher than long term average for rainfall was observed in the month of September (Figure 4.2).

In Cameroon, the cholera onset in 2009 was in the month of September in Extreme Nord Region in the north part of the country (WHO country profile, 2011). The analysis of the elevated temperature shows the month of July, 2009 higher than average of 12 years by around 6\% (Figure 4.2). The deviation analysis for rainfall showed a positive anomaly during the month of August, 2009 with deviation more than $60 \%$ (Figure 4.2).

The incidence of cholera epidemic outbreak in Nassa and Cabo Delgado was in the north part of Mozambique in February, 2013 (WHO country profile, 2013). Figure 4.2 represents 16 years of average air temperature over Nassa and Cabo Delgado in Mozambique, showing that air temperature in the month of December, 2013 was more than 5\% deviation higher than long-term average. Similarity, Nassa and Cabo Delgado received anomalously high rainfall during the month of January, 2013 with more than 16\% deviation (Figure 4.2).

The most recent cholera outbreak was in Juba County in South Sudan on April 26, 2014 (WHO Juba health updates, 2014). The observed air temperature anomaly for the month of February, 2014, two months in advance, was higher than the long term average of 17 years as shown in Figure 4.2. Figure 4.2 shows high precipitation preceding the cholera outbreak in the month of March, 2014 in Juba County with 37\% deviation. The combination of these factors may be linked to the outbreaks of cholera in those five epidemic regions in Africa. The black arrows in all anomalies (figures below) indicate the month of the disease's onset. 


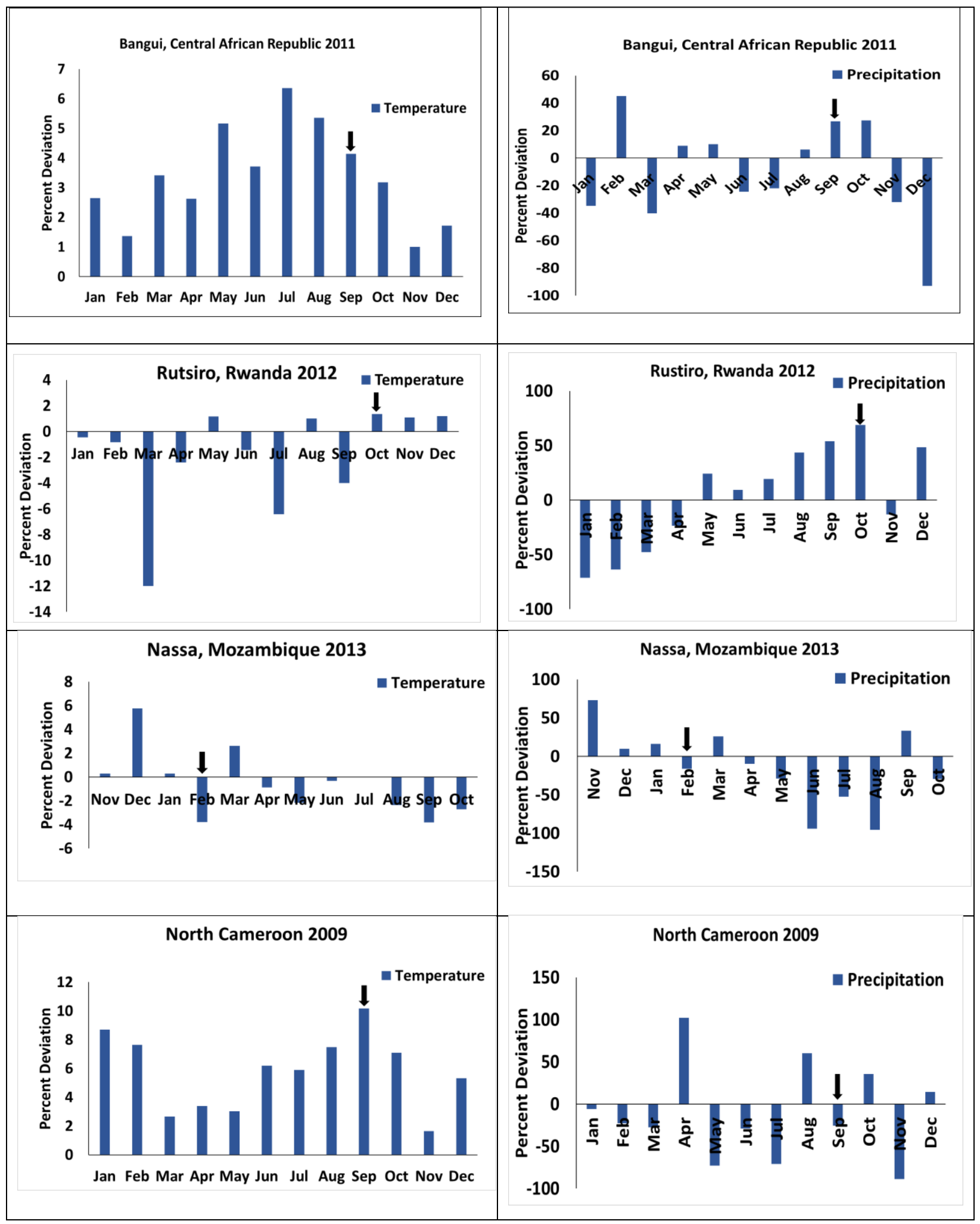




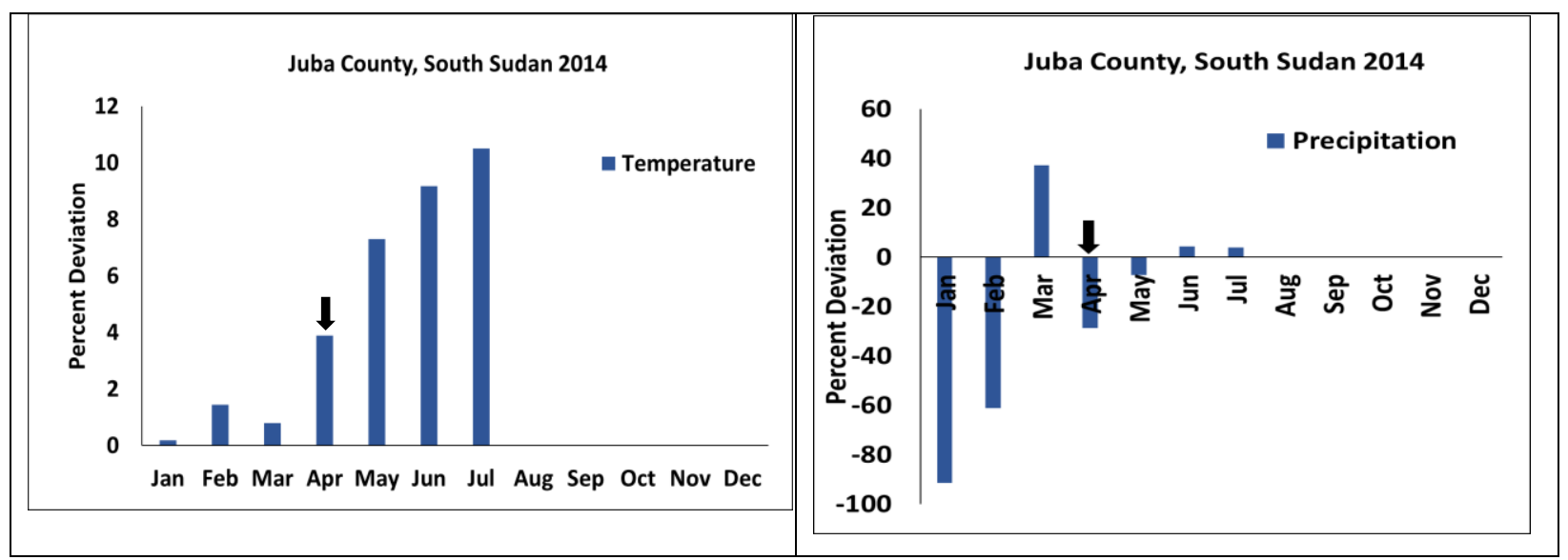

Figure 4.2: Precipitation and temperature anomalies five different regions in Africa. Black arrows on the $x$-axis of plots indicates month when cholera was first reported.

Figure 4.3 shows the difference between month/year deviation of cholera outbreaks and the same month value for many years preceding the disease outbreak performed by using $\mathrm{R}$ software. The point of this plot is to show the definite hydroclimatic controls on cholera risk. There are two lines for each country; the upper one is for precipitation and the lower one is for air temperature. Increased precipitation is represented by the blue color, while the red color represents low precipitation. On the other hand, increased air temperature is represented by the red and blue colors. As an example, in a particular month in 2012 in Rwanda, there was a significant increase in rainfall and also a significant increase in air temperature. Also, we have some other significant increases, such as what happened in the year of 2001. It should be known that the hydroclimatic control is the only one component of our whole framework assessment, and it is not the only reason cholera was triggered in 2001. Maybe there was another reason for cholera outbreak, but we need to analyze the hydroclimatic and non-hydroclimatic conditions. 


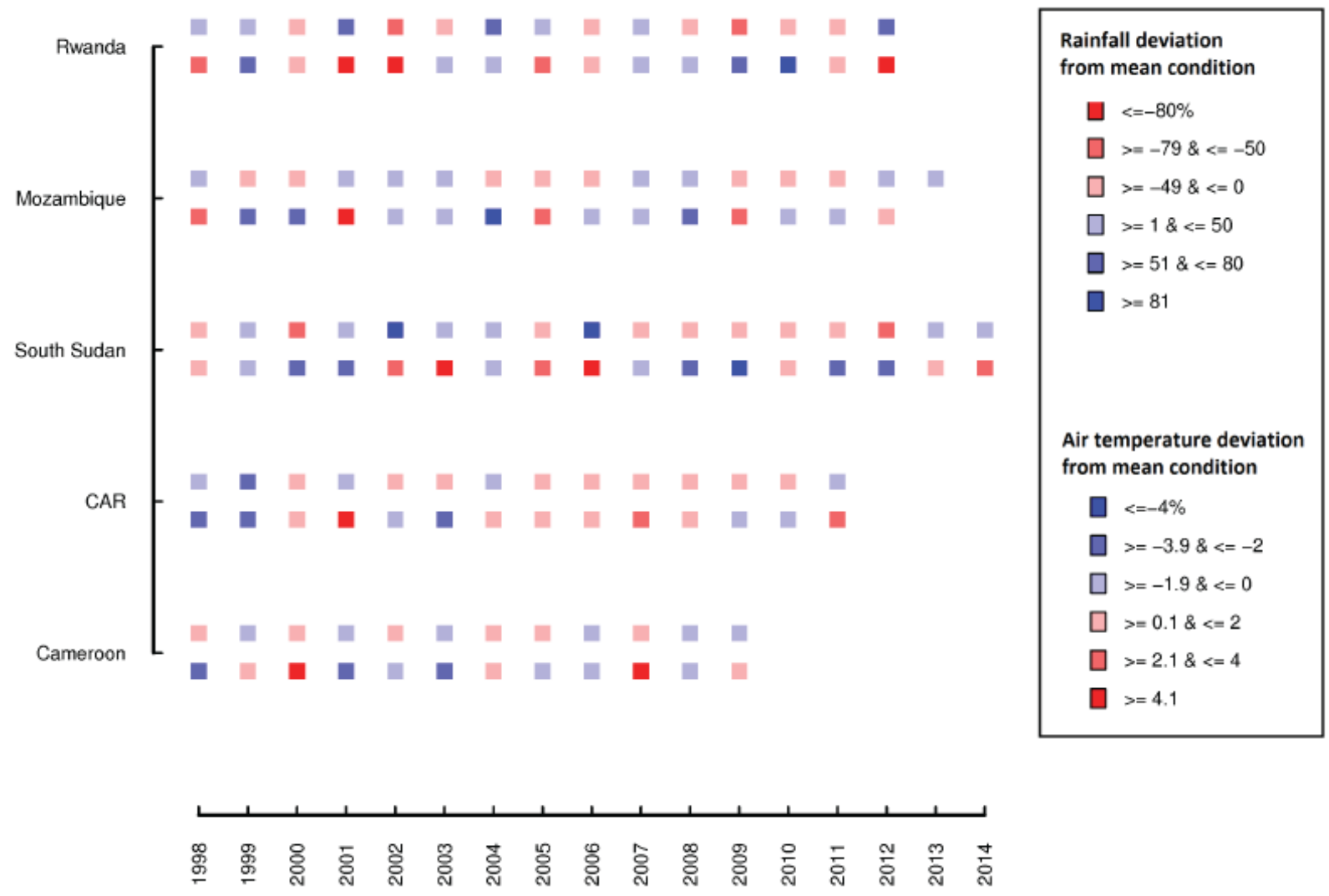

Figure 4.3: The difference between the month/year deviation of cholera outbreaks and the same month value for many years preceding the disease outbreak. Blue color refers to negative deviation while the red indicates the positive deviation in air temperature and the opposite indication with precipitation. 


\subsection{Spatial series analysis}

After checking the temporal series for both air temperature and precipitation, we may check the spatial series of land surface temperature (LST) to validate our findings. Deviation of two months lag were calculated using the following equation:

Deviation $_{\text {month,year }}=\left[\right.$ Month value $_{L S T}-$ Average value $\left._{L S T}\right] \quad \ldots . . . . . .$. Equation 6

For example, the deviation of land surface temperature for the month of April was calculated by using spatial analysis tools, such as cell statistics to get the mean of long term average of 14 years, and math to subtract the month of April from long term average of 14 years. The positive deviation means that the land surface temperature was above the average of long term average, and the negative implies the opposite below the average.

The analysis for the month of July, 2011 in Bangui in the Central African Republic (two months in advance of the cholera outbreak's incidence in September, 2011) showed the deviation of land surface temperature was above the average of a 14 year period of time over the given pixel of Bangui city as shown in Figure 4.4a

Figure 4.4d shows that the observed air temperature for all pixels over the Rutsiro district in Rwanda in the month of August, 2012 was above the average of a fifteen year period of time. Also, the analysis of land surface temperature of the same month and for all pixels showed that many pixels have a positive anomaly, which indicates a favorable environment for cholera bacteria to thrive, if followed by heavy precipitation in the month of September, 2012.

The spatial anomaly map of land surface temperature over Cameroon, showed the ExtremeNord region has a positive anomaly in most parts during the month of July, 2009; as shown in Figure $4.4 \mathrm{e}$, areas with missing data are in white. Figure $4.4 \mathrm{c}$ shows the spatial map anomaly was 
a positive deviation higher than the long term average of 15 years for the affected region of Nassa and Cabo Delgado.

Although the observed air temperature in the month of February, 2014 was higher than average of long term period over Juba town in South Sudan, the spatial series of land surface temperature over the same region showed high positive deviation (Figure 4.4b).

All the affected regions above showed high spots anomaly of land surface temperature two months in advance of the outbreaks. Cholera outbreaks can be linked to our assumption diagram so far. The next step is to check whether the spatial statistics of LST were statistically significant. 

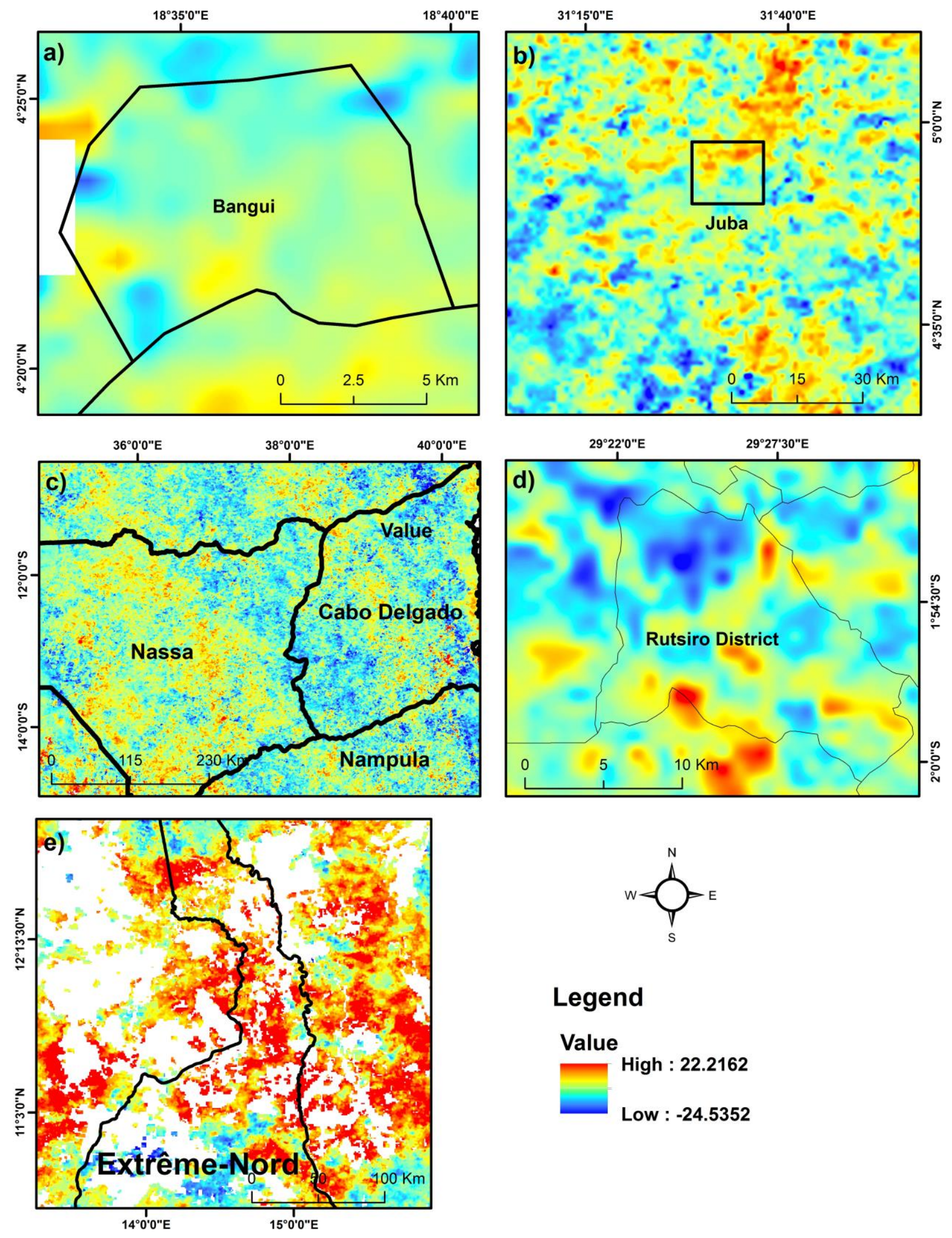

\section{Legend}

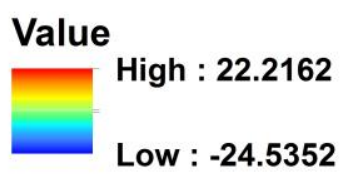

Figure 4.4: Spatial series of land surface temperature; yellow and red indicate values higher than long term average: a) The Central African Republic; b) South Sudan; c) Mozambique; d) Rwanda and e) Cameron. 


\subsection{Optimized Hot spot analysis for LST}

In order to analyze the reasons for cholera outbreaks, the study addresses some factors' effect on this disease by utilizing a density-based spatial clustering called optimized hot spot analysis to study patterns of land surface temperature over the five selected epidemic regions in Africa. Optimized hot spot analysis selects clusters of high and low values. High valued spots are representatives of hot spots and low values are representative of cold spots. Using those points, a map is created using Getis-Ord Gi and ArcMap (argis.com). Results are created by analyzing and evaluating the features of the input data. This analysis results in output which has a z-score, confidence level, and p-value for each feature in the input feature class of land surface temperature.

Data normalized by Z-score transformation can be used directly in the calculation of significant changes of land surface temperature between different anomaly values. We used Zscores to compare between the different spatial series of the dataset. We conclude that the Z-score transformation normalization maps were used to identify statistically significant hot and cold spots. Features in Z-score $+/-2.58$ values are statistically significant at the 99 percent confidence level; features in Z-score +/-1.96 reflect a 95 percent confidence level; features in Z-score $+/-1.65$ reflect a 90 percent confidence level; and the clustering for features with Z-scores between -2.58 and +2.58 are considered not statistically significant in this study. The regions with Z-score more than +2.58 are considered hot spot regions and are statically significant, while z-score less than -2.58 are considered cold spot regions.

The affected regions in the Central African Republic have some regions in the north of Bangui which are statically insignificant with $\mathrm{Z}$ scores between -2.58 and +2.58 . However, all pixels within positive anomaly for the month of July, 2011 (two months lag from the outbreak's onset) were located within hot spot regions with $\mathrm{Z}$ scores greater than +2.58 (Figure $4.5 \mathrm{a}$ ). 
Figure $4.5 \mathrm{~d}$ shows the geographical mean for land surface temperature in the south of Rutsiro in Rwanda located within hot spots of $99 \%$ confidence interval ( $\mathrm{Z}$ score $>+2.58$ ) and the north region within cold spots of $99 \%$ confidence interval $(Z$ score $<-2.58)$, while there were statistically insignificant areas in the center. Also, in the center and the north parts of ExtremeNord in Cameroon, the positive distribution of land surface temperature was located within the hot spots of $99 \%$ confidence interval ( $\mathrm{Z}$ score $>+2.58$ ), while the south parts within cold spots of $99 \%$ confidence interval $(\mathrm{Z}$ score $<-2.58)$, as shown in Figure 4.5e. The other epidemic regions in Mozambique and South Sudan showed high values of hot cluster for the positive deviation of land surface temperature as shown in Figure 4.5c and Figure 4.5b.

The results of the Optimized Hot Spot Analysis showed a high positive correlation between two months lag for the spatial series of land surface temperature and cholera incidence, and very low correlation in other areas. The contributing p-scores range from $0-0.05$ in the $95 \%$ confidence interval, stating that these clusters hold statistical significance. From this analysis above, we are not interested in seeing the hot spot distribution of land surface temperature, but in seeing the significant zone for cholera. The next steps will show if we can detect a specific zone for cholera at least two months in advance. 

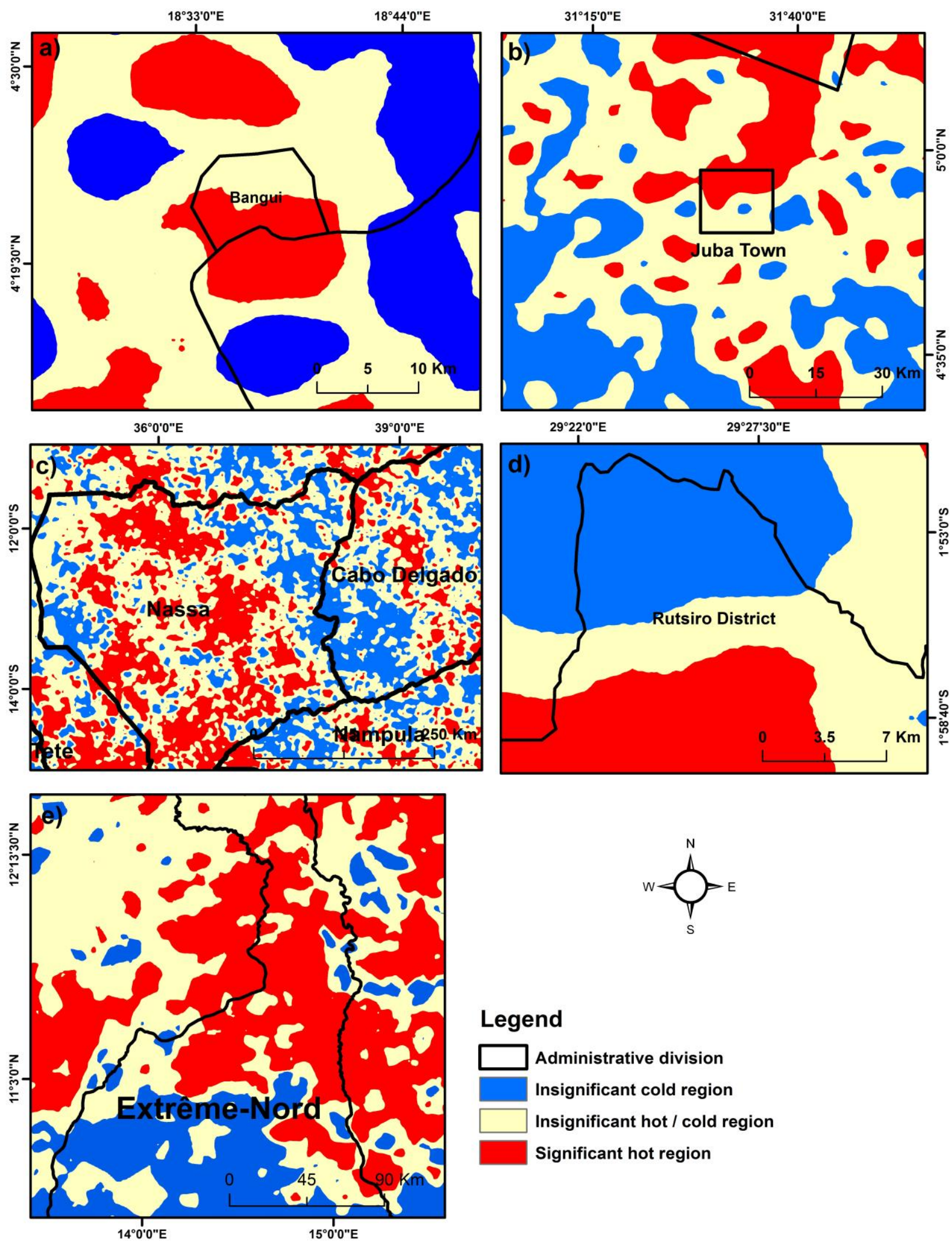

\section{Legend}

$\square$ Administrative division

Insignificant cold region

Insignificant hot / cold region

Significant hot region

Figure 4.5: Optimized hot spot analysis of land surface temperature anomalies: a) The Central African Republic; b) South Sudan; c) Mozambique; d) Rwanda and e) Cameron. 


\subsection{Water bodies}

Water bodies like rivers or lakes are considered important environments for cholera bacteria to grow. Standing water is considered one of the most common sources of cholera infection because cholera bacteria can exist dormant in water for long periods of time. Additionally, contaminated public wells are considered a significant source of cholera outbreaks (Mayo Clinic, 2014). From here there was a need to check how far all epidemic regions above are from the nearest source of water.

V.cholerae can be supported as ubiquitous in its natural habitat as long as specific environmental conditions are met. In different ecosystems such as rivers and inland water bodies, the number of bacteria will rise, which can result in an epidemic if exposed to humans (Hasan et al., 2013). This type of bacteria can occur along coastlines. Cholera survives on these coastlines by attaching to copepods, which are a form of crustaceans. (Fernández et al, 2009).Water temperature increases and urea from sewage and agriculture runoff cause the algae and plankton that copepods feed on to grow dramatically. This information led us to the conclusion that cholera cannot exist without a source of water. Epidemic cholera regions occurred within 25 miles of a major river system (Jutla et al, 2013). Based on that range, we can identify a nearest location of water resources for the five epidemic cholera regions in Africa.

The largest right bank tributary in the Congo River was created by the conjoining of the Bomu and Uele rivers. This is called the Ubangi River. The Democratic Republic of the Congo and the Republic of the Congo are split in half and bordered by the Ubangi River. The river flows northeast of Bangui within the central region of the Central African Republic and extends in the southwest direction (Figure 4.6a). 
Lake Kivu is one of the African Great Lakes that lies on the border between the Democratic Republic of the Congo and Rwanda. Lake Kivu is 5 miles away from Rutsiro in Rwanda as shown in Figure 4.6d. Lake Chad runs along the border of Cameroon and other surrounding countries. Approximately $10.7 \%$ of this lake is in the Extreme-Nord region of the country Figure 4.6e.

The Nassa province in Mozambique is located within the eastern part of Lake Nyasa. Also, Nassa and Cabo Delgado have many rivers and streams that are considered important sources of water and may be considered favorable environments for cholera bacteria to survive (Figure 4.6c). The Albahr Alabyad is part of the Nile River located in South Sudan, and Juba town is located within two miles. The Nile is considered the main source of water in this region (Figure 4.6b).

It should be noted all cases above have many other water sources other than those mentioned above. These other sources are shown in Figure 4.6.

From all cases above, we can reach a conclusion and prove that all five regions are located close to important water sources such as rivers, lakes or the ocean (within 100 miles). Looking at cholera epidemics in the past, one will find that all cases were nearby to important sources of water. There have not been cholera outbreaks in any areas that do not have a source of water, such as the desert. 

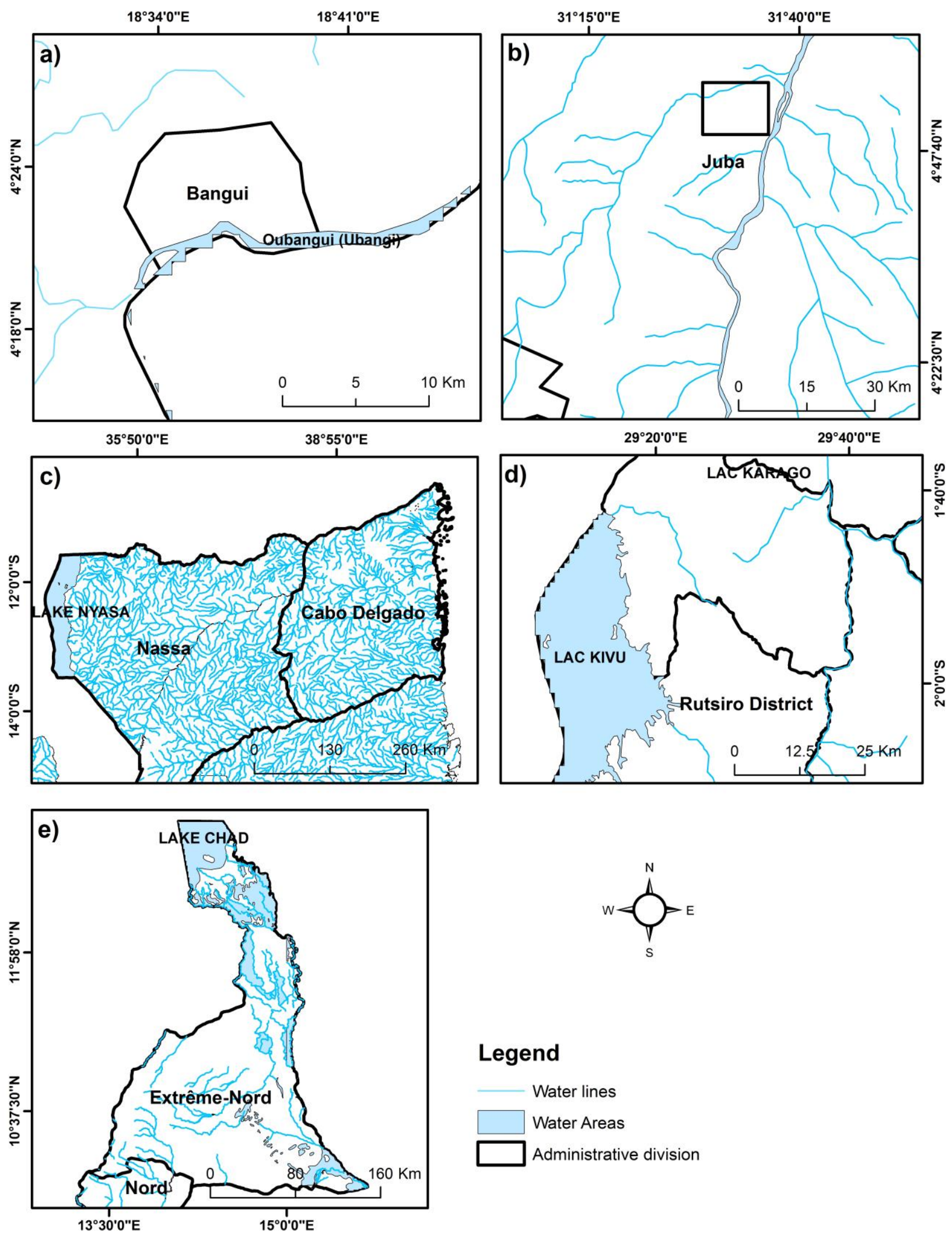

\section{Legend}

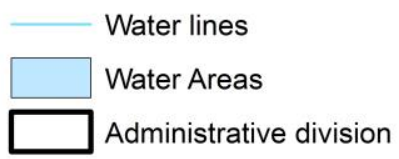

Figure 4.6: Water bodies close to affected disease regions: a) The Central African Republic; b) South Sudan; c) Mozambique; d) Rwanda and e) Cameron. 


\subsection{Non hydro-climatic conditions:}

This part of the study will focus on the effects of population density on cholera epidemics in the five selected regions in Africa. The gridded data were collected from the Socioeconomic Data and Applications Center (SEDAC) and exported into ArcGIS format for further analysis and interpretation. The analysis for population density in 2000 showed that:

1. Bangui, in the Central African Republic, was the densest area with more than 250 persons per square kilometer (Figure 4.7a).

2. Most parts in Rwanda had high population density during the year of 2000 (Figure 4.7d).

3. The affected area in Cameroon was a densely populated area (Figure 4.7e).

4. The affected regions in Mozambique had spots of high density population (Figure 4.7c).

5. Juba County was considered one of the densely populated areas in South Sudan (Figure 4.7b).

High population density is considered a spatial element of cholera in those five epidemics above, as well as the other elements such as poor water supply and poor sanitation. 

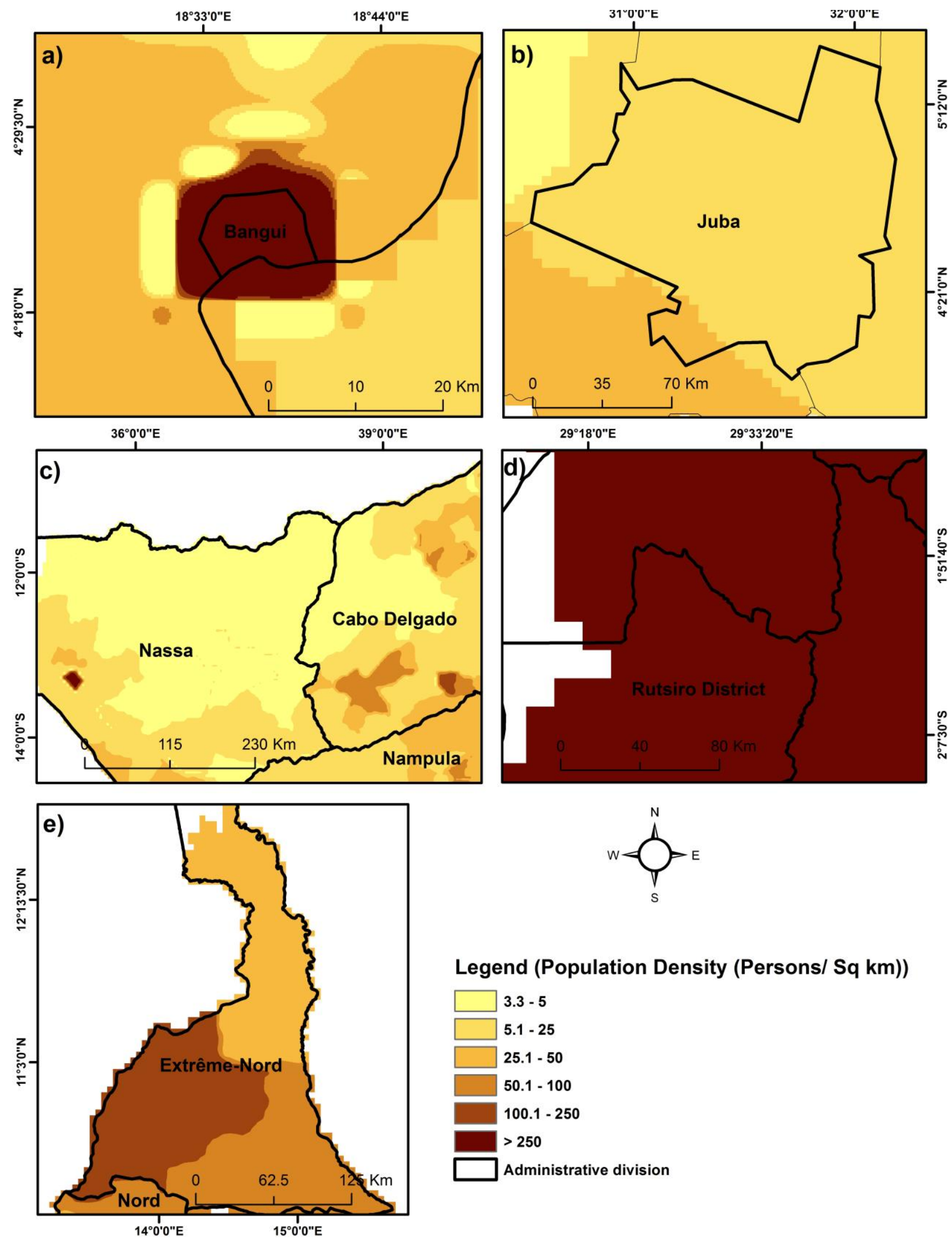

Legend (Population Density (Persons/ Sq km))

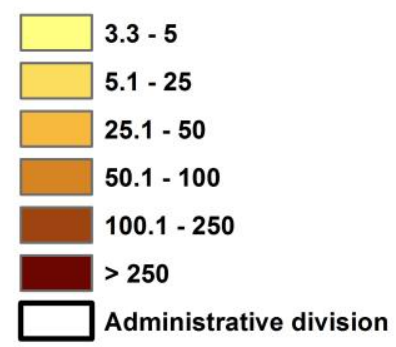

Figure 4.7: Population density in the affected disease regions: a) The Central African Republic; b) South Sudan; c) Mozambique; d) Rwanda and e) Cameron. 
Also, Cholera outbreaks can be linked to destruction of water and sanitation infrastructure after social disruption or natural disaster (Jutla et al, 2013). As shown in Table 4.1, the five epidemic regions in Africa were exposed to some important events before the occurrence of cholera.

Table 4.1: Social disturbance in five epidemic cholera regions in Africa.

\begin{tabular}{|c|c|c|c|c|}
\hline Country & $\begin{array}{c}\text { Reported } \\
\text { Region }\end{array}$ & $\begin{array}{c}\text { Region (Case } \\
\text { Fatality Ratio) }\end{array}$ & $\begin{array}{c}\text { Outbreak } \\
\text { Time }\end{array}$ & $\begin{array}{c}\text { Social } \\
\text { Disturbance }\end{array}$ \\
\hline South Sudan & Juba & $5 \%$ & April 2014 & Civil unrest \\
\hline $\begin{array}{c}\text { Central African } \\
\text { Republic }\end{array}$ & Bangui & $13 \%$ & September 2011 & Floods \\
\hline Rwanda & Rutsiro district & $50 \%$ & October 2012 & Floods \\
\hline Cameroon & Nord Region & $13 \%$ & September 2009 & Floods \\
\hline Mozambique & $\begin{array}{c}\text { Nassa, Cabo } \\
\text { Delgado }\end{array}$ & $1 \%$ & February 2013 & Floods \\
\hline
\end{tabular}

With an increasing rate of violence and civil disputes in January of 2014, the World Health Organization (WHO) announced that citizens of South Sudan have been spreading out throughout the region. Because of violence throughout the country, over 1.8 million people have relocated. Civil disputes and disease were the causes of over 10,000 deaths in 2014. With a goal to escape and flee the area, nearly 450,000 have run away to neighboring countries such as Ethiopia, Kenya, Sudan and Uganda. With lost workers and destroyed health facilities, the health system is not under steady conditions.

As of June 2011, Bangui has been terribly impacted by extreme winds and torrential rains. Later in the month, conditions became more violent and hazardous in seven neighborhoods within the 6th subdivision of Bangui. The neighborhoods' water and sanitation systems were greatly affected (ReliefWeb Central African Republic, 2011). Floods and droughts have a marked impact on cholera outbreaks (Akanda et al., 2013). Torrential rains in the northern region of Cameroon 
resulted in floods and landslides, which covered houses and made toilet pits unusable. With toilet pits unavailable, the death rate of cholera has surpassed 100 (ReliefWeb Cameroon, 2014).

In the beginning of February, 2013 a similar occurrence happened in Mozambique. Large amounts of rain and natural disasters caused dangerous flooding in the central and northern regions. Similarly to Cameroon's situation, the displacement of people and disruptions to water and sanitation systems increased disease throughout the region (ReliefWeb Cameroon, 2014 and WHO Country Profile, 2011). The Western Province of Rwanda was also hit with heavy rains in April of 2012. This natural disaster caused flooding, property damage, and damage to the water treatment and sanitation system (ReliefWeb Rwanda, 2014). However, the 2012 the cholera epidemic in Rwanda followed the flood after six months, but because the usual source of water was no longer available, people went out to search for any other potential water sources. Water sources that people used were not safe drinking water. While looking for a new water source many people moved around and also became homeless because their homes had been flooded. Any water found was not considered to be safe drinking water. All these events led to the spread of waterborne diseases and increased the risk of cholera epidemic in October, 2012. For all these reasons, cholera epidemic in these five regions can be linked to social disruption or natural disaster, which causes damage in water and sanitation infrastructure. 


\subsection{Cholera Risk mapping}

The temporal analysis of climatic data, the spatial analysis of land surface temperature, availability of water bodies and population density do not indicate the most likely prone cholera zone when studied individually. Because we are only interested in the place of the cholera epidemic's onset, the analysis will focus the location 25 miles away from a major river system (Jutla et al, 2013). The Z-score distribution showed some regions are statistically significant for the deviation of land surface temperature, but it doesn't indicate the physical significance of cholera. From here, we selected a scientific zone with a radius of $25 \mathrm{~km}$ around the nearest water source from the affected region in the five epidemic regions to make a risk map for cholera outbreak.

Access to water sources that are contaminated with V.cholerae in any region can increase the risk of cholera outbreaks. The direct impact of water should be in the surrounding regions. To analyze the water bodies' spot using ArcGIS, we will assume one pixel is water accessible because people do not come to the pond, river or stream flow from more than $1 \mathrm{~km}$ away. Because of low resolution we selected one pixel buffer outside water accessibility, so we cannot make it 500 meters or 300 meters; the new buffer zone will represent the water accessibility, which represents hot spots of water bodies.

Now, one may ask if the water warm enough to grow the cholera bacteria for all regions, and the answer will be no; only some parts have significant warmth and will have a chance to have cholera. Hence the concept of risk map, which indicates the impact of increasing air temperature, water bodies and population density on the likelihood of cholera incident in a specific region. A Venn diagram was used to show all possible logical association between the layers of water bodies, land surface temperature and population as show in Figure 4.8. The raster summation of these 
layers result in 7 classifications of cholera risk starting from No Cholera risk to Very high cholera risk.

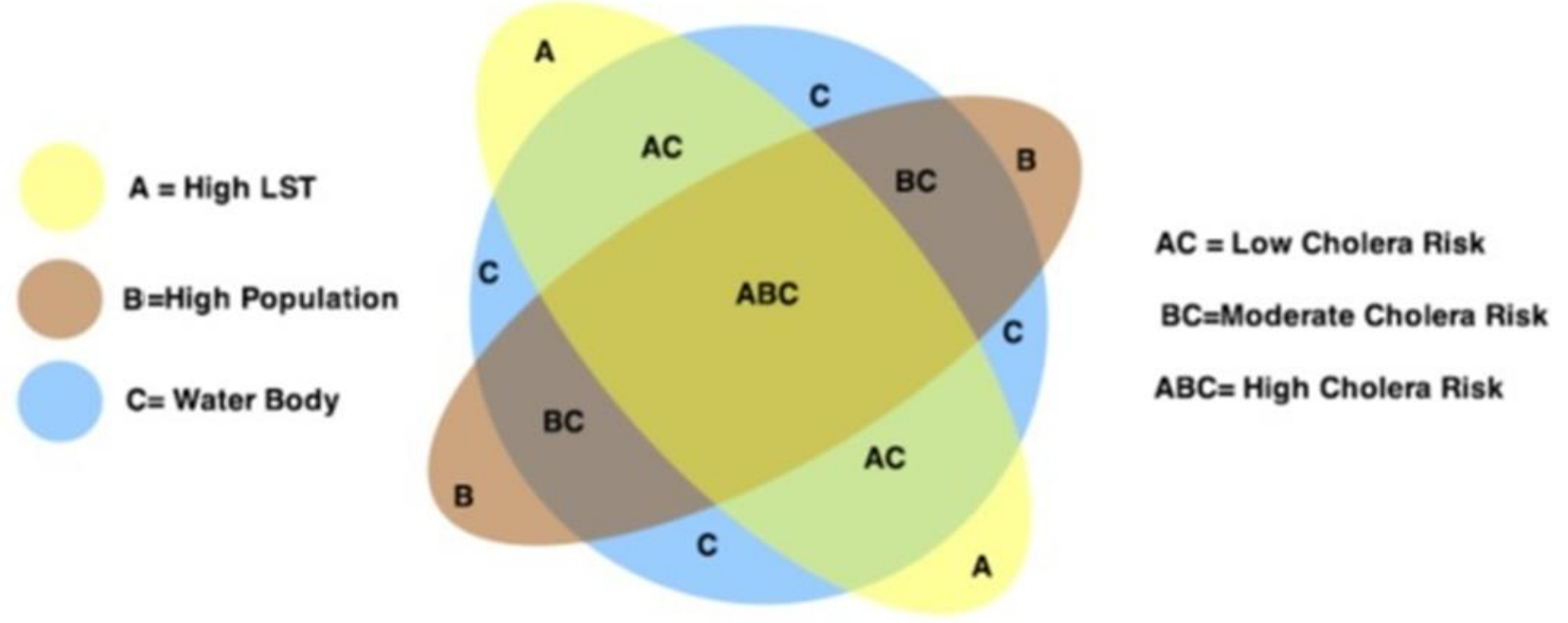

Figure 4.8: Venn diagram for cholera risk mapping principles.

The results show very high risk cholera in Juba County in South Sudan in the months of February, 2014 as shown in Figure 4.9b. Figure 4.9a indicates the probability of very high risk cholera during the month of July, 2011 in Bangui. The region nearby Lake Kivu indicates the highest probability of very high cholera risk in the months of August, 2012 as shown in Figure 4.9d. The analysis for the month of July, 2009 in Cameroon showed the north of Nord region had very high cholera risk while the south of Nord region indicates the likelihood of very low cholera risk as shown in Figure 4.9e. The likelihood of cholera incidence in the month of December, 2013 in Cabo Delgado and Nassa in Mozambique showed many spots indicate very high cholera risk as shown in Figure 4.9c. All those maps indicate some regions have no cholera risk or low risk, that is, people in these regions are safe because they are located in cold spots of land surface temperature and low population density, even if it has water accessibility. 

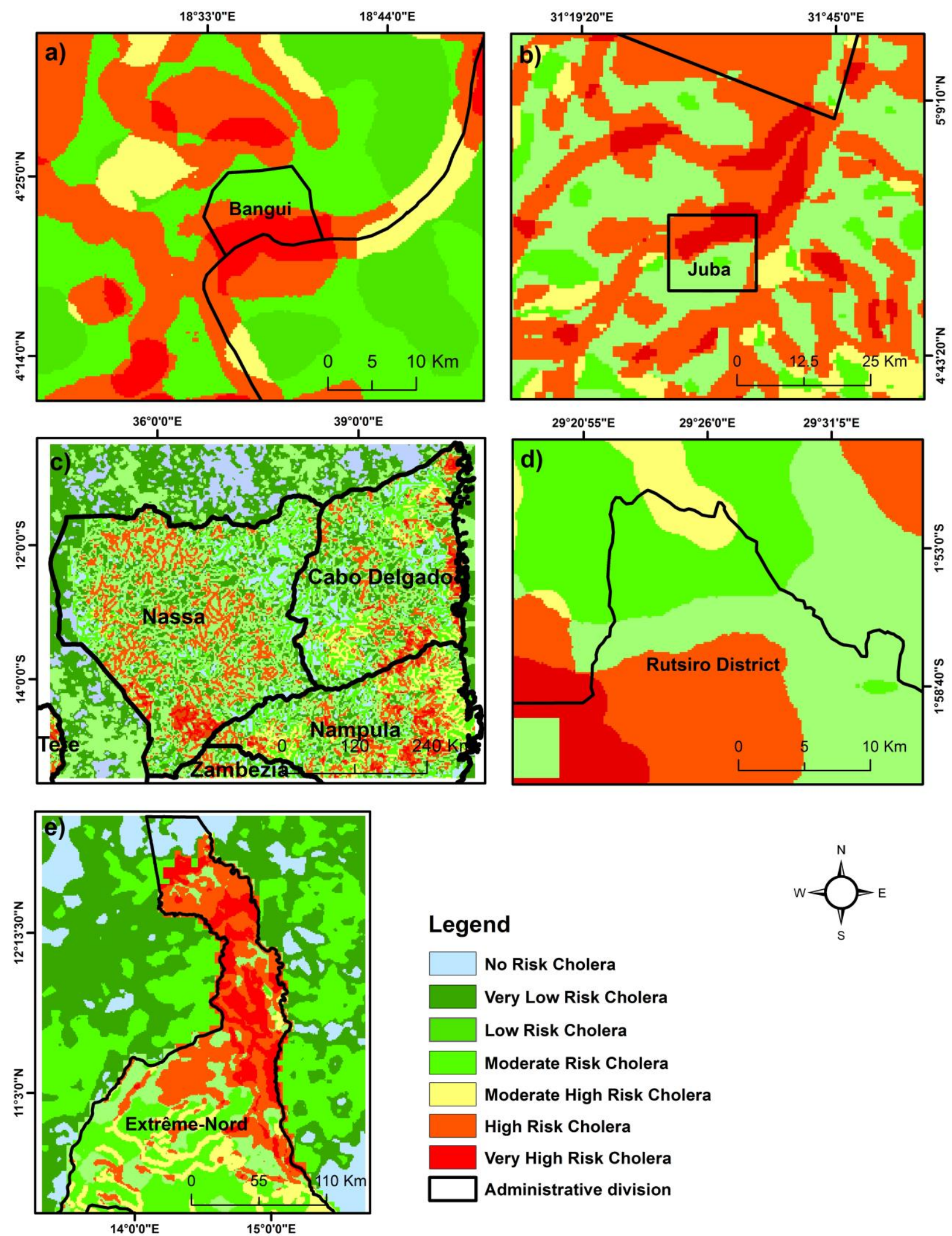

\section{Legend}
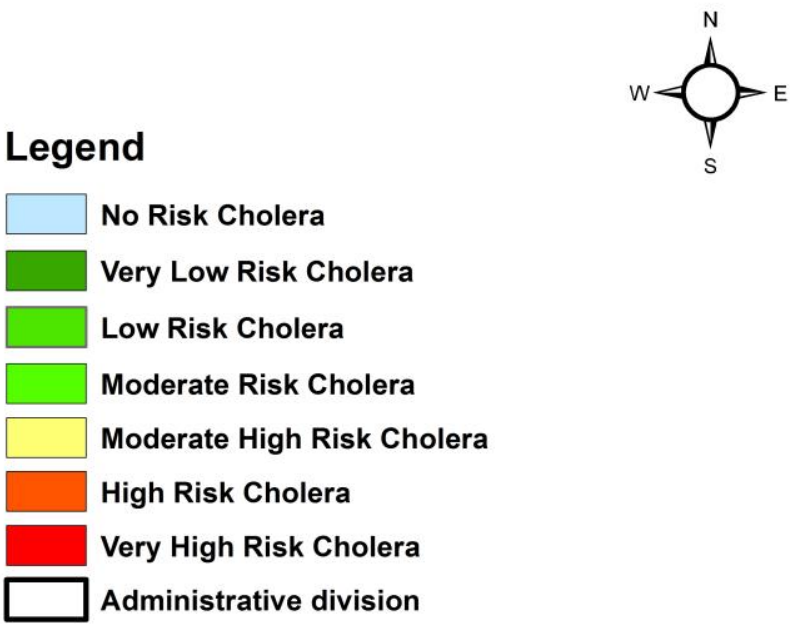

Figure 4.9: Cholera Risk Map: a) The Central African Republic; b) South Sudan; c) Mozambique; d) Rwanda and e) Cameron. 


\section{CHAPTER 5 : SUMMARY AND CONCLUSION}

The occurrence of cholera varies depending on whether it is in an epidemic or an endemic region. When cholera is present in an epidemic region that contains relatively close water sources such as rivers and streamflow, then these types of conditions create a breeding zone for cholera bacteria. Episodes of prevailing warm air temperature followed by heavy precipitation create optimum conditions for the cholera bacteria to grow and transfer from one human to the other. The growing conditions are even more suitable when the sanitation system is inadequate.

Because epidemic cholera occurs sporadically, there are no reliable time series data available for evaluation. To overcome this limitation, we present analysis of recent outbreaks of cholera in five epidemic regions in Africa with different outbreak times. We examined South Sudan, Mozambique, Cameroon, Rwanda and The Central African Republic. The relation of the epidemics and hydroclimatic processes come from the data presented here. With the help of satellites, data can be collected for TRMM precipitation. Combining the rainfall data with gridded air temperatures, cholera expectations can be modeled, for example, hydroclimatic predictability of a lead time to occurrence of cholera. However, due to coarse resolution of both datasets, it is not possible to precisely locate the geographical location of the disease. Here, using Land Surface Temperature (LST) from MODIS sensors, we have developed an algorithm to identify regions susceptible for cholera.

That is, when the temporal series of air temperature and rainfall and the spatial series of land surface temperature are higher than the long-term average for a region, cholera has more opportunity to grow in aquatic habitats because of the optimum conditions. If the water sources and sanitation network are not in unfavorable conditions then cholera will be able to be predicted a month in advance or even more. This was the conditions for what happened in Bangui in 2011. Thus the anomalies of elevated temperature and land surface temperature for two months prior to 
higher than normal rainfall create a potential risk or hazard of cholera. This is especially true if the level of sanitation for the drinking water, accessible medical resources, and reporting methods are high.

The spatial statistics for the deviation analysis of land surface temperature were performed by using Optimized Hot Spot Analysis for all epidemic regions. The output showed that these regions are located within the positive distribution of Z-score greater than 2.58, which are statistically significant for the anomaly of land surface temperature. Our study is interested in finding significant zone for cholera. The physical distance for epidemic regions are 25 miles away from a major river system; for that reason we selected a zone with radius 25 miles for the river from each one of the five countries. High population density, high temperature and accessibility to water bodies were the most important factors for cholera occurrence.

Low resolution of hydroclimatic dataset led to the selection of $1 \mathrm{~km}$ buffer for the water bodies system in the affected regions. Three input raster layers of water bodies, population and land surface temperature were analyzed using ArcMap 10.2. The output of this analysis was a new map showing the most important cholera risk zones in the selected area. This map has an impact factor numbering from zero (No Cholera Risk) to 7 (Very High Cholera Risk); the classification of most of the five affected regions are located within very high cholera risk.

Hydro-climatological risk is geophysical processes and environmental specifications that have the potential for growing bacteria. Societal risk is when there is not sanitary water for drinking and other necessary tasks. If both of these risks occur in a community then the likelihood of cholera spreading is a very high probability. A huge factor for disease growth in a specific population is when the safe drinking water is limited. Therefore both societal risk and community health both contribute to the problem at hand. 
Cholera production analysis and risk map of possible cholera outbreaks could play a valuable role in preparations against the disease. In addition, the prediction of cholera outbreaks can play a significant role in reducing the burden of the disease. Prediction of timing and locations of the disease would allow officials to provide vaccinations for people under risk such as children and elders, gather expert resources such as nurses and public health workers personnel, provide necessary material such as oral hydration therapy and water purification equipment, and spread awareness for epidemic warnings. Furthermore, it is believed that Water, Sanitation and Hygiene (WASH) infrastructure could help in reducing cholera prevalence in developing regions (Jutla et al, 2013).

The overall case-fatality ratio in the five epidemic regions in Africa ranged from $1 \%$ in Mozambique to around $50 \%$ in Rwanda seen during the outbreak period of time. More than $1 \%$ case- fatality rate indicates one of three things that are poor management, late arrival to health care centers or hospitals, or bias of surveillance (World Health Organization, 2004). All the five epidemic regions were suffering either natural disaster or social disruption, which already overburdened water and sanitation infrastructure at a time of the year when both climate and environmental conditions favor proliferation of V.cholerae, these conditions can lead to an epidemic of disease.

The challenge in developing a cholera prediction model for epidemic regions is to identify environmental conditions and enabling transmission mechanisms. If a serious natural disaster is to hit a region or civil disputes are causing variation to population and living circumstances, tracking devices for cholera can be used. Using satellite remote sensing technology, changes in population and water sanitizing can be closely watched. A trustworthy and reasonably accurate prediction can be made with understanding transmission pathways and the necessary environmental parameters. 


\subsection{Recommendations}

The following points are recommended for future research work:

- Check the optimized hot spot analysis for the deviation MODIS land surface temperature over the time period (2004-2014) for all epidemic regions in Africa and compare them with other regions in worldwide.

- Analyze a prediction risk map for all epidemic regions in the world according to land surface temperature, water bodies and gridded population data.

- Develop mathematical prediction model for epidemic cholera regions using hydroclimatic dataset e.g. elevated air temperature and rainfall.

- Detect more details about the water bodies in the affected cholera regions using the Normalized Difference Water Index (NDWI).

- Type I and Type II error investigation can be helpful in supporting the decisions considered. This will depend on the results of the model, since they can determine the reliability for the model. 


\section{REFERENCES}

Zuckerman, J. N., Rombo, L., \& Fisch, A. (2007). The true burden and risk of cholera: implications for prevention and control. The Lancet infectious diseases, 7(8), 521-530.

World Health Organization (WHO. (2004). Cholera outbreak: assessing the outbreak response and improving preparedness. In Cholera Outbreak: Assessing the Outbreak Response and Improving Preparedness. World Health Organization (WHO).

Trærup, S. L., Ortiz, R. A., \& Markandya, A. (2010). The health impacts of climate change: a study of cholera in Tanzania. International Journal of Environmental Research and Public Health, 8, 399-400.

J. Reidl and K. E. Klose. Vibrio cholera and cholera: out of the water and into the host. FEM S Microbiology Reviews, 26:125-139, june 2002.

Lamond, E., \& Kinyanjui, J. (2012). Cholera outbreak guidelines: preparedness, prevention and control.

Jutla, A., Whitcombe, E., Hasan, N., Haley, B., Akanda, A., Huq, A., ... \& Colwell, R. (2013). Environmental factors influencing epidemic cholera. The American journal of tropical medicine and hygiene, 89(3), 597-607.

Payment, P., \& Hunter, P. R. (2001). Endemic and epidemic infectious intestinal disease and its relationship to drinking water. Water quality: guidelines, standard and health. London: IWA Publishing WHO, 61-88.

Nasser Issam (2009). One-step immunochromatographic dipstick tests for rapid detection of Vibrio cholerae O1 and O139 in stool samples. Iraqi J. Comm. Med., JAN. 2009, 23(1), 19-24.

Enserink M. Haiti's Outbreak Is Latest in Cholera's New Global Assault. Science. 2010;330: 738-739. doi:10.1126/science.330.6005.738

Evengård, B., \& Sauerborn, R. (2009). Climate change influences infectious diseases both in the Arctic and the tropics: joining the dots. Global Health Action, 2.

Martinelli Filho, J. E., Lopes, R. M., Rivera, I. N., \& Colwell, R. R. (2010). Vibrio cholerae O1 detection in estuarine and coastal zooplankton. Journal of plankton research, fbq093.

Chicago

Chaignat, C. L., \& Monti, V. (2007). Use of oral cholera vaccine in complex emergencies: what next? Summary report of an expert meeting and recommendations of WHO. Journal of health, population, and nutrition, 25(2), 244.

Emch, M., Feldacker, C., Yunus, M., Streatfield, P. K., Thiem, V. D., Canh, D. G., \& Ali, M. (2008). Local environmental predictors of cholera in Bangladesh and Vietnam. American Journal of Tropical Medicine and Hygiene, 78(5), 823-832. 
Gleick, P., (2008). The World's Water 2008-2009: The Biennial Report on Freshwater Resources. Island Press USA.

Kelly-Hope, L. A., Alonso, W. J., Thiem, V. D., Do Gia Canh, Anh, D. D., Lee, H., \& Miller, M. A. (2008). Temporal trends and climatic factors associated with bacterial enteric diseases in Vietnam, 1991-2001. Environmental health perspectives, 7-12.

Pascual, M., Rodo, X., Ellner, S., Colwell, R., and Bouma, M., (2000). Cholera Dynamics and El Nino-Southern Oscillation. Sciencemag. 8 September, Vol 289. Pp 1766-1769.

Griffith, D., Louise A. Kelly-Hope, and Mark A. Miller. "Review of reported cholera outbreaks worldwide, 1995-2005 (2006)." American Journal of Tropical Medicine and Hygiene 75, no. 5: 973-977.

Reyburn, Rita, Deok Ryun Kim, Michael Emch, Ahmed Khatib, Lorenz von Seidlein, and Mohammad Ali (2011). "Climate variability and the outbreaks of cholera in Zanzibar, East Africa: a time series analysis." The American journal of tropical medicine and hygiene 84, no. 6: 862.

Bompangue, D., Giraudoux, P., Piarroux, M., Mutombo, G., Shamavu, R., Sudre, B., ... \& Piarroux, R. (2009). Cholera epidemics, war and disasters around Goma and Lake Kivu: an eight-year survey. PLoS neglected tropical diseases, 3(5), e436.

Faruque, S. M., Albert, M. J., \& Mekalanos, J. J. (1998). Epidemiology, Genetics, and Ecology of ToxigenicVibrio cholerae. Microbiology and molecular biology reviews, 62(4), 1301-1314.

Gaffga, N. H., Tauxe, R. V., \& Mintz, E. D. (2007). Cholera: a new homeland in Africa?. The American journal of tropical medicine and hygiene, 77(4), 705-713.

Bentivoglio, M., \& Pacini, P. (1995). Filippo Pacini: a determined observer.Brain research bulletin, 38(2), 161-165.

Mendelsohn, J., \& Dawson, T. (2008). Climate and cholera in KwaZulu-Natal, South Africa: The role of environmental factors and implications for epidemic preparedness. International journal of hygiene and environmental health, 211(1), 156-162.

Trærup, S. L., Ortiz, R. A., \& Markandya, A. (2011). The costs of climate change: a study of cholera in Tanzania. International journal of environmental research and public health, 8(12), 4386-4405.

Thompson, A. A., Matamale, L., \& Kharidza, S. D. (2012). Impact of climate change on children's health in Limpopo Province, South Africa. International journal of environmental research and public health, 9(3), 831-854.

Rebaudet, S., Sudre, B., Faucher, B., \& Piarroux, R. (2013). Environmental determinants of cholera outbreaks in inland Africa: a systematic review of main transmission foci and propagation routes. Journal of Infectious Diseases, 208(suppl 1), S46-S54. 
Lan, R., \& Reeves, P. R. (1998). Recombination between rRNA operons created most of the ribotype variation observed in the seventh pandemic clone of Vibrio cholerae. Microbiology, 144(5), 1213-1221.

Fernández, M. Á. L., Bauernfeind, A., Jiménez, J. D., Gil, C. L., El Omeiri, N., \& Guibert, D. H. (2009). Influence of temperature and rainfall on the evolution of cholera epidemics in Lusaka, Zambia, 2003-2006: analysis of a time series. Transactions of the Royal Society of Tropical Medicine and Hygiene, 103(2), 137-143.

Griffith, D. C., Kelly-Hope, L. A., \& Miller, M. A. (2006). Review of reported cholera outbreaks worldwide, 1995-2005. The American journal of tropical medicine and hygiene, 75(5), 973-977.

YOMWAN, P., CAOb, C., ZHAO, J., TIAN, R., \& SUPHAMITMONGKOL, W. EPIDEMIC RISK ASSESSMENT OF ACUTE WATERY DIARRHEA FOR THE 2011 AYUTTHAYA FLOOD DISASTER USING REMOTE SENSING AND WATER QUALITY.

Jagai, J. S., Sarkar, R., Castronovo, D., Kattula, D., McEntee, J., Ward, H., ... \& Naumova, E. N. (2012). Seasonality of rotavirus in South Asia: a meta-analysis approach assessing associations with temperature, precipitation, and vegetation index. PloS one, 7(5), e38168.

Rose-Dye, T. K., Burciaga-Robles, L. O., Krehbiel, C. R., Step, D. L., Fulton, R. W., Confer, A. W., \& Richards, C. J. (2011). Rumen temperature change monitored with remote rumen temperature boluses after challenges with bovine viral diarrhea virus and. Journal of animal science, 89(4), 1193-1200.

Eisenberg, M. C., Kujbida, G., Tuite, A. R., Fisman, D. N., \& Tien, J. H. (2013). Examining rainfall and cholera dynamics in Haiti using statistical and dynamic modeling approaches. Epidemics, 5(4), 197-207.

Jutla, A. S., Akanda, A. S., \& Islam, S. (2012). Satellite remote sensing of space-time plankton variability in the Bay of Bengal: Connections to cholera outbreaks. Remote sensing of environment, 123, 196-206.

Jutla, A. S., Akanda, A. S., \& Islam, S. (2010). Tracking cholera in coastal regions using satellite observations1.

Lobitz, B., Beck, L., Huq, A., Wood, B., Fuchs, G., Faruque, A. S. G., \& Colwell, R. (2000). Climate and infectious disease: use of remote sensing for detection of Vibrio cholerae by indirect measurement. Proceedings of the National Academy of Sciences, 97(4), 1438-1443.

Wang, J., \& Deng, Z. (2012). Detection and forecasting of oyster norovirus outbreaks: recent advances and future perspectives. Marine environmental research, 80, 62-69.

Abdul Rasam, A. R., Noor, A. M., Ahmad, N., \& Ghazali, R. (2011, March). MyGeoHealth: GIS-based cholera transmission risk system in Sabah, Malaysia. In Signal Processing and its Applications (CSPA), 2011 IEEE 7th International Colloquium on (pp. 474-479). IEEE.

Luquero, F. J., Banga, C. N., Remartínez, D., Palma, P. P., Baron, E., \& Grais, R. F. (2011). Cholera epidemic in Guinea-Bissau (2008): the importance of "place". PloS one, 6(5), e19005. 
WHO. Cholera, 2008. Weekly Epidemiological Record 2009;84(31):309-324.

Penrose, K., de Castro, M. C., Werema, J., \& Ryan, E. T. (2010). Informal urban settlements and cholera risk in Dar es Salaam, Tanzania. PLoS neglected tropical diseases, 4(3), e631.

WHO | South Sudan cholera outbreak in Juba health updates [Internet]. [cited 12 Oct 2014]. Available: http://www.who.int/hac/crises/ssd/sitreps/juba_cholera_outbreak/en/

WHO | Media Centre-Fact sheets-Cholera- update [Internet]. [cited Feb 2014]. Available: http://www.who.int/mediacentre/factsheets/fs107/en/

Rwanda: Floods - Apr 2012. In: ReliefWeb [Internet]. [cited 16 Oct 2014]. Available: http://reliefweb.int/disaster/fl-2012-000067-rwa

Cameroon cholera deaths rising as heavy rains bring flooding. In: ReliefWeb [Internet]. 3 Aug 2010 [cited 16 Oct 2014]. Available: http://reliefweb.int/report/cameroon/cameroon-choleradeaths-rising-heavy-rains-bring-flooding

World Health Organization. Global Task Force on Cholera Control [Internet]. Geneva; p. 2. Available: http://www.who.int/cholera/countries/CameroonCountryProfile2011.pdf

Siddique, A. K., Akram, K., Zaman, K., Laston, S., Salam, A., Majumdar, R. N., ... \& Fronczak, N. (1995). Why treatment centres failed to prevent cholera deaths among Rwandan refugees in Goma, Zaire. The Lancet, 345(8946), 359-361.

Austin, B. (2010). Vibrios as causal agents of zoonoses. Veterinary microbiology, 140(3), 310317.

Faruque, S. M., Chowdhury, N., Kamruzzaman, M., Dziejman, M., Rahman, M. H., Sack, D. A., ... \& Mekalanos, J. J. (2004). Genetic diversity and virulence potential of environmental Vibrio cholerae population in a cholera-endemic area. Proceedings of the National Academy of Sciences of the United States of America, 101(7), 2123-2128.

Acosta, C. J., Galindo, C. M., Kimario, J., Senkoro, K., Urassa, H., Casals, C., ... \& Alonso, P. L. (2001). Cholera outbreak in southern Tanzania: risk factors and patterns of transmission. Emerging infectious diseases, 7(3 Suppl), 583.

Dutta, D., Chowdhury, G., Pazhani, G. P., Guin, S., Dutta, S., Ghosh, S., ... \& Ramamurthy, T. (2013). Vibrio cholerae non-O1, non-O139 serogroups and cholera-like diarrhea, Kolkata, India. Emerging infectious diseases, 19(3), 464.

Mukhopadhyay, A. K., Takeda, Y., \& Nair, G. B. (2014). Cholera Outbreaks in the El Tor Biotype Era and the Impact of the New El Tor Variants. In Cholera Outbreaks (pp. 17-47). Springer Berlin Heidelberg.

Kondo, S., Kongmuang, U., Kalnauwakul, S., Matsumoto, C., Chen, C. H., \& Nishibuchi, M. (2001). Molecular epidemiologic analysis of Vibrio cholerae O1 isolated during the 1997-8 cholera epidemic in southern Thailand. Epidemiology and infection, 127(01), 7-16.

WHO. Cholera, 2013. Weekly Epidemiological Record 2014;89(31): 345-356. 
Waldor, M. K., Tschäpe, H. E. L. M. U. T., \& Mekalanos, J. J. (1996). A new type of conjugative transposon encodes resistance to sulfamethoxazole, trimethoprim, and streptomycin in Vibrio cholerae O139. Journal of bacteriology, 178(14), 4157-4165.

Hoge, C. W., Bodhidatta, L., Echeverria, P., Deesuwan, M., \& Kitporka, P. (1996).

Epidemiologic study of Vibrio cholerae O1 and O139 in Thailand: at the advancing edge of the eighth pandemic. American journal of epidemiology, 143(3), 263-268.

Mukhopadhyay, A. K., Basu, A., Garg, P., Bag, P. K., Ghosh, A., Bhattacharya, S. K., ... \& Nair, G. B. (1998). Molecular epidemiology of reemergent Vibrio cholerae O139 Bengal in India. Journal of clinical microbiology, 36(7), 2149-2152.

Finkelstein, R. A. (1996). Cholera, Vibrio cholerae O1 and O139, and other pathogenic vibrios.

Kitaoka, M., Miyata, S. T., Unterweger, D., \& Pukatzki, S. (2011). Antibiotic resistance mechanisms of Vibrio cholerae. Journal of medical microbiology, 60(4), 397-407.

Falbo, V., Carattoli, A., Tosini, F., Pezzella, C., Dionisi, A. M., \& Luzzi, I. (1999). Antibiotic resistance conferred by a conjugative plasmid and a class I integron in Vibrio cholerae O1 El Tor strains isolated in Albania and Italy. Antimicrobial agents and chemotherapy, 43(3), 693-696.

Pierce, N. F., Banwell, J. G., Mitra, R. C., Caranasos, G. J., Keimowitz, R. I., Thomas, J., \& Mondal, A. (1968). Controlled comparison of tetracycline and furazolidone in cholera. BMJ, 3(5613), 277-280.

Yu, L., Zhou, Y., Wang, R., Lou, J., Zhang, L., Li, J., ... \& Kan, B. (2012). Multiple antibiotic resistance of Vibrio cholerae serogroup O139 in China from 1993 to 2009. PloS one, 7(6), e38633.

Islam, M. S., Siddique, A. K. M., Salam, A., Akram, K., Majumdar, R. N., Zaman, K., ... \& Laston, S. (1995). Microbiological investigation of diarrhoea epidemics among Rwandan refugees in Zaire. Transactions of the Royal Society of Tropical Medicine and Hygiene, 89(5), 506.

Clemens, J. D. (2011). Vaccines in the time of cholera. Proceedings of the National Academy of Sciences, 108(21), 8529-8530.

UNICEF. (2012). Guidance note on the use of oral cholera vaccines for UNICEF. New York: UNICEF.

Brunette, G. W., Kozarsky, P. E., \& Cohen, M. J. (2014). The Yellow Book, CDC Health Information for International Travel 2014.

GLASS, R. I., BECKER, S., Huq, M. I., STOLL, B. J., Khan, M. U., MERSON, M. H., ... \& BLACK, R. E. (1982). Endemic cholera in rural Bangladesh, 1966-1980. American journal of epidemiology, 116(6), 959-970.

Polsky, D., Sochalski, J., Aiken, L. H., \& Cooper, R. A. (2006). Medical migration to the US: trends and impact. LDI issue brief, 12(6), 1-4. 
Bacaner, N., Stauffer, B., Boulware, D. R., Walker, P. F., \& Keystone, J. S. (2004). Travel medicine considerations for North American immigrants visiting friends and relatives. Jama, 291(23), 2856-2864.

Noah, D., \& Fidas, G. (2000). The global infectious disease threat and its implications for the United States (No. NIE-99-17D). NATIONAL INTELLIGENCE COUNCIL WASHINGTON DC.

Steffen, R., Acar, J., Walker, E., \& Zuckerman, J. (2003). Cholera: assessing the risk to travellers and identifying methods of protection. Travel medicine and infectious disease, 1(2), 80-88.

WHO. Cholera, 2012. Weekly Epidemiological Record 2013;88(31): 321-336.

World Tourism Organization. Tourism 2020 Vision. East Asia and Pasfic [Internet]. [cited 1 January, 2001] Available: http:// http://pub.unwto.org/

Alam, M., Hasan, N. A., Sultana, M., Nair, G. B., Sadique, A., Faruque, A. S. G., .. \& Cravioto, A. (2010). Diagnostic limitations to accurate diagnosis of cholera. Journal of clinical microbiology, 48(11), 3918-3922.

Talavera, A., \& Perez, E. M. (2009). Is cholera disease associated with poverty?. The Journal of Infection in Developing Countries, 3(06), 408-411.

Mandal, S., Mandal, M. D., \& Pal, N. K. (2011). Cholera: a great global concern. Asian Pacific journal of tropical medicine, 4(7), 573-580.

Schwartz, B. S., Harris, J. B., Khan, A. I., Larocque, R. C., Sack, D. A., Malek, M. A., ... \& Ryan, E. T. (2006). Diarrheal epidemics in Dhaka, Bangladesh, during three consecutive floods: 1988, 1998, and 2004. The American journal of tropical medicine and hygiene, 74(6), 10671073.

Adagbada, A. O., Adesida, S. A., Nwaokorie, F. O., Niemogha, M. T., \& Coker, A. O. (2012). Cholera epidemiology in Nigeria: an overview. Pan African Medical Journal, 12(1).

de Magny, G. C., Murtugudde, R., Sapiano, M. R., Nizam, A., Brown, C. W., Busalacchi, A. J., ... \& Colwell, R. R. (2008). Environmental signatures associated with cholera epidemics. Proceedings of the National Academy of Sciences, 105(46), 17676-17681.

Pascual, M., Bouma, M. J., \& Dobson, A. P. (2002). Cholera and climate: revisiting the quantitative evidence. Microbes and Infection, 4(2), 237-245.

Lipp, E. K., Huq, A., \& Colwell, R. R. (2002). Effects of global climate on infectious disease: the cholera model. Clinical microbiology reviews, 15(4), 757-770.

Mboera, L. E., Mayala, B. K., Kweka, E. J., \& Mazigo, H. D. (2012). Impact of climate change on human health and health systems in Tanzania: a review. Tanzania journal of health research, 13(5). 
Hashizume, M., Armstrong, B., Hajat, S., Wagatsuma, Y., Faruque, A. S., Hayashi, T., \& Sack, D. A. (2008). The effect of rainfall on the incidence of cholera in Bangladesh. Epidemiology, 19(1), 103-110.

de Magny, G. C., Guégan, J. F., Petit, M., \& Cazelles, B. (2007). Regional-scale climatevariability synchrony of cholera epidemics in West Africa. BMC infectious diseases, 7(1), 20.

Bouma, M. J., \& Pascual, M. (2001). Seasonal and interannual cycles of endemic cholera in Bengal 1891-1940 in relation to climate and geography. In The Ecology and Etiology of Newly Emerging Marine Diseases (pp. 147-156). Springer Netherlands.

Hashizume, M., Chaves, L. F., Faruque, A. S. G., Yunus, M., Streatfield, K., \& Moji, K. (2013). A differential effect of Indian ocean dipole and El Niño on cholera dynamics in Bangladesh. PloS one, 8(3), e60001.

Finger, F., Knox, A., Bertuzzo, E., Mari, L., Bompangue, D., Gatto, M., ... \& Rinaldo, A. (2014). Cholera in the Lake Kivu region (DRC): Integrating remote sensing and spatially explicit epidemiological modeling. Water Resources Research, 50(7), 5624-5637.

Nkoko, D. B. (2011). Dynamics of cholera outbreaks in Great Lakes region of Africa, 19782008. Dynamics.

Henschel, K. M. (2013). The Influences of Climatic and Socioeconomic Variables on Cholera Incidence in India During the Seventh Pandemic, 1961-2008.

Patz, J. A., Epstein, P. R., Burke, T. A., \& Balbus, J. M. (1996). Global climate change and emerging infectious diseases. Jama, 275(3), 217-223.

Patz, J. A. (2002). A human disease indicator for the effects of recent global climate change. Proceedings of the National Academy of Sciences, 99(20), 12506-12508.

Akoachere, J. F. T., \& Mbuntcha, C. K. (2014). Water sources as reservoirs of Vibrio cholerae $\mathrm{O} 1$ and non-O1 strains in Bepanda, Douala (Cameroon): relationship between isolation and physico-chemical factors. BMC infectious diseases, 14(1), 421.

Rita, R. (2009). Cholera and climate: a demonstrated relationship. Transactions of the American Clinical and Climatological Association, 120, 119.

Takemura, A. F., Chien, D. M., \& Polz, M. F. (2014). Associations and dynamics of Vibrionaceae in the environment, from the genus to the population level. Frontiers in microbiology, 5 .

Colwell, R. R., Huq, A., Islam, M. S., Aziz, K. M. A., Yunus, M., Khan, N. H. \& Russek-Cohen, E. (2003). Reduction of cholera in Bangladeshi villages by simple filtration. Proceedings of the National Academy of Sciences, 100(3), 1051-1055.

Food and Agriculture Organization (FAO)|Zambia Nutrition Profile - Nutrition and Consumer Protection Division- update [Internet]. [cited 2009]. Available:

http://www.ftp.fao.org/ag/agn/nutrition/ncp/zmb.pdf 
Codeço, C. T. (2001). Endemic and epidemic dynamics of cholera: the role of the aquatic reservoir. BMC Infectious diseases, 1(1), 1.

Tamplin, M. L., Gauzens, A. L., Huq, A., Sack, D. A., \& Colwell, R. R. (1990). Attachment of Vibrio cholerae serogroup O1 to zooplankton and phytoplankton of Bangladesh waters. Applied and Environmental Microbiology, 56(6), 1977-1980.

Trærup, S. L., Ortiz, R. A., \& Markandya, A. (2010). The health impacts of climate change: a study of cholera in Tanzania. International Journal of Environmental Research and Public Health, 8, 399-400.

Wandiga, S. O. (2006). Climate Change Induced Vulnerability to Malaria and Cholera in the Lake Victoria Region: A Final Report Submitted to Assessments of Impacts and Adaptations to Climate Change (AIACC), Project No. AF 91. International START Secretariat, Washington, DC.

Mayala, B. K., Mboera, L. E. G., \& Gwacha, F. (2004). Mapping of cholera risks using Geographical Information System in Ilala District, Tanzania. Tanzania Journal of Health Research, 5(1), 8-12.

Mathers, C. D., \& Loncar, D. (2006). Projections of global mortality and burden of disease from 2002 to 2030. PLoS medicine, 3(11), e442.

Trærup, S. L., Ortiz, R. A., \& Markandya, A. (2011). The costs of climate change: a study of cholera in Tanzania. International journal of environmental research and public health, 8(12), 4386-4405.

Kosek, M., Bern, C., \& Guerrant, R. L. (2003). The global burden of diarrhoeal disease, as estimated from studies published between 1992 and 2000. Bulletin of the World Health Organization, 81(3), 197-204.

Ringler, C., Zhu, T., Cai, X., Koo, J., \& Wang, D. (2010). Climate change impacts on food security in sub-Saharan Africa. International Food Policy Research Institute (IFPRI) Discussion Paper, 1042.

Sena, A., Barcellos, C., Freitas, C., \& Corvalan, C. (2014). Managing the Health Impacts of Drought in Brazil. International journal of environmental research and public health, 11(10), 10737-10751.

Furgal, C., \& Seguin, J. (2006). Climate change, health, and vulnerability in Canadian northern Aboriginal communities. Environmental health perspectives, 1964-1970.

WHO | Regional office for Europe. Report on a WHO meeting London, United Kingdom 30 June - 2 July 2002: EUR/02/5036813 Available:

http://www.euro.who.int/_data/assets/pdf_file/0007/74734/E77096.pdf

WHO, (2009). Cholera. Retrieved February 1, 2015, from Health topics, http://www.who.int/topics/cholera/about/en/index.html

Volk, W., Benjamin, D., Kadner, R., \& Parsons, T. (1991). Essentials of Medical Microbiology 
(4th ed.). Philadelphia: J. B. Lippincott Company.

World Health Organization, World Health Organization, \& Centers for Disease Control and Prevention. (1999). Laboratory methods for the diagnosis of epidemic dysentery and cholera.

Steffen, R., Acar, J., Walker, E., \& Zuckerman, J. (2003). Cholera: assessing the risk to travelers and identifying methods of protection. Travel Medicine and Infectious Disease, 1, 80-88.

Seas, C. \& Gotuzzo, E. (1996). Cholera: overview of epidemiologic, therapeutic, and preventive issues learned from recent epidemics. International Journal of Infectious Diseases, 1, (1), 37-44.

David A Sack, R Bradley Sack, G Balakrish Nair, A K Siddique. Cholera Seminar. The Lancet Infectious Diseases, Vol 363. January 17, 2004. Available: http:// www.thelancet.com

Aumatell, C. M., Torrell, J. R., \& Zuckerman, J. N. (2011). Review of oral cholera vaccines: efficacy in young children. Infection and drug resistance, $4,155$.

Simanjuntak, C., Totosudirjo, H., Witham, N., Punjabi, N., Burr, D., Sorenson, K., ... \& Cryz, S. (1992). Safety and immunogenicity of single-dose live oral cholera vaccine CVD 103-HgR in 59-year-old Indonesian children. The Lancet, 340(8821), 689-694.

Ryan, E. T., \& Calderwood, S. B. (2000). Cholera vaccines. Clinical infectious diseases, 31(2), 561-565.

WHO | Programmes, International travel and health [Internet]. Retrieved February, 2015. Available: http://www.who.int/ith/vaccines/cholera/en/

Kenner, J. R., Coster, T. S., Taylor, D. N., Trofa, A. F., Barrera-Oro, M., Hyman, T., ... \& Sadoff, J. C. (1995). Peru-15, an improved live attenuated oral vaccine candidate for Vibrio cholerae O1. Journal of Infectious Diseases, 172(4), 1126-1129.

Legros, D., Paquet, C., Perea, W., Marty, I., Kenya Mugisha, N., Royer, H., ... \& Ivanoff, B. (1999). Mass vaccination with a two-dose oral cholera vaccine in a refugee camp. Bulletin of the World Health Organization, 77(10), 837-842.

Martin, S., Lopez, A. L., Bellos, A., Deen, J., Ali, M., Alberti, K., ... \& Sack, D. A. (2014). Postlicensure deployment of oral cholera vaccines: a systematic review. Vaccine, 92(12).

Lucas, M. E., Deen, J. L., von Seidlein, L., Wang, X. Y., Ampuero, J., Puri, M., ... \& Clemens, J. D. (2005). Effectiveness of mass oral cholera vaccination in Beira, Mozambique. New England Journal of Medicine, 352(8), 757-767.

López-Gigosos, R., García-Fortea, P., Reina-Doña, E., \& Plaza-Martín, E. (2007). Effectiveness in prevention of travellers' diarrhoea by an oral cholera vaccine $\mathrm{WC} / \mathrm{rBS}$. Travel medicine and infectious disease, 5(6), 380-384.

Lilliestierna, H., \& Britton, S. (2006). Cholera and car accidents. Lancet, 368(9536), 646-646.

WHO. Cholera: prevention and control. Retrieved February 1, 2015, from Health

Topics, http://www.who.int/topics/cholera/control/en/index.html 
World Tourism Organization. WTO Tourism Highlights, 2005 edn. Madrid: World Tourism Organization, 2005.

Thacker, S. B., Stroup, D. F., Parrish, R. G., \& Anderson, H. A. (1996). Surveillance in environmental public health: issues, systems, and sources. American journal of public health, 86(5), 633-638.

Georges, M. C., Wachsmuth, I. K., Meunier, D. M., Nebout, N., Didier, F., Siopathis, M. R., \& Georges, A. J. (1984). Parasitic, bacterial, and viral enteric pathogens associated with diarrhea in the Central African Republic. Journal of clinical microbiology, 19(5), 571-575.

United Nations in South Sudan. Nature and Resources. http://ss.one.un.org/country-info.html.

WHO. Humanitarian Health Action. Crises. South Sudan cholera outbreak in Juba health updates. Sitrep No. 1. May 16, 2014.

World Travel Guide (2015). Climate and Geography;

Rwanda.http://www.worldtravelguide.net/rwanda.

World Health Organization. Global Task Force on Cholera Control: Mozambique [Internet]. Geneva; p. 2. Available:

http://www.who.int/cholera/countries/MozambiqueCountryProfile2013.pdf

WHO Country office in Cameroon. Country Profile. Last update January 17, 2012. www.who.int/cholera/countries/CameroonCountryProfile2011.pdf.

CDC Foundation. Cholera Outbreak Investigation in the Central African Republic [Internet]. p. 20. Available:

http://www.cdcfoundation.org/sites/default/files/upload/pdf/2011CholeraOutbreakReport.pdf

EAIDSNet. Cholera Outbreak in Kinunu Health Center, Rutsiro District, Western Province, Rwanda. Poste on May 10, 2013. http://eaidsnet.eac.int/cholera-outbreak-in-kinunu-healthcenter-rutsiro-district-western-province-rwanda-october-2012/.

Giovanni. (October 7, 2014). Giovanni - Interactive Visualization and Analysis. Retrieved from http://disc.sci.gsfc.nasa.gov/giovanni\#maincontent.

ESRL NOAA.(n.d). National Oceanic \& Atmospheric Administration. Retrieved from http://www.esrl.noaa.gov/psd/data/gridded/data.ghcncams.html.

NASA Earth Observatory. Global Maps. Land Surface Temperature. Retrieved from: http://earthobservatory.nasa.gov/GlobalMaps/view.php?d1=MOD11C1_M_LSTDA

Edwards, D. P., Halvorson, C. M., \& Gille, J. C. (1999). Radiative transfer modeling for the EOS Terra satellite Measurement of Pollution in the Troposphere (MOPITT) instrument. Journal of Geophysical Research: Atmospheres (1984-2012), 104(D14), 16755-16775.

Barnes, W. L., Xiong, X., \& Salomonson, V. V. (2002, June). Status of terra MODIS and aqua modis. In Geoscience and Remote Sensing Symposium, 2002. IGARSS'02. 2002 IEEE International (Vol. 2, pp. 970-972). IEEE 
Coops, N. C., Duro, D. C., Wulder, M. A., \& Han, T. (2007). Estimating afternoon MODIS land surface temperatures (LST) based on morning MODIS overpass, location and elevation information. International Journal of Remote Sensing, 28(10), 2391-2396.

King, M. D., Menzel, W. P., Kaufman, Y. J., Tanré, D., Gao, B. C., Platnick, S., ... \& Hubanks, P. A. (2003). Cloud and aerosol properties, precipitable water, and profiles of temperature and water vapor from MODIS. Geoscience and Remote Sensing, IEEE Transactions on, 41(2), 442458.

Xu, Y., Shen, Y., \& Wu, Z. (2013). Spatial and temporal variations of land surface temperature over the Tibetan Plateau based on harmonic analysis. Mountain Research and Development, 33(1), 85-94.

NASA Socioeconomic Data and Applications Center (SEDAC). Gridded Population of the World (GPW), v3. Retrieved from: http://sedac.ciesin.columbia.edu/data/set/gpw-v3-populationdensity

DIVA-GIS. (n.d). Retrieved from http://www.diva-gis.org/node/1.

Cleckner et al., 2011. Remote sensing and modeling of mosquito abundance and habitats in coastal Virginia, USA. Remote Sensing 3(12): 2663-2681.

Uz and Yoder, 2004. High frequency and mesoscale variability in SeaWiFS chlorophyll imagery and its relation to other remotely sensed oceanographic variables. Topical Studies in Oceanography 51(10/11): 1001-1017.

Jutla et al. (2011). Warming oceans, phytoplankton, and river discharge: implications for cholera outbreaks. American Journal of Tropical Medicine and Hygiene 85: 303-308.

Henebry, G.M., T. Chuang, J.S. Kimball, D.L. VanRoekel-Patton, M.B. Hildreth, \& M.C. Wimberly. (2012). Satellite microwave remote sensing for environmental modeling of mosquito population dynamics. Remote Sensing of Environment, 125, 147-156.

Jutla et al. (2012). Satellite space-time variability of chlorophyll in Bay of Bengal: connections to cholera outbreaks. Remote Sensing of Environment 123: 196-206.

ArcGIS Resources. (December 16, 2013). ArcGIS Help 10.2. Retrieved from http://resources.arcgis.com/en/help/main/10.2/index.html\#//009z00000003000000.

ArcGIS Resources. (August 26, 2014). ArcGIS Help 10.2. Retrieved from http://resources.arcgis.com/en/help/main/10.2/index.html\#//005p00000058000000.

Watson, D. F., \& Philip, G. M. (1985). A refinement of inverse distance weighted interpolation. Geo-processing, 2(4), 315-327.

Central African Republic: Severe Local Storm - Jun 2011. In: ReliefWeb [Internet]. [cited 16 Oct 2014]. Available: http://reliefweb.int/disaster/st-2011-000073-caf 
Akanda, A. S., Jutla, A. S., Gute, D. M., Sack, R. B., Alam, M., Huq, A., ... \& Islam, S. (2013). Population vulnerability to biannual cholera outbreaks and associated macro-scale drivers in the Bengal Delta. The American journal of tropical medicine and hygiene, 89(5), 950-959.

Hasan, N. A., Ceccarelli, D., Grim, C. J., Taviani, E., Choi, J., Sadique, A., ... \& Colwell, R. R. (2013). Distribution of Virulence Genes in Clinical and Environmental Vibrio cholerae Strains in Bangladesh. Applied and environmental microbiology, 79(18), 5782-5785.

Diseases and Conditions Cholera- Causes. In: Mayo Clinic Web [Internet]. [cited 05 Apr 2014]. Available: http://www.mayoclinic.org/diseases-conditions/cholera/basics/causes/con-20031469 